UNIVERSITY OF REDLANDS

\title{
Program Evaluation: Appreciative Inquiry Model as an Instructional Literacy Approach With \\ Low Socioeconomic Status (SES) Elementary Students
}

\begin{abstract}
A dissertation submitted in satisfaction of the requirements of the of Doctor of Education in Leadership for Education Justice

By

Nicol Richmond Erdmier
\end{abstract}

April 2017

Dissertation Committee:

Dr. Andrew Wall, Ph.D., Committee Chair

Dr. Greg Hamilton, Ph.D.

Dr. Mary Suzuki, Ph.D. 


\section{Rl Redlands}

School of Education

Program Evaluation: Appreciative Inquiry Model as an Instructional Literacy Approach With

Low Socioeconomic Status (SES)

Elementary Students

A dissertation submitted in partial fulfillment of the requirements for the degree of Doctor of Education in Leadership for Educational Justice

By

Nicol Richmond Erdmier

April 2017

Dissertation Committee:

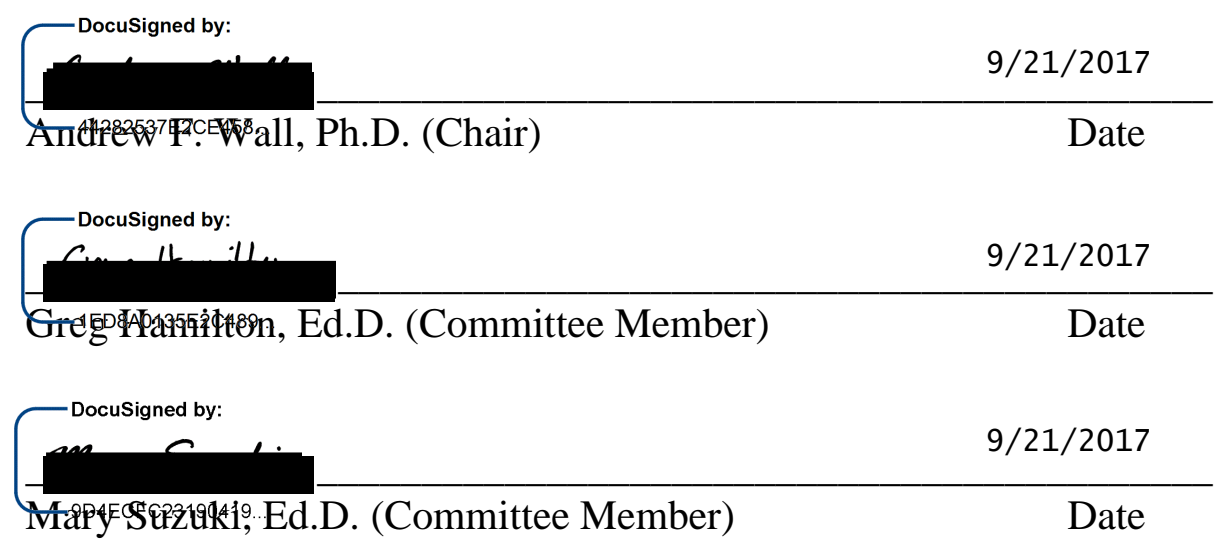

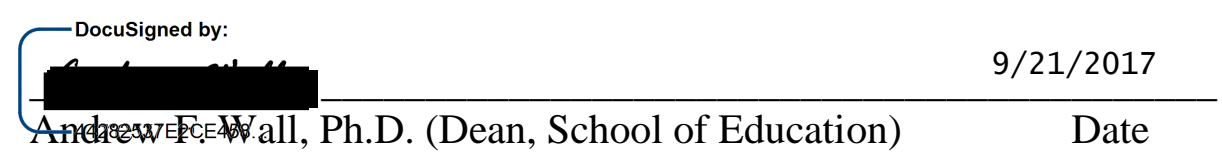




\section{DEDICATION}

To my incredible family who have been my rock throughout this journey. To my husband for his limitless patience and tolerance, and to my beautiful children,

for their contributions, encouragement, and sacrifice throughout this journey. I love you all deeply and appreciate our time together every single day.

To my parents, _ , for embracing my character and courage to fulfill my ambitions and dreams. I miss you both to the depths of my soul. 


\section{ACKNOLOWLEDGEMENTS}

To Dr. Andrew Wall, I would like to thank you for the infinite guidance you have provided throughout this journey. I am deeply grateful for your insight, humor, and support in reaching my goals.

To Dr. Mary Suzuki, and Dr. Greg Hamilton for their guidance, wisdom, and valuable feedback that guided me to completion of my degree.

To all the professors in the University of Redlands, School of Education who influenced the direction of my journey through their own passion for social justice in education, you have each contributed greatly to my development and purpose of my future endeavors.

To all my colleagues for their support and empathy during this process; especially for his sense of humor during the times when I had none, and

who stopped at nothing to make sure I could finish my research including the maternal wisdom that I needed the most. I am eternally grateful.

To Lisa LaRosa, my lifelong friend, who taught me to be a sincerely genuine person. Without you, I would not be who and where I am today. I look forward to sharing the rest of our lives together.

To the students I have taught in the last three years who influenced the direction and purpose of my research. I will work endlessly without hesitation until social justice education becomes the educational ideology driving pedagogy and reform policies that effectively increase achievement for all students. 


\section{TABLE OF CONTENTS}

Dedication.......................................................... 4

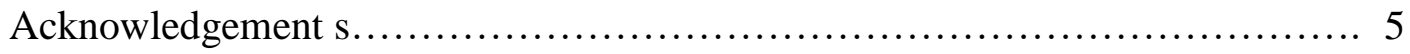

Chapter 1: Introduction................................................. 8

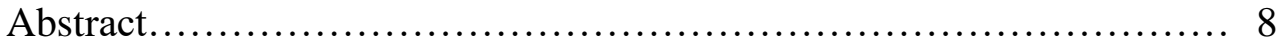

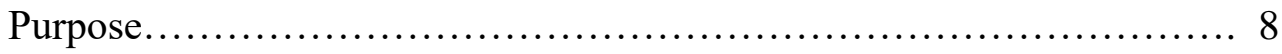

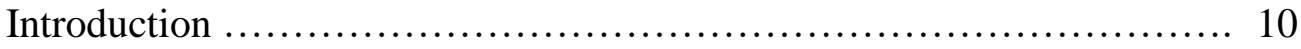

Era of Deficit-based Ideologies ................................. 11

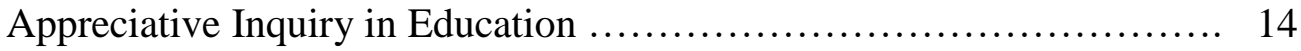

Research Study Instruction Attributes ........................... 15

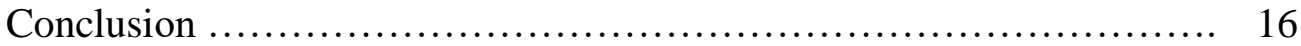

Chapter 2: Literature Review ........................................ 18

Introduction.................................................... 18

Literacy Theory............................................ 19

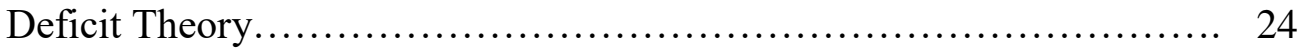

Appreciative Inquiry Theory and Strengths-based Theories............ 26

Classroom Culture................................................ 29

Empirical Evidence of Low SES Student Academic Achievement ......... 31

Key Findings.............................................. 35

Chapter 3: Methodology ............................................ 38

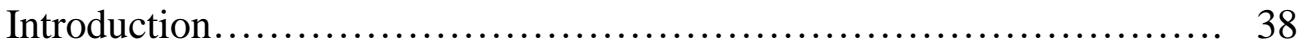

Research Study Timeline...................................... 38

Research Design Methodology.................................. 38

School Setting and Sample........................................ 40

Classroom Setting and Procedure ................................. 41

Data Collection and Instrumentation ............................... 45

Data Analysis ............................................... 49

Conclusions.................................................. 52

Study Logistics............................................ 53

Chapter 4: Research Results and Findings ............................. 55

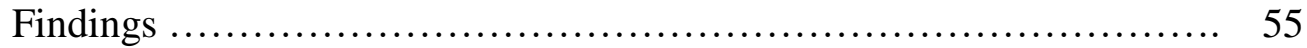

Quantitative Analysis Results................................... 55

Qualitative Analysis Findings...................................... 59

Mixed-Method Analysis Results................................ 64

Chapter 5: Conclusion............................................... 79

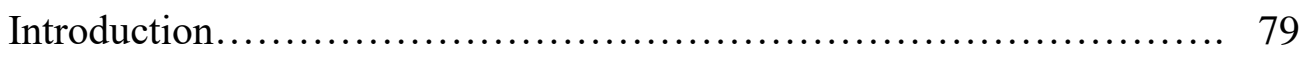

Quantitative Summary........................................... 79

Qualitative Summary ......................................... 80 
Quantitative Summary........................................... 81

Mixed-Method Summary....................................... 83

Conclusions ..................................................... 86

Interpretations............................................... 88

Future Research.............................................. 89

Limitations................................................... 90

Recommendations............................................... 92

Appendices............................................................ 94

References ...................................................... 126 


\section{CHAPTER 1: INTRODUCTION}

\section{Abstract}

This research study is an attempt to learn how students with low socioeconomic status (SES) experience Appreciative Inquiry as an instructional literacy approach when compared to traditional (typically practiced) models of literacy intervention. Key findings will illuminate the effectiveness of strengths-based approaches to literacy achievement and experiences for marginalized students. This study will add to the growing research that policymakers must acknowledge as evidence that a complete overhaul of the deficit-based rationales as the dominant practice in education need to be reconsidered (Orr \& Cleveland-Innes, 2015). It can be postulated that a cultural shift to a strengths-based model within education will significantly impact student achievement for all student groups (Smith, Connolly, \& Pryseski, 2014). Arguably, this could close the achievement gap for marginalized students.

\section{Purpose}

The intent of this comparative research study is to examine the strengths-based instructional models on literacy rates for low SES students at the elementary level. This study intends to answer the research question of how low SES students at the elementary level experience an Appreciative Inquiry model as an instructional literacy approach compared to traditional approaches to literacy instruction.

Students in poverty are often considered deficient in their ability to achieve and are therefore placed in low-achieving, low expectation remedial-type programs to compensate for deficits (Alford, 2014; Bertrand, Perez, \& Rogers, 2015; Burciaga, 2015; Jimenez-Castellanos, 2012; Tung, 2013). However, data from NAEP (2016) shows no measurable shifts in 
achievement gaps between high poverty and low-poverty schools between 2005 and 2013. Data supports the research conclusion that deficit-based models are ineffective in raising student achievement, especially for students in poverty (Anderson, 2005; Burciaga, 2015; Kalchman, 2015), data does not support the argument that students are to blame for their lack of achievement in school (Alford, 2014; Bertrand, Perez, \& Rogers, 2015; Burciaga, 2015; Howard, 2010; Jimenez-Castellanos, 2012; Kalchman, 2015; Ladson-Billings, 2006; Tung, 2013). The literary arguments in line with the aforementioned are profound.

The findings of this study will be important to educators, school districts, and policymakers who "must ensure opportunity for all students," as set by Every Student Succeeds Act (ESSA) (U.S. Department of Education, 2016). Studying the efficacy of different instructional approaches is important to the achievement of high expectations of learning for all students under the Universal Declaration of Human Rights. Article 26 states: Everyone has a right to an education (Greever, 2014; United Nations Human Rights, 2016). The Sustainable Development Goals, 2015, states in target number four: Ensure inclusive and equitable quality education and promote lifelong learning opportunities for all (United Nations, 2015). The Rights of the Child under the 1989 UN Convention, Article 12 encourages adults to listen to the opinion of the child as well as involve them in the decision-making process (Davies \& Lewis, 2013; UNICEF.org, 2016).

Incorporating the California Standards of Teaching Professionals into this study will demonstrate the importance of ongoing professional development that prioritizes strengths-based pedagogies in educational systems. The improvement of classroom climate must be framed as a significant component in improving student achievement. These standards frame the teacher 
performance expectations in California, and their inclusion in this study is necessary to demonstrate that strengths-based approaches also reach performance expectations of teachers in the classroom. The use of these standards will be important in developing an organizational framework to manage and analyze collected data.

\section{Introduction}

Research substantiates the efficacy of strengths-based (also termed asset-based) approaches as alternatives to traditional deficit-based models of instruction. Traditional interventions and strategies for low SES students have not yielded significant growth in achievement for reading comprehension and fluency based on NAEP (2016) scores for National School Lunch Program (NSLP) eligible student subgroups (students in poverty). The funding streams for socioeconomically disadvantaged students are significant but they are not correlate (and arguably, negatively correlate) with student achievement. Yet, for decades, the educational climate has surrounded deficit-based pedagogies with an emphasis on quick-fix program implementation to address disparities between poor students and their more advantaged peers.

Shifting the climate for student learning has not been seriously considered as an alternative for improving student achievement although there is evidence to support such a change (Orr \& Cleveland-Innes, 2015; Smith, Connolly, \& Pryseski, 2014). Climate, from a sociocultural lens, is the environment in which students interact with the teacher and each other, ideally in a mutually respectful, democratic manner (Ikpeze, 2013). Ladson-Billings (2014) argues that cultural competence contributes to the improvement of learning climates through deeper understanding of diverse cultures, including one's own, and sociopolitical consciousness guides students to bridge classroom learning experiences with individual experiences outside the 
classroom. A positive climate embraces student-centered learning, relationship development fostering respect, approval, and esteem, the creation of safe spaces, and knowledge development through critical thinking and critical dialogue (Awan, Noureen \& Naz, 2011; Yilmaz, 2008).

Discernibly, teacher behavior and positive classroom climate inclusive of mutual respect and autonomy are significant factors in motivating students to actively participate in the learning process (Allen \& Innes, 2013; Dallavis, 2013; Elish-Piper, Matthews, \& Risko, 2013; Naude, van den Bergh \& Kruger, 2014; Sever and Guven, 2014; Vaughn \& Faircloth, 2013; Yilmaz, 2008). Active participation in a positive climate contributes to critical understanding of conceptual material with use of higher order thinking skills, resulting in higher retention rates (Johnson, 2014; Tran, 2013).

The potential impact for students includes higher rates of student achievement through rich, student-centered learning environments. Positive student learning experiences can lower dropout rates as well as close the achievement gap for disadvantaged students, especially students in poverty (Costello \& Lawler, 2014; Institute of Education Sciences, 2008; Smith, Connolly, \& Pryseski, 2014).

\section{Era of Deficit-based Ideologies}

The education system in the United States has been perceived as broken from as early as 1966 when the Coleman Report sparked public sentiment that the education system needed to ensure equal education opportunities for all students. Since that time, data has been collected to determine achievement of K-12 student of multiple subgroups, such as gender and race/ethnicity. Longitudinal data does provide evidence of overall growth in reading and math that is statistically significant. However, growth is not substantial with only a range of 5-20-point 
increases in respective categories (NAEP, 2012; Reardon, Valentino, \& Shores, 2012; Vaughn \& Faircloth, 2013). Regardless, there has been a widening of the achievement gap for groups in poverty compared with high-income students (NAEP, 2012; Reardon, Valentino, \& Shores, 2012) which is critical to address as well as the large inequities for groups designated by race, gender, and ethnicity (NAEP, 2012; Reardon, Valentino, \& Shores, 2012).

The Coleman Report fueled the federal government to further develop programs ensuring equitable education for all students. These programs provided funding for Title I programs across the country. Title I is a federal program providing funding to school districts that have a population of students qualified as high poverty. Title I emerged out of the Elementary and Secondary Education Act in 1965 as an attempt to ensure that all children meet state standards for academics.

Research shows that students living in high poverty areas have lower achievement compared to other groups (NAEP, 2012; Reardon, Valentino, \& Shores, 2012). The high poverty population is determined through the NSLP. Title I programs institute interventions in core subject areas to assist students who are failing or are at-risk of failing state assessments for content standards (U.S. Dept. of Education, 2015). Typically, students eligible for Title I programs are pulled out of regular classroom instruction for intensive focus on reinforcing skills (most significantly in reading and math) to close the achievement gap with their more advantaged peers.

Research is mixed on effectiveness of Title I funding in reducing the achievement gap for poor students. Research by Sousa \& Armor (2016) analyzed national assessment data between 1966 and 2011 and concluded that evidence of Title I funding significantly impacting student 
achievement is limited in both math and reading. Overall, research data shows some growth in achievement but the long-term sustainability of this growth is questionable (Editorial Projects in Education Research Center, 2004).

This lack of substantial growth supports the argument that alternative approaches to instruction and learning are necessary to increase student achievement rates. More specifically, a dramatic shift away from deficit ideologies toward asset-based ideologies emphasizing positive classroom climate needs to be seriously considered as a research-driven, viable course of action to increase student achievement for all learners, especially disadvantaged students.

The National Center for Education Statistics (NAEP, 2016) published The Nation's Report Card in 2012, which showed a thirteen-point average gain in reading scores for all nineyear old's taking the state standardized tests compared to scores in 1971. According to NAEP, these gains are statistically significant but do not signify substantial improvement. In 2012, students were disaggregated into groups identifying race and gender only. According to NAEP (2015), the state assessment scores in 2015 disaggregated students into subgroups including Race/Ethnicity, Gender, NSLP eligibility, Students with Disabilities, and English Language Learners. The data shows that average reading scores for 4th graders were not significantly different than scores in 2013, and only six points higher than in 1992 (NAEP, 2016). Nationally, only $36 \%$ of fourth graders scored at or above Proficient in reading. These are dismal findings considering the significant federal funding streams and legislative efforts to increase student achievement during that same time period.

The laudable funding streams for Title I programs serving poor populations and the longstanding political philosophy that more money means more growth (Hanushek, Peterson, \& 
Woessmann, 2012) should garner significant positive correlation with increased levels of student achievement. However, the research does not provide evidence for such findings (NAEP, 2016).

Considering these dismal findings within national data of student achievement in elementary reading and math since the early 1970s (NAEP, 2016), it can be postulated that traditional deficit-based educational pedagogies continue to fail our students. There is an abundance of scientific research evidencing increased student achievement when strengths-based and inquiry-based instructional models frame the learning climate (Abdi, 2014; Dallavis, 2013; Davies \& Lewis, 2013; Fifolt \& Lander, 2013; Giles \& Alderson, 2008; Lehner \& Hight, 2006; Lehner \& Ruona, 2004; Naude, van den Bergh \& Kruger, 2014), yet these models have not taken hold in education (Yilmaz, 2008).

\section{Appreciative Inquiry in Education}

Appreciative Inquiry (AI) is a proven model to create positive and lasting change within organizations (Calabrese \& Cohen, 2013; Cooperrider \& Whitney, 2005; Giles \& Alderson, 2008; Harrison \& Hasan, 2013; Johnson, 2014; Lehner \& Hight, 2006), but there is very little research on Appreciative Inquiry as a model in educational settings (Lehner, Ruona, \& Georgia, 2004). Orr and Cleveland-Innes argued that AI would be easily transferable to learning environments with equivalent results (Johnson, 2014; Orr \& Cleveland-Innes, 2015). Further research is needed to fill the gap of scientific data evidencing positive correlations of strengthbased instructional models with increased student achievement to do away with current pedagogy and cultivate strength-based alternative pedagogies (Orr \& Cleveland-Innes, 2015). The intent of this study is to contribute relevant research supporting the statement that enacting 
strength-based pedagogies in place of deficit-based pedagogies is paramount to increasing student achievement nationally.

Research literature of $\mathrm{AI}$ in the field of education is mostly found at the secondary level and into higher education (Lehner, Ruona, \& Georgia, 2004). The paucity of research at the elementary level needs consideration as national test scores provide evidence that traditional models of instruction fall short in substantially improving literacy rates for students. One study, by Lehner, Ruona, and Georgia (2004), argued that AI can strengthen educational learning cultures, and that more applications and study of AI are necessary in educational environments. The authors offer the following as an approach: "Another avenue for future research could be a comparative study of two learning events - one that maintains a traditional format and one that actively incorporates an AI approach" (p. 1085). This study will fill the gap of scientific research comparing student achievement in settings using traditional instruction to learning environments using strengths-based instruction framed in AI theory model.

\section{Research Study Instruction Attributes}

For this research study, "traditional literacy instruction" is defined as daily skill-based instruction that is organized using predictable and consistent teaching methods and strategies (Herrera, Truckenmiller, and Foorman, 2016). Instruction is teacher-led with skill practice using rote-learning techniques (lower-order thinking skills of memorization through repetition, reproduction, and recall). Deficit-based mindset drives instruction and practice to meet daily lesson objectives. Reading and writing proficiency is assessed informally through verbal questioning, using lower-level cognitive thinking, and worksheets that reinforce reading content 
and mechanics of writing, with questions requiring simple answers through fill-in-the-blank, copy, rearrange, and rewrite formats.

An Appreciative Inquiry model instructional approach is defined as a strengths-based model where growth mindset drives needs-based instruction. Instruction is student-led, and skill practice uses a variety of learning techniques that include group and partner collaboration (problem-solving, informational text analysis, student-led teaching, etc.). Growth-based mindset drives instruction and practice of daily lessons objectives. Reading and writing proficiency is assessed informally through critical dialogue and examination of reading content, using higher order thinking skills to cite evidence supporting interpretations and conclusions drawn from text.

\section{Conclusion}

This study intends to answer the research question of how low SES students at the elementary level experience Appreciative Inquiry model as an instructional literacy approach compared to traditional instructional literacy approaches. The method to answering this question will be to conduct a program evaluation study utilizing mixed methods to understand the differences in student achievement and experiences in traditional literacy instructional approach settings and Appreciative Inquiry model instructional literacy approach settings. Additionally, a clearer understanding of low SES student experiences in different instructional approach settings will emerge from parallel mixed analysis of qualitative and quantitative data analysis.

The answer to this research question may contribute to proven models of success, found in scientific research, in raising student achievement, especially for marginalized students. It is clear in the research that the educational system has failed the students. Data supports what education researchers have proclaimed for years: Asset-based approaches are more effective in 
raising student achievement compared to traditional deficit-based approaches (Anderson, 2005; Burciaga, 2015; Darling-Hammond, 2015; Valencia, 2012). The AI model instructional format for this study may provide evidence in support of shifting embedded educational pedagogies that surround deficit theory, influencing policymakers in determining alternative approaches to increase student achievement, as well as direct inclusion of courses in teacher preparation programs that drive social justice for all students through a lens of strengths-based ideologies in educational practices. 


\section{CHAPTER 2: LITERATURE REVIEW}

\section{Introduction}

To gain a deeper understanding of effective instructional literacy approaches, both strengths-based and deficit-based, the review of literature focused on the following theories: Literacy Theory, Deficit Theory, and Appreciative Inquiry theory. The theoretical perspective for this study highlights the differing foundations of literacy theory, how deficit theory is woven into current educational pedagogy, and the effectiveness of asset-based theories (Appreciative Inquiry) as an alternative pedagogy in raising student achievement. Literature that highlights the impact of classroom culture on student achievement and the need to consider academic success through social aspects of student experiences is also included. Finally, literature related to empirical evidence of academic success and achievement of low SES students is reviewed.

This review of literature frames historical views of literacy as a measure of privilege and justification of oppression documented from early civilization. The literature also illustrates the impact of deficit-based approaches and strengths-based approaches on student achievement. The review establishes the theoretical foundation of the study to define how low SES students at the elementary level experience Appreciative Inquiry as an instructional literacy approach compared to traditionally practiced approaches to literacy instruction. Three educational theories are emphasized as the theoretical framework for this research study. However, there are multitudes of theories that could contribute to future studies, including Friere's Critical Pedagogy Theory, Critical Race Theory, Vygotsky's Sociocultural Theory, Bourdieu's Cultural Capital Theory, Social Constructivism, Sociocultural Theory, Social and Cultural Reproduction Theories, Moll's Funds of Knowledge, Critical Literacy Theory, Conflict Theory, Durkheim's Functionalism 
Theory, Marxism, and Weber's Theory of Social Class. Future studies using asset-based pedagogies through the lens of any of the above theories are needed to address the disparities between current deficit-based educational reform policies and contrasting research evidence to effectively raise student achievement and close the achievement gap.

\section{Literacy Theory}

Literacy Theory prominently emerged in the mid-to late- $20^{\text {th }}$ century academic literature although there are documented accounts of theoretical foundations of literacy written within early civilizations including ancient Greece, Islam, and Christianity (Diehl, 1979, 2000;

saylor.org, 2011). Throughout history, literacy has been used as a measure of the prominence and acceptance of dominant White culture as well as justification to oppress, marginalize, discriminate, and embed caste barriers (Diehl, 1979, 2000) in society. Literacy was considered a form of power over others as well as means from which to gain power (Diehl, 1979, 2000). This view of literacy became permanently entrenched in society through the passage of laws in the early $20^{\text {th }}$ century (such as legislation led by Henry Cabot) that excluded less than literate peoples from immigrating, thereby legitimizing literacy as capital for the privileged and a determinant of classism (Diehl, 1979, 2000).

Major reforms in conceptual literacy took hold in the 1950s through the 1960s with the Supreme Court ruling in Brown v. Board of Education in 1954 as well as the Civil Rights movement thereafter (Diehl, 1979, 2000). The 1970s established education as a meritocracy, providing "equal opportunities only" over democracy, which ensured "roughly equal results from education" (Diehl, 1979, 2000). Meritocratic practice, influenced by Industrialization and social Darwinism, favored sorting the workforce by “natural” ability (Diehl, 1979, 2000). It wasn't 
until that late 1970s that meritocratic approaches in education were recognized as unjust segregating students "of merit" and those "without merit". Democratic approaches were initiated to strive for equality among all student's proponents of these approaches continue to struggle against legislative and public movements intended to reinstate meritocratic dominance (Diehl, 1979, 2000).

Historically, meritocratic movements in education have manifest as competency assessments or qualifying exams intended to determine concept mastery and achievement. Assessments heavily weighted in literacy comprehension and fluency mask student skills and abilities in content areas outside of literacy competence (Diehl, 1979, 2000; Kirsch \& Guthrie, 1978); thereby immediately designating those not fluent in literacy (predominantly poor and English learners) as having not met achievement standards (perceived as "failing") regardless of subject matter competence. This exemplifies literacy as a measure that undermines equality in education, and limits equal opportunities, shifting responsibility onto the student and away from institutionalized ideologies. From a neoliberal lens (Hursh \& Henderson, 2015), literacy assessments propagated as measures to collect rich data determining effective teaching practices that ensure academic achievement for all students fulfills the hidden agenda of the dominant culture to perpetuate classism, oppression, and marginalization that maintains systemic power (Diehl, 1979, 2000). Additionally, such standardized assessments justify placing greater financial sanctions on underperforming schools, which inevitably are the poorest schools, already struggling to provide high quality education for their students (Maranto, 2015).

Sociological perspectives and Essentialism have been the major influences in the literacy theory of $20^{\text {th }}$ century culture (Diehl, 1979, 2000). Again, literacy continued to be the measure 
determining privilege, competence, and qualification within the realm of military, immigration, political, and industrial policies regulated by the government. The adoption of industrialization models in education resulted in tracking systems while exemplifying occupational opportunities requiring more and less literacy skill acquisition (Diehl, 1979, 2000). This demonstrates historical perpetuation of classism under the guise of literacy acquisition as a measure of individual academic achievement or lack of achievement by the dominant culture from early civilization to the latter $20^{\text {th }}$ century.

Based on this historical context of literacy, current research is situated within two predominant themes. One literature perspective, framed as meritocratic and neoliberalistic, supports the cognitive aspect of literacy and teaching (Hursh \& Henderson, 2015; Kretz, 2014). This literature promotes a cognitive. or teacher-centered, approach to literacy with efforts to develop standardized curricula, initiatives for public awareness related to the importance of literacy development, assessment and accountability, and resource allocation as effective means through which to teach literacy (Berman, 2009; Barrett-Tatum, 2015; Costello, 2012; Dole, 2015; Goatley \& Hinchman, 2013; Lucariello, Butler, \& Tine, 2012; Mokhtari, Neel, Kaiser, \& Le; 2015; Unver, 2014).

Within this perspective, knowledge is delivered with curricula adopted using a top-down approach, and student are passive recipients. Teachers deliver this curricula with focus on mastery of content knowledge through assessments. The commonly held position under this approach is that programs impact successful mastery of knowledge, and that those programs need to be evidence-based and research driven (Berman, 2009; Barrett-Tatum, 2015; Costello, 
2012; Dole, 2015; Goatley \& Hinchman, 2013; Lucariello, Butler, \& Tine, 2012; Mokhtari, Neel, Kaiser, \& Le; 2015; Unver, 2014).

This assumption fails to recognize that programs do not have the capability to fix-all, and that many programs that are successful in one demographic may not have the same results on another. This approach also fails to recognize that emphasis on standardized assessments measuring core subject academic achievement may be argued as invalid measures simply due to the weight of literacy competency needed to ensure scores indicating content mastery. Standardized assessment scores, used as a singular source of data, does not accurately depict student achievement, teacher quality, and program effectiveness. Singular data sources such as national assessments can mislead public perceptions of the quality and effectiveness of public school districts, schools, and teachers, and therefore the quality of public education.

Based on such singular data sources, public sentiment has shifted toward the perception that public education is failing to provide high quality education to students. As a result, the popularization of private schools, charter schools, and alternative education programs (homeschooling, independent study, and hybrid learning models) has increased absent singular data sources evidencing higher achievement outcomes for alternative educational programs. Research evidencing increases in student achievement levels, as well as no difference in student achievement levels, when scores from private education or charter schools are compared with public education data, are found in the literature (National Center for Education Statistics, 2016).

The second perspective argues for approaching literacy from the principle of human learning (Elish-Piper, Matthews, \& Risko, 2013) and the learning environments are the focus as a means for growth (Blas, 2014; Center on Education Policy, 2012; Elish-Piper, Matthews, \& 
Risko, 2013; Senturk \& Camiliyer, 2016; Sever \& Guven, 2014; Vaughn \& Faircloth, 2013). This approach calls for inquiry-based and strengths-based learning (Abdi, 2014; Corkett, Hatt, \& Benevides, 2011; Howard, 2010; Ladson-Billings, 2006; Senturk \& Camiliyer, 2016). Students are active participants in learning, and they feel empowered, respected, recognized, validated, and safe within their learning environment (Kretz, 2014). The research literature argues that these students make more meaningful connections to their learning and are willing to personally invest in the learning process, resulting in academic acquisition and success. Research clearly indicates, when comparison groups are measured, that students within human-based learning environments have higher scores on post-tests compared to traditional approaches to learning (Abdi, 2014; Senturk and Camiliyer, 2016; Sever and Guven, 2014). It is assumed that such posttests are content specific, resulting in higher scores of achievement than on standardized tests that cover broad content.

Although research indicators lean towards the conclusion that a human-based learning approach is a more effective means of raising achievement levels, policymakers continue to institute funding for program implementation through traditional, teacher-centered instruction, without considering the proven research that rigid focus on content coverage alienates opportunities to develop meaningful relationships within the learning environment. This rigidity leads to disenfranchised students who resist learning (Costello \& Lawler, 2014; Sever \& Guven, 2014) and contributes to lowered achievement for students, especially marginalized students.

\section{Deficit Theory}

As early as colonization, deficit discourse has been utilized to describe differences in intelligence (Bertrand, Perez \& Rogers, 2015). In the early twentieth century, such discourse 
became a stratagem to identify cultural disadvantage, which justified racial inequality and discrimination. Currently, deficit theories are used to define marginalized groups as "inherently at-risk," deferring failures in the system to the individual (Alford, 2014; Bertrand, Perez, \& Rogers, 2015; Burciaga, 2015; Jimenez-Castellanos, 2012; Kalchman, 2015; Rios-Aguilar, Kiyama, Gravitt \& Moll, 2011; Tung, 2013). This omnipresent discourse "locates its explanations of the underperformance or underachievement of non-dominant students in the nonalignment of the cultural practices of the home and school" (Alford, 2014; Ladson-Billings, 2006; Rios-Aguilar, Kiyama, Gravitt \& Moll, 2011), and is embedded the language used to explain school failure for EL and high poverty populations. The inferred belief that cultures, traits, home and family factors all contribute to student deficits and therefore cause school failure shifts the blame away from institutional failure to the student as the failure.

This shifting of blame to individuals is documented throughout history but William Ryan codified the phrase "blaming the victim" in 1971 (Schoellkopf, 2012). Shifting blame for school failure onto the individual releases educational systems, policies, and practices from responsibility allowing the status quo to continue.

The Coleman Report of 1966 supported the premise of deficit theory and concretized this form of systematic blaming of the individual throughout education. The report claimed that schools did not impact academic outcomes as much as outside biological, cultural and environmental factors (Jimenez-Castellanos, 2012). Regardless of the strong criticisms of this report, educational policies have been influenced by deficit ideologies attempting to compensate for such deficiencies (Bertrand, Perez \& Rogers, 2015; Jimenez-Castellanos, 2012). Since that time, research has shown that deficit models are ineffective in closing the achievement gap for 
marginalized groups (Alford, 2014; Bertrand, Perez, \& Rogers, 2015; Burciaga, 2015; JimenezCastellanos, 2012; Kalchman, 2015; Tung, 2013).

Deficit models limit opportunities for marginalized students through requirement of remediation services eliminating opportunities for high quality core curriculum instruction (often replacing subjects as history, science, art, music or P.E.) and college-ready courses (Alford, 2014). Through this exclusion, students begin to identify themselves as less capable and less valuable than their higher performing peers. Educators also lower expectations of these students with provisions of low quality curriculum in the form of tracking and remediation programs excluding marginalized students from core curriculum designed to prepare these students for advanced or college-ready coursework (Jimenez-Castellanos, 2012; Kober \& McMurrer, 2011; Rios-Aguillar et.al. 2011).

There is no research to be found that supports deficit-based models as effective pedagogies in raising student achievement. Yet deficit ideologies continue to be embraced within the educational system and are so entrenched that deficit thinking remains a bulwark in education practice. This omnipresent discourse contributes to the maintenance of power within the dominant culture (Alford, 2014; Rios-Aguillar et al., 2011), and systemic racism and classism in education (Bertrand, Perez, \& Rogers, 2015). These deficit discourses continue to blame marginalized students for lack of educational achievement, identify failure to achieve as “inherent," deflect responsibility of institutional inadequacies, promote justification of segregation, and maintain the status quo in which the dominant culture prevails (Bertrand, Perez \& Rogers, 2015; Rios-Aguilar et al, 2011). 
Systemic oppression through aspects of education such as literacy can be traced throughout civilization evolving into political rhetoric that exalts policies intended to provide equal educational opportunities for all students while simultaneously leveraging those policies as instruments to justify the status quo of the dominant culture (Capper, 2015; Giroux, 1983). The evolution of asset-based pedagogies lies in the resistance to legitimized systemic oppression framed historically in the context of educational outcomes by capitalist and reproductionist rationales supported by liberals and neoliberals (Giroux, 1983).

Overwhelmingly, research evidences successful academic achievement for all students, especially marginalized students, when asset-based approaches drive instruction (Orr \& Cleveland-Innes, 2015). Yet this evidence is neglected in academic policies. This research study intends to illustrate the profundity of asset-based pedagogies in educational instruction, highlighting Appreciative Inquiry model as an effective strengths-based approach to literacy instruction for low SES students at the elementary level.

\section{Appreciative Inquiry Theory}

- Strengths-based pedagogies situated in social, cultural, and instructional practices of education are found throughout the literature. Theories grounded in strengths-based perspectives, drawing attention to the talents, skills, and best qualities of students are documented as early as the $18^{\text {th }}$ and $19^{\text {th }}$ centuries (Gardner $\&$ Toope, 2011). More recently, strengths-based perspectives were developed in the social work arena of the 1980s. Work produced by Weick, Rapp, Sullivan, and Kishardt at the University of Kansas School of Social Welfare (1989) developed the term "strengths perspective" (Saleebey, 2008). Thereafter, various strengths-based approaches have emerged in opposition to deficit-based ideologies in multiple fields in addition to education, 
including sociology, psychology, social work, and community development (Gardner \& Toope, 2011). These theories are framed within the humanistic approach in which individual potential is underscored. Literature by Vygotsky (Smagorinsky, 2012), Durkheim (Peca, 2000), Bourdieu (Klibthong, 2012), and Rousseau (Diehl, 1979, 2000) are only a few contributors significant in identifying necessary strengths-based approaches as successful approaches to student achievement. These theorists define their work as contrary to normalized approaches that sustain achievement gaps for marginalized groups.

Appreciative Inquiry (AI) is strengths-based methodology originally developed for business organizations by David Cooperrider and Suresh Srivastva in the early 1980s (Lehner \& Hight, 2006; Orr \& Cleveland-Innes, 2015). AI is based on the heliotropic principle of "what gives life to human systems when they function at their best" (Allen, 2013; Johnson, 2014; Kerka, 2003; Lehner \& Hight, 2006; Lehner \& Ruona, 2004; Naude, van den Bergh \& Kruger, 2014; Orr \& Cleveland-Innes, 2015; Randolph, 2006; Rogers \& Fraser, 2003; Steyn, 2009). AI is a system framed around the transformation of individuals based on strengths, hopes and dreams (Randolph, 2006). The premise is about asking questions to heighten one's strengths and positive potential.

The underlying principles of AI include constructivism (reality is derived from social interactions), simultaneity (people naturally place all of their attention to the first concept or question proposed), poetics (storytelling is the medium in which holistic information is gathered), anticipation (actions are derived innately as well as through anticipation of future possibilities), and positive (positivity is equally as contagious as negativity) (Fifolt and Lander, 
2013; Johnson, 2014; Kerka, 2003; Lehner and Hight, 2006; Lehner \& Ruona, 2004; Orr \& Cleveland-Innes, 2015).

Appreciative Inquiry has four phases of implementation, referred to as the 4-D Cycle, and defined as Discovery (group storytelling of most positive experiences and successful practices), Dream (individuals describe what they would love to see occur within the organization), Design (individuals determine the needs and active roles in order to achieve the dreams that will be realized), and Destiny -also referred to as Deliver (monitoring the effectiveness of the action plans in place to ensure a true visualization of the Dream). A fifth phase, Define (target inquiry focuses on positive aspects of the organization) may be considered the first phase of the implementation process (Allen, 2013; Davies \& Lewis, 2013; Fifolt \& Lander, 2013; Kerka, 2003; Lehner \& Hight, 2006; Lehner \& Ruona, 2004; Naude, van den Bergh \& Kruger, 2014; Steyn, 2009).

There is little research on the implementation of Appreciative Inquiry in education. What is available surrounds studies at the secondary and higher education levels. The findings in the literature suggest potential for AI in the elementary setting (Giles \& Alderson, 2008) and encouraging more study on the matter (Lehner \& Ruona, 2004). Furthermore, the available research evidences increased scores on assessments, increased self-efficacy and motivation as well as for students when Appreciative Inquiry was utilized both quantitatively and qualitatively (Abdi, 2014; Davies \& Lewis, 2013; Fifolt \& Lander, 2013; Giles \& Anderson, 2008; Lehner \& Hight, 2006; Naude, van den Bergh \& Kruger; 2014).

\section{Classroom Culture}


Research shows that students' positive self-concept is directly correlated with student achievement (Awan, Noureen \& Naz, 2011; Hagenauer \& Hascher, 2014; Howard, 2010; Ladson-Billings, 2006). Increased self-concept and increased student achievement scores are synchronous. Appreciative Inquiry lends to this theory by taking positive experiences and applying them to current learning to assist students in building a positive self-concept and achieving academic goals (Martina, 2006; Rios-Aguillar et al., 2011).

Improving student success rates starts with belief in the students. One must believe that students can achieve no matter where the bar of achievement is set. This is important in determining whether program implementation is a success or a failure (Housman \& Martinez, 2001; Howard, 2010; Ladson-Billings, 2006). The literature identifies - classroom culture as a primary element in determining student success (Beneky \& Ostrosky, 2009; Brady, 2011; Dembo \& Seli, 2004). Classroom cultures that are student-centered, include critical dialogue where all members are respected, safe, and empowered, and where there is a genuine belief from the teacher that all students can excel show increased student motivation and higher retention of course content contributing to increased scores on assessments (Goering, 2013; Khalil \& Brown, 2015; Ladson-Billings, 2016; Lehner \& Ruona, 2004).

Empirical evidence shows that low SES students achieve at comparable rates to their peers in other subgroups when elements of positive climate - emphasizing motivation, confidence, persistence, and student self-efficacy - are considered (Bergeron, Chouinard, \& Janosz, 2011; Huang, 2015; Yang, Lai, Yao, \& Huang, 2014). An ideology approaching student learning from where students are instead of from what they lack is necessary to begin 
transitioning toward effective, long-term growth in student achievement at all levels, especially for low SES students (Bromberg \& Thokas, 2013).

Appreciative Inquiry falls under constructivist theory as well as culturally relevant pedagogy in that it emphasizes the capital students bring to the classroom as the building blocks for learning (Elish-Piper, Matthews, \& Risko, 2013). These pedagogies also embrace the idea that academic achievement is acquired through growth. Students succeed when they build the capital they bring to the classroom (Bertrand et al., 2015).

The premise that students come to class with "capital" and the belief that they can achieve will be themes woven into literacy instruction for the study Treatment group receiving AI model approach in literacy instruction. This is the basis for the Appreciative Inquiry model. Appreciative Inquiry relies on past successes to produce future successes (Lehner \& Hight, 2006). This approach is in direct contrast with traditional practices using deficit-based models to drive instruction.

A strengths-based approach counters deficit-based approaches and diminishes resistance behaviors in learning through the establishment of a meaningful environment in which all students contribute meaningfully using their individual strengths. Students in such an environment have higher achievement, positive attitudes towards learning and expectations, and less resistance (Elish-Piper, Matthews, \& Risko, 2013; Howard, 2011; Ladson-Billings; 2006).

Conversely, traditional deficit ideologies view and label students who score far below grade level in standardized assessment as "at-risk for failure" and remediation and tracking interventions are the provisions for increasing student achievement. Unfortunately, students who are enrolled in remediation-type intervention programs often never exit. Students come to 
identify themselves as failures in learning and not worthy of the same education as their more successful peers (Vaughn \& Faircloth, 2013).

Strength-based models eliminate the embedded views that students, their parents, or the home circumstances are responsible for insubstantial academic achievement. Within the strength-based model, achievement is realized through growth in content skill acquisition. Although predetermined baselines for grade level achievement are necessary to gauge growth, those baselines do not determine success or failure for student achievement. Individual measured growth determines successful knowledge acquisition, thereby alienating dialogue referring to failure to reach desired outcomes.

The literature strongly leans toward strengths-based approaches, student efficacy, and learning environments as contributing factors in student achievement (Alford, 2014; Costello \& Lawler, 2014; Elish-Piper et al., 2013; Ladson-Billings, 2006; Martina, 2006; Orr \& ClevelandInnes, 2015; Rios-Aguillar et al., 2011; Tran, 2013). Yet, embedded education policies and practices continue to foster deficit-based approaches as the dominant means of increasing student achievement.

\section{Empirical Evidence of Low SES Student Academic Achievement}

Historically, poor students have consistently scored low in academic achievement. For decades, the achievement gap between poor students and their more advantaged peers has prompted policymakers to enact numerous programs to increase student achievement for disadvantaged students (Center for Education Policy, 2011). The Elementary and Secondary Education Act of 1965 included provisions for federal funding to directly aid high poverty students (Title I) (CEP, 2011). Reardon (2012) evidences research compiled from the Early 
Childhood Longitudinal Study, Kindergarten Cohort (ECLS-K) ${ }^{\text {from }} 1998$ to 2007 which documented that low-income students fell, on average, five years behind in literacy skill development than higher income students by grade 4 , and that the gap then continued to widen (Reardon, 2012; Silvernail, Sloan, Paul, Johnson, Stump, 2014). The relationship between income and achievement is evidenced throughout the research (Aber, 2012; Blazer, 2009; Hedges, Laine, \& Greenwald, 1994; Reardon, 2013; Silvernail, et.al, 2012). Attributes that correspond to this relationship range from poor health and diet to limited vocabulary development in the home as well as limited participation in activities outside of school. Blazer, 2009, cited numerous research studies of national data, reiterating the same findings for achievement gaps of students in poverty.

However, there is ample research, both quantitatively and qualitatively, evidencing the modality of successful academic achievement of low SES students when comparable variables exist, such as instructional style and implementation, climate and cultural competency, positive student-teacher relationship, sociocultural awareness, and student social and emotional development, among others (Beecher, 2001; Gay, 2010; Kosmoski, Gay \& Vockell, 1990; Lemberger, Brigman, Webb, \& Moore, 2011; Trowbridge, 1972; Willis, 2009; Walker-Dalhouse \& Risko, 2008).

A study of school influences on the black-white achievement gap using data from the Texas School Project and the Early Childhood Longitudinal Survey by Hanushek and Rivkin (2007) argued that "school quality plays an important role in the determination of achievement and racial achievement differences", (p. 30). 
Brackett, Reyes, Rivers, Elbertson, and Solovey (2011), conducted a study using fortyfour schools in a northeastern U.S. urban school district, isolating classroom emotional climate, teacher affiliation, and student conduct in 90 fifth and sixth grade English Language Arts classrooms. Their findings indicated that emotionally supportive classroom environments positively impacted student conduct with increases in respect and likeness toward teachers.

The Student Success Skills (SSS) program is founded in shared learning experiences and success in classrooms. Research by Lemberger, Brigman, Webb, and Moore (2011/2012), detailed five efficacy studies that encompassed 1,279 students from fourth to ninth grades that used the SSS program invariably showed "significant increases in math and reading scores on standardized achievement tests" (p. 90). Another study by Conner, Morrison, Fishman, Ponitz, Glasney, Underwood, Piasta, Crowe, and Schatschneider (2009), examined the results of using the Individualized Student Instruction (ISI) classroom observation and coding system using a series of cluster-randomized control field trials in first grade classrooms. Their findings showed that classroom environment positively correlated to students' gain in reading skills.

Kosmonski, Gay, and Vockell (1990), studied the interconnectedness of cultural literacy (shared knowledge within a society) and academic achievement. Analysis of data from 611 fifth graders in sixteen northwestern urban elementary schools evidenced the following: (1) A positive relationship between cultural literacy and academic achievement was statistically significant, (2) SES, type of school, and ethnicity had an effect on student achievement of cultural literacy, and (3) The correlative pattern was not affected by those same subgroups (high or low scores in cultural literacy paralleled high or low academic achievement scores respectively). The authors argued that students outside of the dominant culture are at a disadvantage when taking 
standardized assessments that comprise the cultural literacy of the dominant American culture, and that the results of those measures should not be compared equivalently to the results of their White counterparts.

This is supported with literature by Willis, (2009) who found that a review of aggregated research in classroom instruction, interaction, achievement, and literacy learning demonstrated “...how, in clearly identifiable contexts, effective literacy instruction and supportive teacherstudent interaction help to improve student academic achievement, in contrast to focal studies" (p. 528). Willis (2009) argued that academic achievement for poor students, bilingual students, and poorly performing students is measured by standardized assessments that "...reflect a perception of the average U.S. school-child as White, middle to upper class, native English speaking, and native born" (p. 529). Outcomes of national standardized assessment results comparing White middle-class groups with minority subgroups consequently signify that U.S. education underserves minority populations.

Willis (2009) argued that federal educational reform policies intended to serve minority populations are primarily premised on scientific quantitative research where "histories, cultures, politics, and ideological influences escape scrutiny" (p. 529), regardless of the qualitative research made available under the federal educational research guidelines. A review of articles by Willis (2009) that inform federal educational policies found common characteristics, including federally funded research, evidencing increased teacher quality and classroom management from singular databases (poor schools) focused on generalizable attributes (disadvantaged students). Federal policies do not account for the qualitative scientific research that details direct correlations of classroom interactions with student achievement. Qualitative 
methods (case studies, ethnographies, narratives, etc.) are often discounted or rejected as simply descriptive accountings and are overlooked in educational research guiding federal educational reform movements. Willis' argument explains the persistence of deficit-based practices and policies regardless of research data evidencing failure to close achievement gaps and raise student achievement for poor students.

\section{Key Findings}

Historically, research literature evidences embedded practices of marginalization of disadvantaged groups with the dominant culture using deficiencies in literacy skills as justified oppression to maintain the status quo. These ideologies continue to drive educational reform policies and legislation guidelines.

Federal education reform policies are primarily premised on federally funded quantitative scientific research with a scope limited to teacher quality and program improvement, simultaneously disregarding available qualitative research data evidencing that increased student achievement is directly related to positive classroom climate, especially for poor students.

Although decades of scientific research link income itself attributing to the achievement gap between poor students and their more advantaged peers, federal educational reform policies reject scientific qualitative research evidencing practices that eliminate gap trends between advantaged and disadvantaged groups, even in pursuit of equitable education. Research literature consistently evidences positive correlations between classroom environment and student achievement, including literature specific to strengths-based instructional practices leading to increased student achievement, student motivation, student self-efficacy, and positive teacher-student interactions. 
Disadvantaged students, especially low SES students, benefit from instructional climates that are engaging, supportive, positive, and safe. Student participation, motivation, concept retention, and achievement increase in positive classroom climates founded in a growth mindset framework. Deficit-based mindsets limit equal education opportunities and experiences that continue to marginalize and oppress, with remedial skill and drill courses, limited exposure to higher order thinking skill development, disqualification of advanced level (or college-ready) courses, and instruction that reduces student motivation, efficacy, and academic growth by reinforcing deficiencies and minimalizing strengths of students and mislead perceived causes for lack of academic progress.

Findings throughout the literature evidence that low income students continue to be disadvantaged regardless of educational policies to raise student achievement for these students; the implicit values and beliefs of the dominant class continues to marginalize disadvantaged students with deficit-based pedagogies; and positive student experiences directly combat the elements that continue to marginalize poor students.

It can be argued that to enforce federal educational research guidelines (that includes the use of qualitative research data) would disrupt the status quo where the hidden agenda is the focal point to drive policies most profitable to private corporations within the dominant group. This perspective explains why reform policies that continue to fail students, sustain achievement gap levels of disadvantaged groups, and reject qualitative scientific research continue to persist.

Deficit-based theoretical practices have been embedded into society since early civilization, which will make shifting beliefs and practices daunting. Strengths-based research and empirical data evidencing the effectiveness of raising student achievement, student 
motivation, student self-efficacy, and classroom culture need to become the driving forces to elevate social consciousness surrounding these issues and work collectively to help students succeed.

This research study intends to demonstrate correlations between student experiences and behaviors and strength-based instructional literacy approaches for low SES students compared to traditional instructional models. The findings may contribute to research literature correlating student experience and achievement with instructional approach settings, both quantitatively and qualitatively. These findings may support existing literature arguing the need for strength-based approaches as the dominant educational ideology for increasing achievement for all students, especially marginalized populations. Without such shifts, education will continue to fail poor and marginalized students across the nation. 


\section{CHAPTER 3: METHODOLOGY}

\section{Introduction}

The approach to the research question, "How do low SES students at the elementary level experience Appreciative Inquiry model as an instructional literacy approach compared to traditional instructional literacy approaches?" will be to conduct a program evaluation study utilizing mixed methods to understand the differences in traditional instructional literacy approaches and Appreciative Inquiry model as an instructional literacy approach. Additionally, a clearer understanding of low SES student experiences and achievement through different instructional approaches settings will emerge from qualitative and quantitative data analysis.

\section{Research Study Timeline}

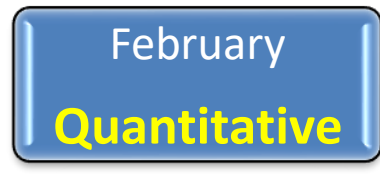

February 6, 2017

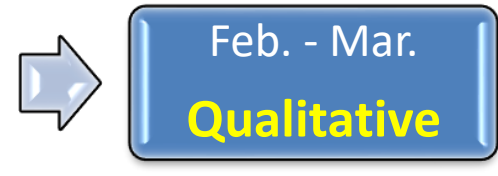

Qualitative

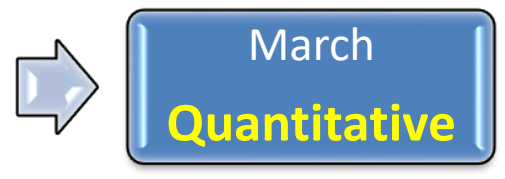

March 17, 2017

\section{Research Design Methodology}

This research study will be framed by a QUANT $\rightarrow$ qual $\rightarrow$ QUANT deductive theoretical design- using data from two different instructional group settings (Appendix F). One study group will receive instruction employing a strengths-based approach modeled around Appreciative Inquiry theory, while the second group will receive instruction employing current teaching approaches practiced in the research study site Title I reading intervention program. The project will include 10-12 students in each instructional group, 20-24 students in total, from fourth grade. 
Data collection will include quantitative data in the form of pre-reading comprehension and fluency assessment scores at the beginning of the study, qualitative data collection (in the form of external observation note-taking and narrative reflection throughout the study), and quantitative data in the form of post-reading comprehension and fluency assessment scores concluding the study (Tashakkori \& Teddlie, 2003).

The quantitative data (comprehension and fluency assessment scores) will be generated at the beginning and again at the end of the six-week study. The assessments are designed to be completed in 45-60 minutes, and therefore will take participants approximately 90-120 minutes in total for pre- and post-test examinations. These tests are routinely part of the experience of students at the study site, and thus represent a common educational practice. The reading comprehension and fluency assessment instruments, commonly employed in schools nationally, are validated and research driven. There will be six to nine qualitative observations of each instructional group; these observations will be documented by an external observer using an External Observation Framework Form developed by the PI in collaboration with her advisor and vetted by seven experienced classroom teachers.

The PI will replace participant identifiers with coded ID's for all research study data collected and will securely store all research data in a locked file drawer to maintain confidentiality for the duration of the study. The PI will collect 20-24 pre-and post-assessment data cases and 12-18 observation note sets for analysis. The PI will keep data translated into electronic form in a password-protected file folder on a password-protected computer on a hard drive. An additional electronic copy of the file will be kept on a password protected USB drive in the PI's possession. 
Data will first be examined within methodological tradition (quantitative data will be examined for differences in pre- to post-test scores in both instructional groups; qualitative data will be examined through thematic coding of narrative observation records), and then data will be mixed between methods. Comparative analysis will be conducted through triangulation of mixed data, using cluster and correspondence analysis to evidence congruence or incongruence of different instructional approaches when compared with academic assessment rates, Behavior Domain Scale rates, and student behaviors and experiences in both instructional settings. Preand post-reading comprehension and fluency performance assessments will be quantitatively analyzed to measure growth in student achievement levels within and between group settings. External Observation forms will measure qualitative data for student behavior and experiences within and between settings. Final analysis will compare both forms of data to measure congruence and/or incongruence of student achievement and behaviors/experiences within and between group settings to provide a full understanding of how low SES students experience and achieve in these different settings.

\section{School Setting and Sample}

The participants in this study will be fourth grade students attending a small, rural TK-6 school with a student population of approximately 300 students. The school's student population is approximately $60 \%$ Hispanic or Latino and approximately $40 \%$ White with less than $1 \%$ in other student groups. The school qualifies as Title I school with approximately $83 \%$ of the population socioeconomically disadvantaged (Appendix D). The school district serves approximately 2,500 students TK-12 comprising three elementary schools (grades TK-6), one 
middle school (grades 7-8), one high school (grades 9-12), one continuation (alternative) high school, and a Virtual Academy serving approximately 40 students spanning from $5^{\text {th }}-12^{\text {th }}$ grade. Out of 40 fourth grade students, there are approximately 18 currently receiving Title I services at the study site. These students will continue receiving the services they are entitled to and will be included in the participant pool. Six more students will need to be included in the participant pool and the PI will request recommendations from the Title I Interventionist. Random selection of participant pool will be a limiting factor due to small population, but it will not be a limiting factor for dividing participants into two groups. Participant pool selection will occur at the school site by the PI. Once parental consents are returned, a participant list will be generated by the PI, replacing names with coded ID's, and the ID list will be randomly divided into two groups ensuring random selection. The list with student names will be shredded.

Selection criteria but may not be necessary to determine eligibility based on the small population size. Criteria include: (a) reading comprehension and fluency rates below grade level standards, (b) flat rates in literacy skill development, (c) receive Title I literacy intervention services. Based on the percentage of Hispanic students in $4^{\text {th }}$ grade, it is estimated that approximately $35 \%$ (about 12 fourth graders) receive Title I services currently so CELDT levels will not be used as criteria. Assessment data will not be used as criteria for participant selection in this research study.

\section{Classroom Setting and Procedure}

Two study groups of 10-12 participants will attend 40-minute sessions during the morning English Language Arts (ELA) block, 5 days per week for 6 weeks consecutively therefore totaling of 20 hours of group participation. Time requirements for pre- and post- 
assessments may exceed the allotted time for study instruction by approximately 1-2 additional hours. Participation will total 21-22 hours over the study period. It should be noted that Title I reading intervention classes will occur with or without the study.

This study will replicate literacy instructional lessons and materials in the current Title I study site program with one group receiving a traditional model with no change in current instruction and a second group receiving an Appreciative Inquiry model as an approach to literacy instruction.

The study will occur in the classroom of the Title I Interventionist with each group session occurring during separate scheduled times. Teachers for each instructional group will not be permitted to observe or interrupt the alternative study group and will be required to maintain confidentiality. Instructional aides in the Title I program will continue their current assignments and will also be required to maintain confidentiality.

The Title I classroom is arranged using three large tables for learning stations in reading, writing, and listening skill review. The study group participants will be divided and seated at two learning stations for reading and writing instruction. The learning stations are taught in 20minute intervals with participants rotating between reading lessons with the teacher and writing lessons with the instructional aide. The reading and writing lessons and activities are the same for both study groups; they use textbook and assessment tools (Tour, 2012) from the site Title I program. Lesson instruction and delivery follow a consistent routine every day (Samples found in Appendix E).

The reading lesson taught by the teacher focuses on reading comprehension and fluency skill development with participants reading short passages aloud (partner-reading, group read- 
aloud, etc.), followed by group discussion to ask and answer questions, and group collaboration to complete comprehension instructional sheets.

The writing lesson taught by the instructional aide focuses on writing content and mechanics with skill review and practice. Lessons focus on specific writing skills (grammar, spelling, context, structure, etc.) with practice in writing sentences, short paragraphs, and/or completing skill-based instructional sheets.

The listening station has group sets of audio books (replaced each week) for students to read while listening to the story on audio devices using headphones. This additional station provides an informal activity for occasional use by students completing activities early and does not include follow-up practice activities.

For this study, the AI model instructional approach will implement four phases each week adapted from the Appreciative Inquiry theory 4-D Cycle. The PI has determined 4-D Cycle adaptations to align for use at the elementary level by slightly shifting the focus for each phase. The following illustrates adaptations made within each 4-D Cycle phase compared with AI 4-D Cycle phases of implementation.

The four phases in 4D AI were adapted by the PI for use with elementary populations respectively: Discovery (group storytelling of most positive experiences and successful practices) to Discovery (group storytelling of what skills and knowledge one already has) cognition of capital,- Dream (individuals describe what they would love to see occur within the organization) to Dream (what you can do with acquired capital-imagine your reality), Design (individuals determine the needs and active roles in order to achieve the dreams that will be realized) to Design (application of skills and knowledge to new learning-transforming habits of 
learning), and Destiny/Deliver (monitoring the effectiveness of the action plans in place to ensure a true visualization of the Dream) to Destiny (why one's is knowledge important -practice empowerment and voice).

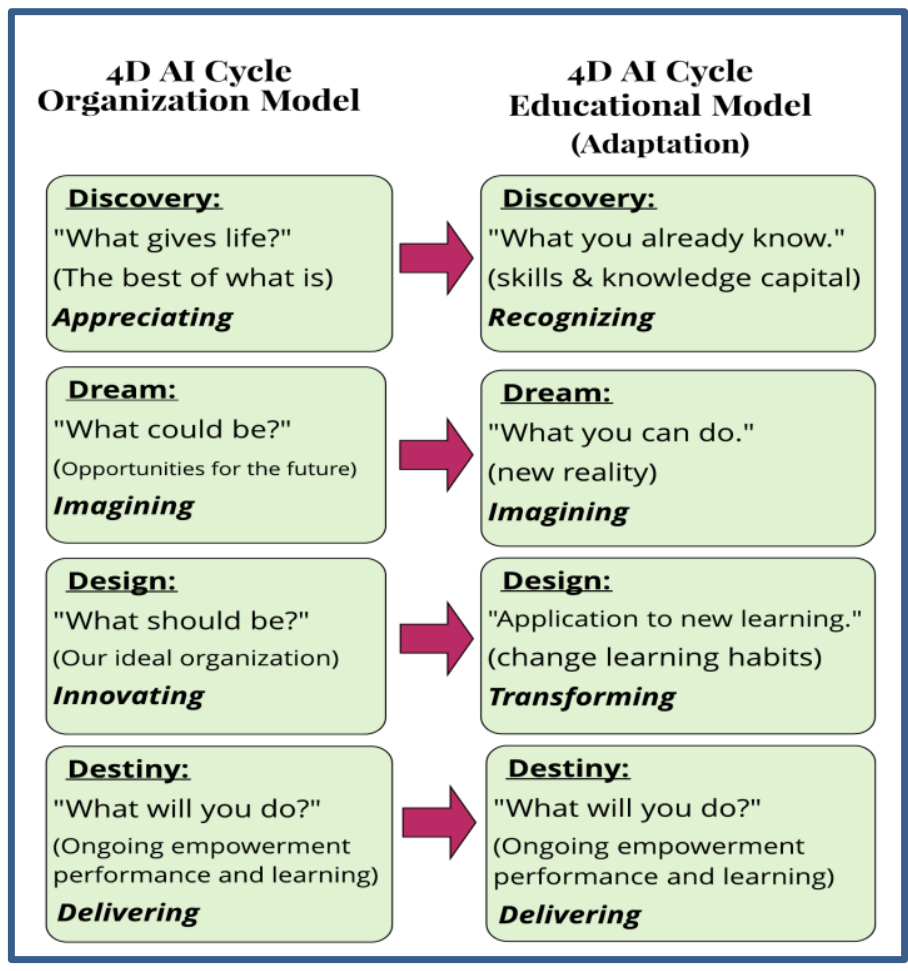

AI Destiny Adaptation additional question: "Why is your new knowledge important?"

\section{Data Collection and Instruments}

Quantitative Strand: Quantitative data using pre- and post-reading comprehension and reading fluency testing instruments collected prior to after concluding study timeframes. External observations of student and teacher behaviors in four specific categories (Behavior Domains: student comprehension of material, student fluency of material, teacher behavior and engagement, and student engagement and experience) records frequency and intensity levels measured with a scaled-score rating system. (instrument- from Part 1 of the External Observation Framework form) (Appendix B.1). 
Pre- and post-test data for reading comprehension and fluency collected at the beginning and end of the research study, will be comparatively analyzed. This data will measure any changes in reading comprehension and fluency achievement levels for both instructional groups. Behavior Domain data collection will occur the first, third and final week of the research study period. The external observer (not the research PI) will observe both study groups on any two days during alternating weeks. Quantitating observation data will provide a clearer understanding of how students experience different literacy instructional approaches. Quantification increases reproducibility and reliability of data analysis. Behavior Domain scaled scores of observed teacher and student behaviors will analyze frequency and intensity levels of behavior in four specific behavior domains for both instructional groups' settings.

The reading comprehension test instrument (Appendix G.1) is an on-line Reading Inventory Assessment that measures rates of reading comprehension referred as "Lexile" levels. According to the Lexile Framework for Reading website (lexile.com, 2016), the Lexile framework for reading is a program that matches readers with texts correlated to comprehension level. The program is the national standard for state and district assessments in reading comprehension. The website states that Lexile measures are the "gold standard for college and career readiness" and are research driven. Typical Reader Measures for fourth grade range from Lexile level 445-810. These measures determine the range of comprehension across grade spans.

The Lexile assessment instrument consists of an online exam where students read multiple passages approximately a paragraph in length. At the end of each passage, the student chooses the word missing from the last sentence that best fits within the context of the paragraph. Students are given four multiple-choice words to choose from in determining the answer. The 
exam takes approximately thirty minutes to an hour depending on student progression. The Lexile software then reports a numerical score that identifies reading comprehension level based on text complexity, sentence length and word count.

The reading fluency instrument is administered manually using Read Naturally Progress Monitoring to measure rates during a timed reading of short grade level text passages.

According to the Read Naturally website (readnaturally.com, 2016), Read Naturally is a research-driven intervention program designed to increase student achievement in reading fluency, comprehension, vocabulary development, and skill development in phonics and phonemic awareness. Fluency assessments constitute the use of a one-page reading passage and the students are timed for one minute, during which they read the passage aloud to the instructor. The words-correct-per-minute score is calculated to determine fluency rate. Grade level fluency rates are determined using the Reading Fluency Progress Monitor assessment, which, according to the Read Naturally website is an "efficient, valid, and reliable assessment to measure a student's progress in reading." Fluency rates are reported as percentiles. Fourth grade rates range from 94-103 in the fiftieth percentile and 145-180 in the ninetieth percentile. For this study, there will be no set goal to reach in comprehension and fluency. The focus will be on a rate of growth model under contrasting instructional approach methodologies in determining literacy achievement gains quantitatively.

The instrument for student and teacher behaviors and experiences will be recorded using the External Observation Framework Form. The framework form, developed by the PI in collaboration with her advisor, incorporates the California Standards for the Teaching Profession (CSTP) as an organizing framework to manage and analyze qualitative data. 
Quantitative data will be collected using recorded observations in four Behavior Domains in Part1 of the External Observation Form. The four behavior domains emerged from the six CSTP standards. Each behavior domain has three category levels (high, medium, and low type). Each occurrence of observed behaviors recorded will use a 3-point intensity scaled-score (1: low, 2: mid; 3: high). Qualitative observations in Part 1 will be transformed to quantitative data to measure frequency and intensity levels of behaviors in each domain (Brackett, Reyes, Rivers, Elbertson \& Salovey, 2011).

Student behavior and experiences in different instructional approach settings will be recorded by the external observer, collected, and securely stored by the PI after each study group session. Students will not be interviewed or interact with the external observer at any time throughout the study.

Qualitative Strand: Qualitative data will be recorded from an external observer using the External Observation Form, Part 2: Narrative Reflection during each observed group session. Part 2 contains two sections for narrative reflection that will be coded into interpretive categories: (1) narrative examples of observed teacher behaviors and practices framed around the six California Standards of Teaching Professionals published by the Commission on Teacher Credentialing in 2009, and (2) personal critical analysis narrative summarizing all observed behaviors and experiences with the instructional approach utilized during the session, including specific examples to support the overall critique.

Qualitative data collected from external observations of student and teacher behaviors and experiences will be compared for each instructional group to determine any correlations with 
quantitative data findings. Qualitative data may also provide anecdotal evidence to support findings in quantitative data analysis.

\section{External Observation Form and Procedure}

The external observer will arrive, obtain an observation form from the PI, and unobtrusively observe the interactions of students and teacher during each study group session. The observer will record behaviors directly observed throughout the session on the form. Once the session is over, the observer will then reflect on their observations, narrating specific examples of behaviors observed. This process will be repeated for each study group observation. The observer will return the observation forms to the researcher concluding each observation session.

Part 1 assigns specific student and teacher behaviors into four domains: 1) Student comprehension of material, 2) student fluency of material, 3) teacher behavior and engagement toward students, and 4) student behavior and engagement toward teacher and text. Each domain includes three levels rated as (a) Full, Some, None, (b) Fluently, Struggling, Difficulty, or (c) Positive, Flat, Negative. The assigned values are scored on a three-point scale (1: low, 2: mid, 3: high) based on intensity and frequency of all observed behaviors (Brackett, et al., 2011).

Part 2, Section 1, is a narrative reflection of teaching practices using the six California Standards for the Teaching Profession. Part 2, Section 2, is a critical analysis narrative of overall session observation, summarizing the critique using examples that evidence the analysis.

Analysis of data using external observations may clarify student experiences and achievement related to different approaches to literacy instruction for low SES students that may not emerge from quantitative data analysis alone. 


\section{Data Analysis}

Quantitative Data: Quantitative analysis of data from pre- and post- reading comprehension and fluency scores will employ non-parametric statistics; the analysis will use a repeated measure T-Test for each group as a comparison to examine individual and group differences within the data from pre- to post- assessment. Descriptive statistical analysis will first describe mean scores for the two different groups at pre- and post- and then seek to determine if there are statistically meaningful differences between the two groups at the pre- test and again at the post- test.

Qualitative data from External Observation form, Part 1 will be examined and transformed into qualitative data using a scaled-score to compare mean data of each domain from both instructional groups. Transposing the observational data into quantitative scores will allow for description of total domain scores aggregated from all session observation forms for each group, therefore yielding a frequency and intensity score for Behavior Domain Scale. Behavior Domain Scale scores for both groups will be compared using between-method triangulation for evidence of dominant congruence or incongruence of different instructional approaches and student experience levels.

Data within the four behavior domains will be analyzed using repeated measure to make comparisons of statistical significance within and across instructional groups. The domain data will also be calculated using descriptive statistics to determine a total domain score for each external observation. The total domain scores for all sessions of each group will then be calculated to create a cumulative score in each domain. The cumulative scores from each group will be analyzed using cluster/correspondence analysis for congruence or incongruence of 
instructional approach effectiveness related to student behaviors and experiences within and across groups.

Qualitative Data: The qualitative data will be analyzed using a grounded theory coding approach. Qualitative data from External Observation form, Part 2A and B: Narrative Reflection will be transcribed into a Word document and categorically coded using color differentiation. Thematic coding using a triple sorting process will facilitate further data reduction. The first read will code major overarching themes, the second read will code categories with common characteristics within each major theme, and the third read will code anomalies or outliers found within the observer narratives. Narrative data will be represented in quotes under coded themes.

Cluster analysis for three dimensions will be analyzed separately on Part 2A of the observation form for each instructional group: 1) Narrative evidence within CSTP standards 1-6; 2) Overall teacher and student rates within CSTP standard 1-6;3) Critical narrative analysis and overall session rating in Part 2B. Cluster and correspondence analysis of coded data will be used for evidence of congruence or incongruence of instructional approaches and student experience levels and rates of growth comparisons in different learning environments.

Mixed-method Data: Comparative analysis through triangulation of mixed data, using cluster and correspondence analysis, will be used to evidence congruence or incongruence of different instructional approaches when compared with student experiences, and academic assessment rates in both instructional approach settings.

Triangulation of mixed data will be used in developing a grounded theory of effective instructional practices and student achievement. Legitimation will be determined using parallel 
mixed analysis of dependent and variable data, making contrasts/comparisons, and peer debriefing to ensure validity of final conclusions, implications, and recommendations.

Final Analysis: Mixed methods comparative analysis will be used to determine if the results of qualitative data do or do not support evidence of growth patterns in the results of quantitative data in different instructional settings. Mixed methods data analysis will provide a framework for conclusions drawn from qualitative analysis to confirm or reject conclusions drawn from quantitative analysis strengthening study findings.

The final analysis will also contribute to ensuring external validity of the research study's conclusions. Finally, results from both quantitative and qualitative data from both data sets will be evaluated for correlations between student experiences in different learning environments and student achievement.

\section{Conclusion}

This study is designed to collect evidence of differences in low SES student achievement and experiences using two different instructional approaches. The intent of this study is to empirically evidence the relationship between strengths-based instructional settings and academic achievement in literacy for low SES students.

The objectives of this research study are: (a) compare (quantitative) data through examination assessment scores in a strengths (or appreciative)-based instructional approach and a traditional instructional approach as a means to better understand how to increase student academic achievement (literacy focus), especially for low SES students; (b) describe (qualitative) AI model and traditional instructional literacy pedagogy to gain insight into how different instructional approaches impact student learning experiences; and, (c) describe the experiences 
(qualitative and quantitative) of low SES students in different literacy instructional settings, in order to gain insight into the relationship between instructional approaches, student behaviors/experiences, and student achievement through analysis (examining areas of convergence, divergence, and expansion) of mixed methods data as a means to increase teacher effectiveness in providing a high quality education for all learners, especially for low SES students. Though this study focuses on literacy intervention instruction, results may be extrapolated to other subject areas.

The results of this study will determine if an Appreciative Inquiry model as an instructional literacy approach has a significant impact on student achievement and experiences compared to traditional literacy instructional approaches for low SES students at the elementary level. Although this study is limited to literacy rates, the results may be generalizable to TK-12 core curriculum delivery methods.

The findings of this research may be used to determine the validity of using an alternative asset-based approach in raising student academic achievement, especially for low SES students. A mixed methods approach is intended to reciprocate strand outcomes, thereby providing answers about student experiences in differing literacy intervention settings.

\section{Study Logistics}

Prior to conducting the study, selection of instructor and external observer participants was determined. This determination followed a logical approach whereas the Title I Interventionist, having taught in this capacity for over 6 years at the study site using traditional instructional pedagogies, was an ideal candidate as a controlled variable within the parameters of 
the study. An informal conversation was held where the Interventionist agreed to participate within the study parameters.

Selection of external observers was determined through inquiries of available volunteer's familiar with student and teacher behaviors and experiences recognized in educational settings. An invitation to participate in the capacity of observer was extended and accepted after learning the study parameters. The external observer's role will strictly adhere to observation objectivity and a commitment to bias exclusion.

Approvals for conducting the study with human subjects needed to be collected as well. The first approval was from the school district. This Letter of Support stated conceptual approval for conducting this study once IRB approval was confirmed. The letter defined district guidelines for the Governing Board of Education approval is subsequent to IRB approval of human subjects; but in concept the district supports conducting the study (Appendix C.1). A Letter of Support from the site administrator (Appendix C.2) that stated conceptual approval for the study to be conducted at the site following the study framework pending district approval also needed to be collected. Once that was granted, Parental Consent Forms (Appendix C.3: English; Appendix C.4: Spanish) were distributed. These forms contained an outline that detailed study parameters and expectation requirements of student participation. Parental consent forms were collected and retained by the researcher prior to commencement of the study. Study participants will sign an Assent form (Appendix C.5) prior to participation in the research study. The final approval needed was IRB approval for the study.

The next area was to focus on planning the interventions for each week of the study. The Title I Interventionist and the teacher collaboratively planned activities for each day of the week 
that would support literacy development for these students. Planned activities included reading books that would be used, activities such as games for blending practice, writing activities to solidify comprehension of readings, listening activities where audiobooks were chosen followed by group discussions that were led by questions designed by the collaborators, and vocabulary development using group critical thinking strategies and discussions to determine context clues and dictionaries.

Once those elements were in place, there was a pilot test performed prior to the study with the external observers using the Framework Observation form. The purpose of this pilot test was to ensure the adequacy and validity in collecting the desired data as well as training the observer on specific behaviors during observations that include not interrupting the learning environment as much as possible and not interacting or interviewing students. The observers toured the classroom setting prior to the study to determine best placement for the observer. 


\section{CHAPTER 4: RESEARCH RESULTS AND FINDINGS}

\section{Chapter Overview}

The purpose of this research study was to conduct a program evaluation comparing low SES student achievement and experiences in two instructional settings; one using an Appreciative Inquiry model as an approach to literacy instruction and one using a traditional (commonly practiced) approach to literacy instruction.

A QUANT $\rightarrow$ qual $\rightarrow$ QUANT deductive theoretical design framed comparative research methods using descriptive statistics that measured quantitative data collected from prereading comprehension and reading fluency testing instruments and observation data recorded in Part I, Behavior Domains, of the External Observation Form. Qualitative data recorded in Part I, Behavior Domains, on the External Observation Form instrument, first transformed into quantitative data for statistical analysis using SPSS. Thematic coding methods, employed using a grounded theory approach, to measure qualitative observation narrative data recorded in Part II, Narrative Reflection, on the External Observation Form instrument, was first transcribed into a Word document, capturing narrative observations in quotations under emergent themes found during coding analysis. Finally, quantitative data from post-reading comprehension and reading fluency scores measured similarities and differences in achievement levels within and between Group A and Group B pre-to post-test analysis. These data sets were analyzed using comparative research methods as well.

The research study was set in a small rural school during the second semester of the school year 2016-2017. Pooled participants totaled twenty-two fourth graders; eleven receiving Title I program instruction, and eleven teacher recommendations, all received invitations. 
Twenty returned invitations to participate with two declines. Participants totaled twenty fourth graders (50\% of the grade level) with the following percent of students receiving program services: 10\% SAI (Specialized Academic Instruction), 15\% Speech, 50\% ELD, 55\% Title I, programs, and 25\% not receiving any program services outside of the general education classroom.

Twenty 4th grade students participated in the six-week study, with ten participants in each instructional group setting. The PI employed an AI model as an instructional approach in Group A and the Title I teacher maintained current instruction in study Group B for comparison. An external observer recorded observations during six sessions per group throughout the sixweek study.

To answer the research question, "How do low SES students experience Appreciative Inquiry model as an instructional approach compared to a traditional instructional approach?", multiple statistical analysis methods measured qualitative and quantitative data using SPSS statistics analysis and NVivo coding software data management systems. Data collected from twelve external observation forms, ten reading comprehension pre-and ten post-tests, and ten reading fluency pre- and ten post-tests comprised the instruments for comparative analysis to answer the research question. The results and findings demonstrate promising positive trends using alternative instructional approaches to increase achievement levels and positive experiences for all students.

\section{Quantitative Analysis Results}

\section{Reading Comprehension and Fluency Pre- and Post-test Analysis}


Quantitative pre- and post-comprehension and fluency data variables organized into an SPSS spreadsheet appear in Table 1.

Table 1 Variable Information

\begin{tabular}{|l|l|l|l|l|l|l|}
\hline Name & Position & Label & $\begin{array}{l}\text { Measurement } \\
\text { Level }\end{array}$ & Format & $\begin{array}{l}\text { Column } \\
\text { Width }\end{array}$ & Alignment \\
\hline Group A & 1 & <none> & Scale & F8 & 8 & Right \\
Order A & 2 & <none> & Scale & F8 & 8 & Right \\
PreCompGpA & 3 & <none> & Scale & F8 & 10 & Right \\
PostCompGpA & 4 & <none> & Scale & F8 & 11 & Right \\
PreFluGpA & 5 & <none> & Scale & F8 & 8 & Right \\
PostFluGpA & 6 & <none> & Scale & F8 & 8 & Right \\
Group B & 7 & <none> & Scale & F8 & 8 & Right \\
Order B & 8 & <none> & Scale & F8 & 8 & Right \\
PreCompGpB & 9 & <none> & Scale & F8 & 8 & Right \\
PostCompGpB & 10 & <none> & Scale & F8 & 8 & Right \\
PreFluGpB & 11 & <none> & Scale & F8 & 8 & Right \\
PostFluGpB & 12 & <none> & Scale & F8 & 8 & Right \\
APretoPost & 13 & <none> & Scale & F8.2 & 12 & Right \\
BPretoPost & 14 & <none> & Scale & F8.2 & 12 & Right \\
\hline
\end{tabular}

Table 1 Pre- and post-comprehension and fluency variable view

After setting up my data in SPSS, I first ran a set of descriptive statistics, these included measures of central tendency, mean, median, and mode, standard deviation, variance, skew, range, sum, and percentiles found in Table 2.

Table 2

Descriptive Statistics

\begin{tabular}{|l|l|l|l|l|l|l|l|}
\hline & \multirow{2}{*}{} & Sum & Mean & $\begin{array}{l}\text { Std. } \\
\text { Deviation }\end{array}$ & Variance & \multicolumn{2}{|c|}{ Skewness } \\
\cline { 2 - 8 } & & & & & & \multicolumn{2}{|l}{$\begin{array}{l}\text { Std. } \\
\text { Etror }\end{array}$} \\
\hline PreCompGpA & 10 & 6510 & 651.00 & 256.234 & 65656.000 & -.179 & .687 \\
PostCompGpA & 10 & 6883 & 688.30 & 248.912 & 61957.344 & -.703 & .687
\end{tabular}




\begin{tabular}{|l|l|l|l|l|l|l|l|} 
PreFluGpA & 10 & 988 & 98.80 & 41.569 & 1727.956 & .211 & .687 \\
PostFluGpA & 10 & 1198 & 119.80 & 35.090 & 1231.289 & -.084 & .687 \\
PreCompGpB & 10 & 4217 & 421.70 & 143.957 & 20723.567 & -.421 & .687 \\
PostCompGpB & 10 & 4495 & 449.50 & 137.408 & 18880.944 & -.489 & .687 \\
PreFluGpB & 10 & 656 & 65.60 & 19.845 & 393.822 & -.071 & .687 \\
PostFluGpB & 10 & 818 & 81.80 & 19.871 & 394.844 & -.401 & .687 \\
Valid N & 10 & & & & & & \\
(listwise) & & & & & & & \\
\hline
\end{tabular}

Table 2 SPSS descriptive statistics pre- and post-comprehension and fluency data

A one-sample T-Test showed mean differences within and between Group A's and Group B's pre- and post-comprehension and fluency data at the $95 \%$ confidence interval of the difference. Analysis showed higher mean differences pre- to post-comprehension and fluency for Group A. Group A's mean difference in comprehension pre- to post-test was 37.3\%, fluency preto post-test was $21.0 \%$ compared with Group B's mean difference pre- to post-comprehension of $27.8 \%$ and pre-to post-fluency was $16.2 \%$. This tells us that both groups showed increased mean differences pre-to post-test analysis in comprehension and fluency. Group A had substantially higher mean differences than Group B during that same period. These results show positive mean growth trends in Group A and Group B with higher trends in Group A than Group B preto post-test analysis. While Group A observed mean difference trends in the hypothesized direction, the T-Test examining mean difference between the two groups did not reveal a statistically significant difference at the $95 \%$ confidence level. The results showed mean differences between groups at pre-test and post-test, but did not analyze for differences between growth in each group pre- to post-test.

Table 3 One-Sample Test

Test Value $=0$ 


\begin{tabular}{|c|c|c|c|c|c|c|}
\hline & \multirow[b]{2}{*}{$\mathrm{t}$} & \multirow[b]{2}{*}{ df } & \multirow[b]{2}{*}{ Sig. (2-tailed) } & \multirow{2}{*}{$\begin{array}{l}\text { Mean } \\
\text { Difference }\end{array}$} & \multicolumn{2}{|c|}{$\begin{array}{l}95 \% \text { Confidence Interval of } \\
\text { the Difference }\end{array}$} \\
\hline & & & & & Lower & Upper \\
\hline PreCompGpA & 8.034 & 9 & .000 & 651.000 & 467.70 & 834.30 \\
\hline PostCompGpA & 8.744 & 9 & .000 & 688.300 & 510.24 & 866.36 \\
\hline PreFluGpA & 7.516 & 9 & .000 & 98.800 & 69.06 & 128.54 \\
\hline PostFluGpA & 10.796 & 9 & .000 & 119.800 & 94.70 & 144.90 \\
\hline PreCompGpB & 9.263 & 9 & .000 & 421.700 & 318.72 & 524.68 \\
\hline PostCompGpB & 10.345 & 9 & .000 & 449.500 & 351.20 & 547.80 \\
\hline PreFluGpB & 10.453 & 9 & .000 & 65.600 & 51.40 & 79.80 \\
\hline PostFluGpB & 13.018 & 9 & .000 & 81.800 & 67.59 & 96.01 \\
\hline
\end{tabular}

Table 3 Pre- and post-comprehension and fluency one-sample T-Test output data

Overall, Group A showed higher mean scores at pre-test analysis, post-test analysis, and pre- to post-test analysis than Group B mean scores measures. Positive mean growth trends preto post-test comprehension and fluency in both groups showed no statistically significant differences.

\section{Behavior Domains Frequency/Intensity Analysis}

Qualitative data collected from direct observations for Group A and Group B measured skill level frequency and intensity rates of behaviors in four domains. The qualitative observational data transformed into quantitative data using SPSS spreadsheet for 25 variable inputs. The variables define behavior domains as: D1- Domain 1: Comprehension of material; D2- Domain 2: Fluency of material; D3- Domain 3: Teacher behavior/engagement; D4- Domain 4: Student engagement/experience.

Three skill levels (Full, Some, None) define the weight of demonstrated skill level for each observed domain behavior. Three intensity scale-scores $(3=$ high, $2=$ mid, $1=$ low $)$ define intensity rates of demonstrated skill level behavior observed. Domain behaviors, skill levels, and 
intensity rates totaled 36 variable inputs. Behavior skill level "none" contained no recorded observation data and subsequently excluded, leaving 24 variable inputs for analysis. Frequency analysis measured behavior rates of occurrence observed in Group A and Group B. Six observation forms collected from each group during the study totaled 12 data sets for analysis.

Descriptive statistics using Independent Sample T-Tests measured behavior domain sum totals for both Group A and B. Analysis comparisons between group A and B produced overall behavior domain mean frequency, intensity, and sum comparisons as well as each variable behavior mean frequency, intensity, and sum comparisons within each domain. Mean data was also computed using quantitative data from SPSS spreadsheet data view source.

Table 6

\begin{tabular}{|l|r|r|}
\hline \multicolumn{3}{|c|}{ Descriptive Statistics } \\
\hline & $\mathrm{N}$ & \multicolumn{1}{|c|}{ Sum } \\
\hline Dom1Full3 & 12 & 30 \\
D1F2 & 12 & 54 \\
D1F1 & 12 & 10 \\
D1S3 & 12 & 7 \\
D1S2 & 12 & 45 \\
D1S1 & 12 & 18 \\
D2F3 & 12 & 18 \\
D2F2 & 12 & 36 \\
D2F1 & 12 & 8 \\
D2S3 & 12 & 8 \\
D2S2 & 12 & 27 \\
D2S1 & 12 & 16 \\
D3F3 & 12 & 44 \\
D3F2 & 12 & 36 \\
D3F1 & 12 & 0 \\
D3S3 & 12 & 5 \\
D3S2 & 12 & 26 \\
D3S1 & 12 & 4 \\
D4F3 & 12 & 2 \\
\end{tabular}




\begin{tabular}{|ll|r|r|}
$\mathrm{D} 4 \mathrm{~F} 2$ & & 12 & 47 \\
$\mathrm{D} 4 \mathrm{~F} 1$ & & 12 & 7 \\
$\mathrm{D} 4 \mathrm{~S} 3$ & & 12 & 2 \\
$\mathrm{D} 4 \mathrm{~S} 2$ & & 12 & 32 \\
$\mathrm{D} 4 \mathrm{~S} 1$ & & 12 & 13 \\
Valid & $\mathrm{N}$ & 12 & \\
(listwise) & & & \\
\hline
\end{tabular}

Table 6 Behavior Domain quantitative descriptive statistics

Table 7

Group Statistics

\begin{tabular}{|c|c|c|c|c|c|}
\hline & ObsGroup/Form & $\mathrm{N}$ & Mean & Std. Deviation & $\begin{array}{l}\text { Std. Error } \\
\text { Mean }\end{array}$ \\
\hline \multirow[t]{2}{*}{ Dom1Full3 } & 1 & 6 & 4.67 & 3.983 & 1.626 \\
\hline & 2 & 6 & .33 & .516 & .211 \\
\hline \multirow[t]{2}{*}{$\mathrm{D} 1 \mathrm{~F} 2$} & 1 & 6 & 4.00 & 2.191 & .894 \\
\hline & 2 & 6 & 5.00 & 1.265 & .516 \\
\hline \multirow[t]{2}{*}{ D1F1 } & 1 & 6 & .67 & 1.211 & .494 \\
\hline & 2 & 6 & 1.00 & .894 & .365 \\
\hline \multirow[t]{2}{*}{ D1S3 } & 1 & 6 & .83 & 1.169 & .477 \\
\hline & 2 & 6 & .33 & .816 & .333 \\
\hline \multirow[t]{2}{*}{$\mathrm{D} 1 \mathrm{~S} 2$} & 1 & 6 & 3.33 & 2.503 & 1.022 \\
\hline & 2 & 6 & 4.17 & 1.472 & .601 \\
\hline \multirow[t]{2}{*}{ D1S1 } & 1 & 6 & 1.50 & 1.975 & .806 \\
\hline & 2 & 6 & 1.50 & 1.517 & .619 \\
\hline \multirow[t]{2}{*}{$\mathrm{D} 2 \mathrm{~F} 3$} & 1 & 6 & 2.83 & 3.371 & 1.376 \\
\hline & 2 & 6 & .17 & .408 & .167 \\
\hline \multirow[t]{2}{*}{$\mathrm{D} 2 \mathrm{~F} 2$} & 1 & 6 & 2.33 & 1.862 & .760 \\
\hline & 2 & 6 & 3.67 & 2.160 & .882 \\
\hline \multirow[t]{2}{*}{$\mathrm{D} 2 \mathrm{~F} 1$} & 1 & 6 & .17 & .408 & .167 \\
\hline & 2 & 6 & 1.17 & 1.329 & .543 \\
\hline \multirow[t]{2}{*}{$\mathrm{D} 2 \mathrm{~S} 3$} & 1 & 6 & 1.00 & 1.095 & .447 \\
\hline & 2 & 6 & .33 & .816 & .333 \\
\hline \multirow[t]{2}{*}{$\mathrm{D} 2 \mathrm{~S} 2$} & 1 & 6 & 1.50 & 1.975 & .806 \\
\hline & 2 & 6 & 3.00 & 1.673 & .683 \\
\hline D2S1 & 1 & 6 & .83 & 1.329 & .543 \\
\hline
\end{tabular}




\begin{tabular}{|c|c|c|c|c|c|}
\hline & 2 & 6 & 1.83 & 1.835 & .749 \\
\hline \multirow[t]{2}{*}{ D3F3 } & 1 & 6 & 5.83 & 4.622 & 1.887 \\
\hline & 2 & 6 & 1.50 & 2.345 & .957 \\
\hline \multirow[t]{2}{*}{ D3F2 } & 1 & 6 & 1.50 & 2.811 & 1.147 \\
\hline & 2 & 6 & 4.50 & 3.209 & 1.310 \\
\hline \multirow[t]{2}{*}{ D3F1 } & 1 & 6 & .00 & $.000^{\mathrm{a}}$ & .000 \\
\hline & 2 & 6 & .00 & $.000^{\mathrm{a}}$ & .000 \\
\hline \multirow[t]{2}{*}{ D3S3 } & 1 & 6 & .67 & 1.211 & .494 \\
\hline & 2 & 6 & .17 & .408 & .167 \\
\hline \multirow[t]{2}{*}{ D3S2 } & 1 & 6 & 1.33 & 1.966 & .803 \\
\hline & 2 & 6 & 3.00 & 2.366 & .966 \\
\hline \multirow[t]{2}{*}{ D3S1 } & 1 & 6 & .17 & .408 & .167 \\
\hline & 2 & 6 & .50 & .837 & .342 \\
\hline \multirow[t]{2}{*}{ D4F3 } & 1 & 6 & .33 & .816 & .333 \\
\hline & 2 & 6 & .00 & .000 & .000 \\
\hline \multirow[t]{2}{*}{$\mathrm{D} 4 \mathrm{~F} 2$} & 1 & 6 & 3.17 & 3.189 & 1.302 \\
\hline & 2 & 6 & 4.67 & 2.733 & 1.116 \\
\hline \multirow[t]{2}{*}{ D4F1 } & 1 & 6 & .33 & .816 & .333 \\
\hline & 2 & 6 & .83 & 1.329 & .543 \\
\hline \multirow[t]{2}{*}{ D4S3 } & 1 & 6 & .33 & .816 & .333 \\
\hline & 2 & 6 & .00 & .000 & .000 \\
\hline \multirow[t]{2}{*}{ D4S2 } & 1 & 6 & 2.83 & 2.714 & 1.108 \\
\hline & 2 & 6 & 2.50 & 2.258 & .922 \\
\hline \multirow[t]{2}{*}{$\mathrm{D} 4 \mathrm{~S} 1$} & 1 & 6 & 1.00 & 1.265 & .516 \\
\hline & 2 & 6 & 1.17 & 1.472 & .601 \\
\hline
\end{tabular}

a. $\quad t$ cannot be computed because the standard deviations of both groups are 0 .

Table 7 Behavior Domain mean frequency and intensity comparisons from group statistics

Table 7a

\begin{tabular}{|l|l|l|l|l|l|l|l|l|} 
Group & $\begin{array}{l}\text { D1 } \\
\text { Sum }\end{array}$ & Freq. & \multicolumn{3}{|l|}{ Intensity } \\
& & & $\begin{array}{l}\text { D1 } \\
\text { F3 }\end{array}$ & $\begin{array}{l}\text { D1 } \\
\text { F2 }\end{array}$ & $\begin{array}{l}\text { D1 } \\
\text { F1 }\end{array}$ & $\begin{array}{l}\text { D1 } \\
\text { S3 }\end{array}$ & $\begin{array}{l}\text { D1 } \\
\text { S2 }\end{array}$ & D1 \\
\hline A & 90 & .592 & 4.67 & 4.0 & .67 & .83 & 3.33 & 1.50 \\
\hline B & 62 & .408 & .33 & 5.0 & 1.0 & .33 & 4.17 & 1.50 \\
\hline Total & 152 & 1.00 & & & & & & \\
\hline
\end{tabular}




\begin{tabular}{|l|l|l|l|l|l|l|l|l|} 
Group & $\begin{array}{l}\text { D2 } \\
\text { Sum }\end{array}$ & Freq. & \multicolumn{3}{|l|}{ Intensity } & & & \\
& & & D2 & D2 & D2 & D2 & D2 & D2 \\
F2 & F1 & S3 & S2 & S1 \\
\hline A & 104 & .630 & 2.83 & 2.33 & .17 & 1.0 & 1.50 & .83 \\
\hline B & 61 & .370 & .17 & 3.67 & 1.17 & .33 & 3.00 & 1.83 \\
\hline Total & 165 & 1.00 & & & & & & \\
\hline
\end{tabular}

\begin{tabular}{|l|l|l|l|l|l|l|l|l|} 
Group & $\begin{array}{l}\text { D3 } \\
\text { Sum }\end{array}$ & \multicolumn{2}{|l|}{ Freq. } & \multicolumn{2}{|l|}{ Intensity } & & & \\
& & & D3 & D3 & D3 & D3 & D3 & D3 \\
& & & F3 & F2 & F1 & S3 & S2 & S1 \\
\hline A & 114 & .633 & 5.83 & 1.50 & .00 & .67 & 1.33 & .17 \\
\hline B & 58 & .337 & 1.50 & 4.50 & .00 & .17 & 3.00 & .50 \\
\hline Total & 172 & 1.00 & & & & & & \\
\hline
\end{tabular}

\begin{tabular}{|l|l|l|l|l|l|l|l|l|} 
Group & $\begin{array}{l}\text { D4 } \\
\text { Sum }\end{array}$ & Freq. & \multicolumn{3}{|l|}{ Intensity } & & & \\
& & & D4 & D4 & D4 & D4 & D4 & D4 \\
& & F2 & F1 & S3 & S2 & S1 \\
\hline A & 94 & .630 & .33 & 3.17 & .816 & .83 & 2.83 & 1.00 \\
\hline B & 55 & .370 & .00 & 4.67 & .83 & .00 & 2.50 & 1.17 \\
\hline Total & 149 & 1.00 & & & & & & \\
\hline
\end{tabular}

Table 7a Behavior Domain mean frequency and intensity tables

Table 7a condenses mean frequency, intensity, and skill level comparisons between Group A and Group B for each domain. Analysis showed Group A's mean frequency. 63\%, higher in all domains than Group B, 37\%. Analysis also showed Group A with higher mean intensity in FULL skill level rated at the highest (demonstrated behavior) intensity (F3) and SOME skill level at the highest (demonstrated behavior) intensity (S3) than Group B in all four domains. Group B's mean intensity was higher in FULL and SOME skill level rated at the midand low (demonstrated behavior) intensity (F2/F1; S2/S1) than Group A in all four domains (D4S2 diverges with Group A's mean intensity of 2.83\% compared with Group B's mean intensity of $2.50 \%)$. 
This showed Group A higher FULL skill levels at HIGH (“3”) intensity rates in all behavior domains and Group B showed higher FULL skill levels at MID (“2”) intensity and LOW ("1") intensity rates in all behavior domains. Group A showed higher SOME skill levels at HIGH intensity rates in all behavior domains and Group B showed higher SOME skill levels at MID and LOW intensity rates in all behavior domains. Data diverges in Domain 1 with Group B showing the equal mean intensity rates for SOME reading comprehension skills with low intensity demonstrated behaviors. Diverging data found in Domain 4 showed Group A's mean intensity higher than Group B's mean intensity in SOME mid-intensity rates of observed teacher engagement behavior.

Finally, domain sum comparisons between groups showed higher total observations in each domain for Group A than Group B. This showed differences in student and teacher behaviors in different instructional settings with Group A's mean behavior frequency and intensity of skills observed at higher rates than Group B.

Overall, Group A's observed behaviors, on average, demonstrated higher skill levels at higher rates of intensity more frequently than Group B. Group B's observed behaviors, on average, demonstrated mid-to low skill levels at lower rates of intensity less frequently than Group A.

\section{Qualitative Analysis}

\section{CSTP Narrative Observations}

The instrument to analyze qualitative data from External Observation Form, Part 2: Narrative Reflection contained two Sections (A and B) and six CSTP categories. Section A contained only one recorded observation and subsequently excluded from coding transcriptions. 
The first thematic coding transcribed narrative quotes from Group A and B chronologically into predefined code themes using the six CSTP categories. Color-coding identification (Appendix H) allowed quick reference with Group A's code transcriptions colorcoded red listed first in all coding sources and Group B's transcriptions color-coded blue throughout analysis. The second thematic coding restructured data into emerging themes. Emerging theme categories organized Group A and Group B quote codes for: Classroom Instruction, Classroom Environment/Climate, Teacher Behavior and Student Engagement. Subcategory themes and Memos (to document initial interpretations) were included in the second code transcription. The second thematic coding organized data into a table labeling Category (highlighted in yellow)/Subcategory, Study Group (A=AI, B=TI), Reference Number (Observation number and CSTP number), Narrative (color-coded quotes), and Memos (my interpretations as I developed the document) (Appendix I). Two additional transcription documents coded Group A and B's narrative quotes separately for comparative analysis.

All coded transcriptions entered into NVivo 11 coding software as project internal. Analysis of qualitative data continued using NVivo Plus to code themes, nodes, queries, patterns, and visual diagrams. Major code themes became Parent Nodes for Classroom Environment, Classroom Instruction, Student Engagement, and Teacher Behavior. Child Nodes defined Parent Nodes specifically for Group A (labeled “AI”) and Group B (labeled “TI”).

Consistent patterns emerged from multiple manual queries and NVivo auto-queries during qualitative analysis. Three major Code Category themes emerged from group comparison analysis: Code Category 1: Student-controlled learning and Teacher-controlled learning; Code Category 2: Classroom Environment- Climate and Setting; and Code Category 3: Active student 
learning and Passive student learning. Code categories illustrate differences between Group A and B teacher behavior, student experiences, and instructional environment qualitatively.

The first instrument compared Group A and B thematic code responses using text queries for "engage," "method," "teacher engagement," and "positive." Word Tree auto-code diagrams illustrated comparisons for Group A and Group B. Text queries illustrated differences between group behaviors for student-controlled learning and teacher-controlled learning patterns. Table 10 illustrates "engage" and "positive" word auto-queries comparisons. Code Category 1:

Student-controlled learning and Teacher controlled-learning emerged from observed teacher and student behavior differences between group A and B.

Table 10
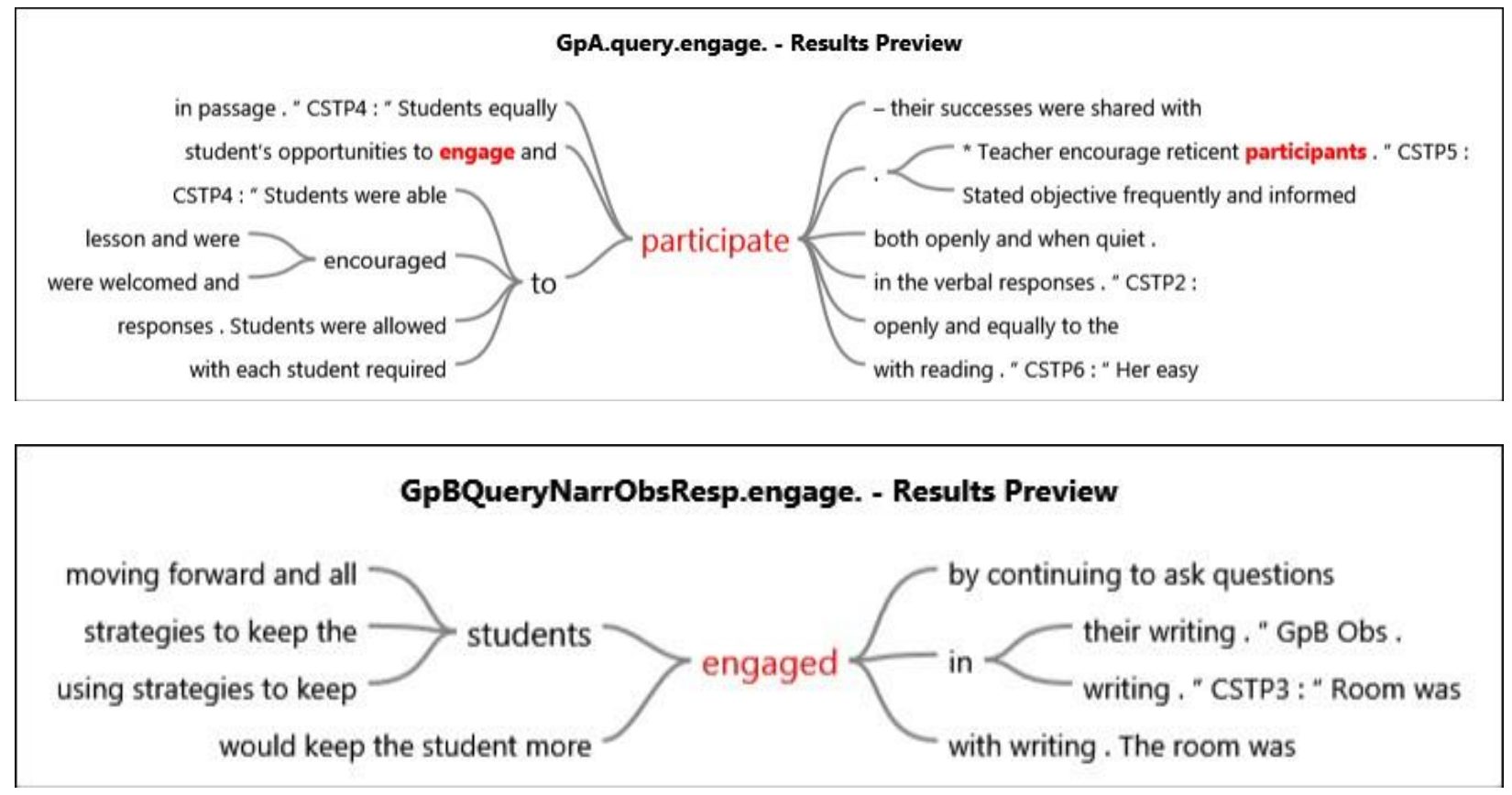

Table 10 NVivo text auto-query "engage” comparisons between Group A and Group B

Text auto-query comparisons for Group A and Group B showed word patterns and emerging themes in word tree diagrams. Findings from "engage" word tree comparisons illuminated student-controlled learning and teacher-controlled learning patterns. Reading word 
trees left to right, auto-queries for Group A illustrated behaviors such as "students equally participate...both openly and when quiet," "student's opportunities to engage and participate...openly and equally," "student were able (also "encouraged," "allowed," "required") to participate in the verbal responses (also "with reading")". Auto-queries for Group B "engage" word tree illustrated behaviors such as "moving forward and all students engaged...in writing," "strategies to keep the students engaged...with writing," "using strategies to keep student engaged," and "would keep the student more engaged...by continuing to ask questions."

These tree diagrams show differences in control of learning outcomes either placed with "students required to participate" or "using strategies to keep students engaged." These findings illustrated situated control of learning comparisons. Group A's codes showed student-controlled learning (with emphasis on students' actions to engage) whereas, coded narratives for Group B show teacher-controlled learning (with emphasis on strategies to engage students).

Auto-query text search for "positive" compared between Group A and Group B showed "positive" teacher and student behavior observed in instructional setting, instructional climate, and direct instruction themes.

Table 10-1

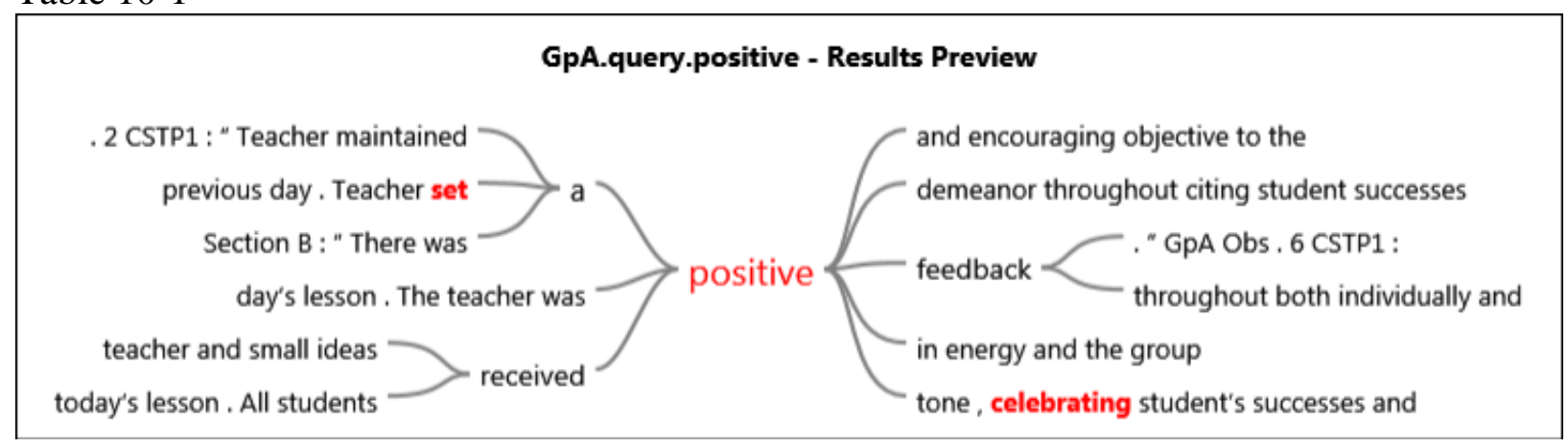




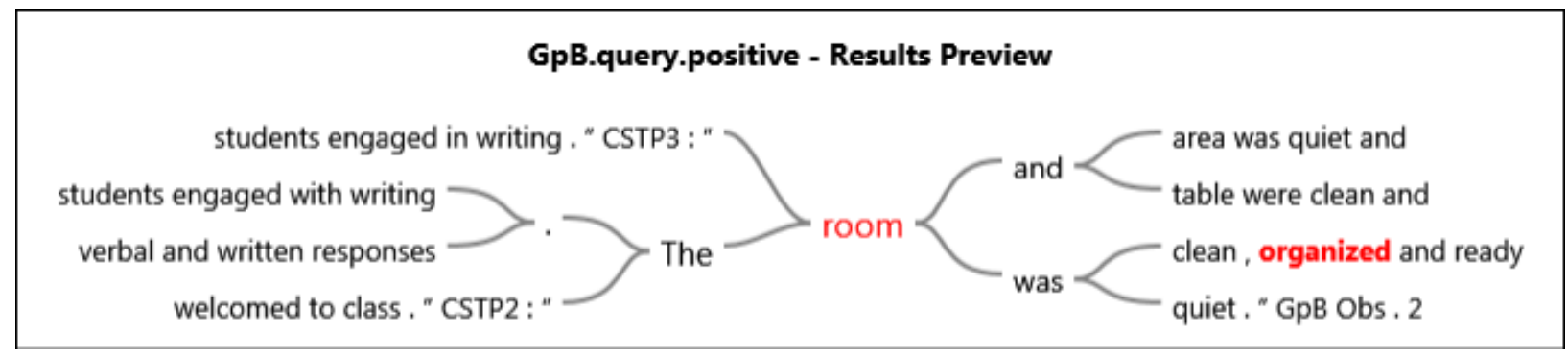

Table 10-1 NVivo text auto-query "positive” comparisons between Group A and Group B

Positive instructional climate emerged in Group A compared with student behaviors and classroom setting emergent in Group B. The "positive" word tree diagrams showed instruction directed toward positive student experiences and outcomes compared with instruction directed toward strategies for positive student experiences and outcomes. Auto-query analysis produced clarity of qualitative findings illustrated in the depth of rich data connecting behaviors and experiences in different instructional settings to learning outcomes that may not emerge from quantitative data analysis alone.

Code Category 2: Classroom Environment-Climate and Setting emerged from Classroom Environment Node comparison analysis between Group A and Group B. Table 11 illustrates differences between Group A and B's coded Classroom Environment Nodes.

Table 11

\begin{tabular}{|c|c|}
\hline $\begin{array}{l}\text { - } \text { " } \text { "Shild Node: AI Environment } \\
\text { made student learning very engaged! } \\
\text { Students were called on by name to respond } \\
\text { or collaborative response was also } \\
\text { encouraged." } \\
\text { - "Both groups participated with same level } \\
\text { of engagement; were able to give ideas and } \\
\text { input on the story. The teacher kept the } \\
\text { discussion active and thoughtful." }\end{array}$ & $\begin{array}{l}\text { - } \text { Child Node: TI Environment } \\
\text { - "The teacher allowed and welcomed all } \\
\text { responses and kept the lesson moving } \\
\text { forward and all students engaged in } \\
\text { writing." } \\
\text { - "Teacher kept class working and } \\
\text { environment neat and clean." } \\
\text { - "Classroom neat and orderly. Teacher is } \\
\text { prepared for students." } \\
\text { - "Classroom and worktable was clean and } \\
\text { prepped for lesson." }\end{array}$ \\
\hline
\end{tabular}


- "Full/3 - Students were welcomed and encouraged to participate - their successes were shared with other students."

- “*small group. *accepting, emphasizes mistakes as building blocks."

- "Students understood lesson and participated actively in responses to questions."

- "Students greeted as they came to table and sat down. A couple of students were slower to engage, but they were continually urged into the action and were successful after encouragement."
- "All students were asked to read passage allowing others to hear them."

- "The room and table were clean and prepped for writing lessons."

Table 11 Classroom Environment Node Comparisons, Group A (AI Environment), Group B (TI Environment)

Group A's codes reference classroom climate whereas Group B codes reference classroom setting. These patterns demonstrate observations unique to each group with little overlap Classroom Environment Nodes. Classroom climate details established norms and performance expectations (the "tone") of the classroom. Group A's codes emphasized climate with, "student learning very engaged," "students called on by name," "successes were shared," and "emphasized mistakes as building blocks." Classroom setting details the physical appearance of the classroom. Group B's codes emphasized setting with multiple references to "classroom and worktable clean and prepped for students," and "teacher is prepared for students."

Classroom Environment Node comparisons illuminated differences in classroom setting and climate between group A and B thematic code CSTP 3: Understanding and Organizing Subject Matter for Student Learning, category analysis. Appendix J contains all thematic codes for Group A and B. 
Thematic coding analysis within and between Group A and Group B revealed Code Category 3: Active Learning and Passive Learning. Table 11 compares code themes (words and phrases in black identify category reference) for Active and Passive student learning between Group A (“AI") and Group B (“TI").

Table 11

\begin{tabular}{|c|c|c|}
\hline Grou & Active Learning & Passive Learning \\
\hline AI & $\begin{array}{l}\text { - "Sound out words utilizing learned } \\
\text { strategies and techniques." } \\
\text { - "Asked students to support answers } \\
\text { from text." } \\
\text { - "Evidence of higher level questions, led } \\
\text { students to draw evidence-based } \\
\text { conclusions as well as inference." }\end{array}$ & $\begin{array}{l}\text { - "Teacher kept the students thinking } \\
\text { about how the story might turn out } \\
\text { differently." } \\
\text { - "Students were welcomed and } \\
\text { encouraged to participate." } \\
\text { - "Always keeping students in control } \\
\text { and engaged in lessons." }\end{array}$ \\
\hline TI & $\begin{array}{l}\text { - "Effective strategies to engage students } \\
\text { to learn and practice new and fun ways } \\
\text { to write sentences." } \\
\text { - "After verbal discussion, teacher and } \\
\text { students did verbal construction of } \\
\text { sentences." } \\
\text { - "Students were called on randomly or } \\
\text { were requested to verbalize their } \\
\text { responses to one another." }\end{array}$ & $\begin{array}{l}\text { - "Formal questioning to try to garner } \\
\text { responses that would help with } \\
\text { writing portion of lesson." } \\
\text { - "All students were allowed and } \\
\text { encouraged to participate in the } \\
\text { lesson to the best of their ability." } \\
\text { - "...keep the students writing their } \\
\text { sentences." }\end{array}$ \\
\hline
\end{tabular}

Table 11 Code Category 3: Active/Passive student learning thematic code comparisons

Group A codes referenced active student learning as “...utilized learned strategies and techniques," "support answers from text," and "draw evidence-based conclusions" and Group B codes referenced active student learning as "...learn and practice new and fun ways to write sentences," "verbal construction of sentences," and "verbalize responses to one another." Group A codes referenced passive student learning as, "teacher kept students thinking...," and "always keeping students in control and engaged in lesson...” compared with Group B codes referenced 
passive student learning as "...questioning to try to garner responses...," "participate to best of their ability," and “...keep students writing..." Thematic code comparisons illustrated instruction generating active or passive learning outcomes. As well, active student learning and studentcontrolled learning theme comparisons showed similar behaviors while passive student learning and teacher-controlled learning themes showed similar behaviors when compared between Group A and Group B.

Thematic coding comparisons for Student Engagement and Teacher engagement between Group A and Group B showed emerging patterns in student behaviors and teacher behavior. For instance, Group A's teacher engagement code reference of "evidence of higher-level questions" generated student engagement code reference of "discussion prompted and reinforced by peers." Group B teacher engagement reference of "utilized strategies to keep students engaged" generated student engagement reference as "allow students to come up with their responses needed to write the sentence/s." This showed parallels in teacher engagement and student engagement outcomes. Table 12 shows code responses for Teacher Engagement and Student Engagement themes between Group A and Group B.

Table 12

\begin{tabular}{|c|c|c|}
\hline Group & Teacher Engagement & Student Engagement \\
\hline \multirow[t]{5}{*}{ AI } & $\begin{array}{l}\text { 1. "Asked students to support answers } \\
\text { from text." }\end{array}$ & $\begin{array}{l}\text { 1. "Discussion prompted and reinforced } \\
\text { by peers." }\end{array}$ \\
\hline & 2. "Teacher encouraged reticent & 2. "Students equally participate." \\
\hline & participants." & 3. "Students always had the opportunity \\
\hline & $\begin{array}{l}\text { 3. "...opportunities to engage and } \\
\text { participate." }\end{array}$ & $\begin{array}{l}\text { to add their thoughts to the } \\
\text { discussion." }\end{array}$ \\
\hline & $\begin{array}{l}\text { 4. Bloom's Taxonomy type } \\
\text { questions." }\end{array}$ & $\begin{array}{l}\text { 4. "Evidence of higher-level questions } \\
\text { led students to draw evidence-based } \\
\text { conclusions as well as inference." }\end{array}$ \\
\hline
\end{tabular}




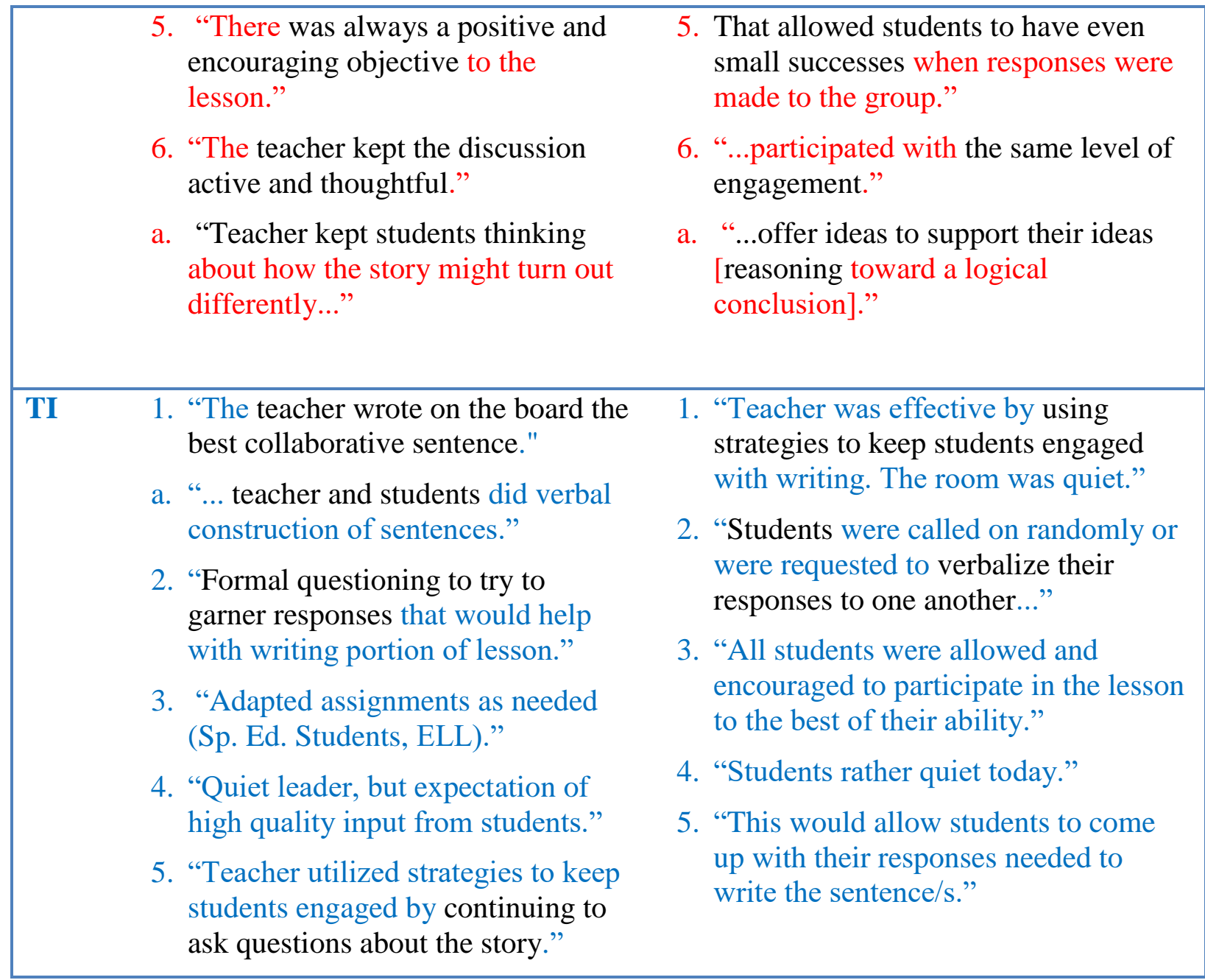

Table 12 Group A and Group B comparisons for Teacher and Student Engagement code themes

Common behavior patterns for positive teacher and student engagement, active student learning, student-controlled learning, and positive classroom climate emerged from qualitative analysis comparisons between Group A and Group B. Comparatively, common behavior patterns for classroom setting, teacher-controlled learning, passive student learning and teacher and student engagement also emerged from thematic code comparisons between both groups. Qualitative analysis comparisons clarified how students experience and behave in different instructional approach settings. 


\section{Mixed Methods Analysis}

Mixed-method analysis of quantitative results and qualitative findings for Group A and Group B showed parallel growth trends across all measures. Table 12 illustrates cross-analysis methods confirm and expand thematic findings with one divergent thematic outlier.

Table 12

\begin{tabular}{|c|c|c|}
\hline Cross-Method Analysis & Thematic Finding & $\begin{array}{l}\text { Do other methods confirm, } \\
\text { expand, or diverge? }\end{array}$ \\
\hline $\begin{array}{l}\text { Quantitative Analysis Pre-to- } \\
\text { Post-tests } \\
\text { 1)Expand: } \\
\text { Quantitative } \\
\text { Behavior Domains } \\
\text { 2)Expand: Qualitative } \\
\text { Thematic Coding }\end{array}$ & $\begin{array}{l}\text { Group A: Greater mean growth } \\
\text { than Group B, but not } \\
\text { statistically significant. } \\
\text { Comprehension: } \\
\text { Gp A: } 37.3 \% \quad \text { Gp B: } 27.8 \% \\
\text { Fluency: } \\
\text { Gp A: } 21.0 \% \quad \text { Gp B: } 16.2 \%\end{array}$ & $\begin{array}{l}\text { 1)Expand: T-Test group } \\
\text { statistics for behavior domain } \\
\text { variables: } \\
\text { Gp A: } 63 \% \text { mean freq. } 55 \% \\
\text { mean intensity (but no stat. sig. } \\
\text { differences) } \\
\text { Gp B: } 37 \% \text { mean freq. } 45 \% \\
\text { mean intensity } \\
\text { 2)Expand: Auto Code Node- } \\
\text { "Student active Engagement" } \\
\text {-Transcription Gp A only: } 12 \\
\text { references } \\
\text {-Transcription Gp B only: } 5 \\
\text { references }\end{array}$ \\
\hline Cross-Method Analysis & Thematic Finding & $\begin{array}{l}\text { Do other methods confirm, } \\
\text { expand, or diverge? }\end{array}$ \\
\hline $\begin{array}{l}\text { Transformed Observations Data } \\
\text { 1) Confirm: } \\
\text { Quantitative Analysis } \\
\text { Pre-to Post } \\
\text { 2) Expand: Qualitative } \\
\text { Thematic Coding }\end{array}$ & 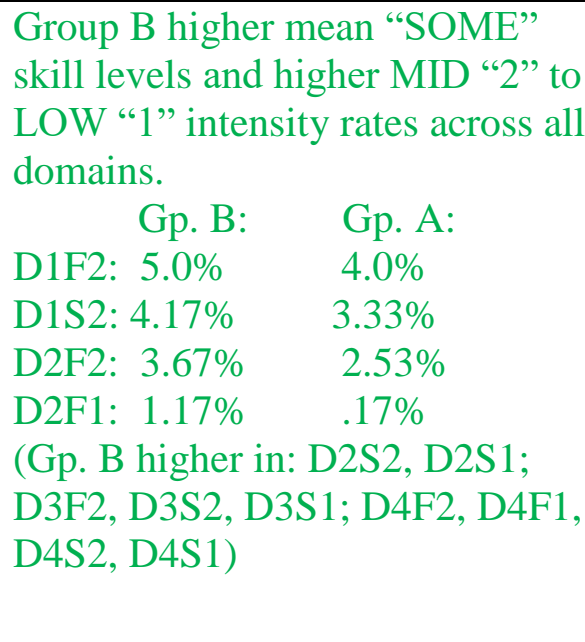 & $\begin{array}{l}\text { 1) Confirm: Group B: Pre-to } \\
\text { post- tests MODERATE } \\
\text { mean/median growth. } \\
\text { Comprehension: } \\
\text { Mean: } 27.8 \% \text { Median: } 29.5 \% \\
\text { Fluency: } \\
\text { Mean: 16.2\% Median:17.5\% } \\
\text { 2) Expand: ALL Auto-code } \\
\text { Nodes } \\
\text { Query: "passive learning" } \\
\text { Internal: GpB only transcript } \\
\text { Group B: } 68 \%\end{array}$ \\
\hline
\end{tabular}




\begin{tabular}{|c|c|c|}
\hline Cross-Method Analysis & Thematic Finding & $\begin{array}{l}\text { Do other methods confirm, } \\
\text { expand, or diverge? }\end{array}$ \\
\hline $\begin{array}{l}\text { Qualitative Coding } \\
\text { 1) Expand: } \\
\text { Quantitative } \\
\text { Behavior Domains } \\
\text { 2) Confirm: } \\
\text { Quantitative } \\
\text { Pre-Post-tests }\end{array}$ & $\begin{array}{l}\text { Group A higher energy } \\
\text { levels/higher-order thinking } \\
\text { directly observed. } \\
\text { - "Teacher engages all students- } \\
\text { actively involved." } \\
29 \% \text { coverage } \\
\text { - "The group was continually } \\
\text { encouraged to join in and } \\
\text { eventually all students were } \\
\text { actively engaged and were } \\
\text { participating." } \\
71 \% \text { coverage } \\
\text { - "Evidence of higher-level } \\
\text { questions. Led students to draw } \\
\text { evidence-based conclusions as } \\
\text { well as inference."/ "Bloom's } \\
\text { Taxonomy type questions." } \\
\text { 62\% coverage }\end{array}$ & $\begin{array}{l}\text { 1) Expand: T-Test for behavior } \\
\text { domains Gp. A: higher mean in: } \\
\text {-FULL skill level } 57 \% \\
\text { (Gp. B: 43\%) } \\
\text {-High “3" intensity 55\% } \\
\text { (Gp. B: 45\%) } \\
\text { - Frequency 63\% } \\
\text { (Gp. B: 37\%) } \\
\text { 2) Confirm: Group A: Higher } \\
\text { Mean Comprehension Growth: } \\
\text { Gp. A: } 37.3 \% \text {; Gp. B: } 27.8 \% \\
\text { Median Comp. Growth: } \\
\text { Gp. A: } 87.9 \% \text {; Gp. B: } 29.5 \% \\
\text { Mean Fluency Growth: } \\
\text { Gp. A: } 21 \% \text {; Gp. B: } 16.2 \% \\
\text { Median Fluency Growth: } \\
\text { Gp. A: } 87 \% \text {; Gp. B: } 17.5 \%\end{array}$ \\
\hline Cross-Method Analysis & Thematic Finding & $\begin{array}{l}\text { Do other methods confirm, } \\
\text { expand, or diverge? }\end{array}$ \\
\hline $\begin{array}{l}\text { Between Method Findings } \\
\text { 1) Confirm: Quantitative } \\
\text { Pre-Post-tests } \\
\text { 2) Expand: Quantitative } \\
\text { Behavior Domain statistics }\end{array}$ & $\begin{array}{l}\text { Group A higher mean growth: } \\
\text { 1-Quant.pre-post-tests } \\
\text { Gp. A: Comp:37.3\% Flu: 21.0\% } \\
\text { Gp. B: Comp: } 27.8 \% \quad \text { Flu: 16.2\% } \\
\text { 2-Quant. Behavior } \\
\text { frequency/intensity/skill levels } \\
\text { Gp.A:Freq: 63\% Int: 55\% } \\
\text { Gp.B:Freq: 37\% Int: 45\% } \\
\text { FULL skill levels (all Domains): } \\
\text { Gp A: } 57 \% \quad \text { Gp. B: 43\% } \\
\text { 3-Qualitative Auto-coding: } \\
\text { Engagement } \\
\text { Gp A: } 12 \text { references } \\
\text { Gp B: } 5 \text { references }\end{array}$ & 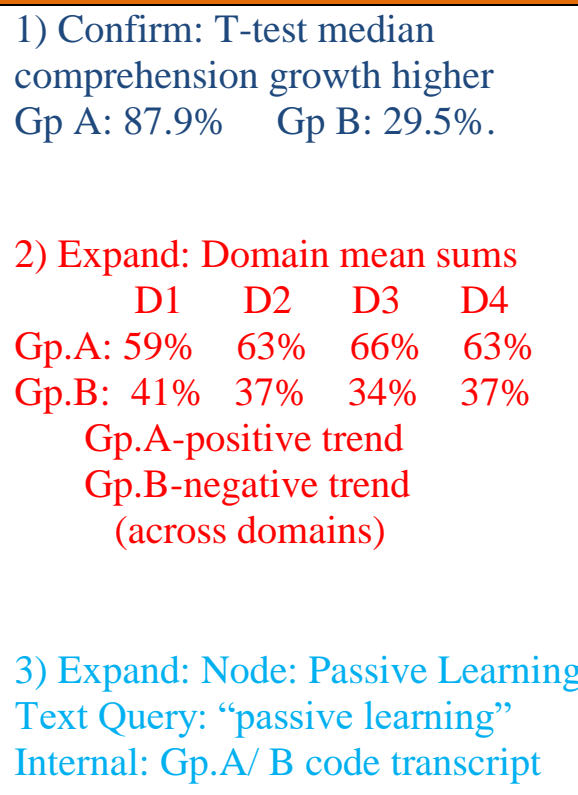 \\
\hline
\end{tabular}




\begin{tabular}{|c|c|c|}
\hline $\begin{array}{l}\text { 4) Diverge: } \\
\text { Quantitative } \\
\text { Pre-Post-tests } \\
\text { One-Sample Statistics }\end{array}$ & $\begin{array}{l}\text { 4) Diverge: Not statistically } \\
\text { significant differences at pre-test: } \\
\text { Gp.A: Comp: } 651.00 \text { sd: } 256.234 \\
\text { Gp.B: Comp: } 421.70 \text { sd: } 143.957 \\
\text { Gp.A: Fluen: } 98.80 \text { sd:41.569 } \\
\text { Gp. B: Fluen: } 65.60 \text { sd: } 19.845\end{array}$ & $\begin{array}{l}\text { Group A: 7\% Group B: 68\% } \\
\text { 3a) Expand: Node: Active Learning } \\
\text { Text Query: "active learning" } \\
\text { Internal: Gp. A\&B code transcript } \\
\text { Group A: 64\% Group B: } 36 \% \\
\text { 4) Diverge: Comp/Flu pre-post } \\
\text { means not statistically sig. } \\
\text { differences. Post-tests maintain } \\
\text { differences Gp. A and Gp. B. }\end{array}$ \\
\hline
\end{tabular}

Table 12 Cross-analyses methods confirm, diverge, and/or expand thematic findings

The table illustrates the use of cross-method analysis connecting quantitative and qualitative analyses to thematic findings followed by methods confirming, expanding, or diverging from findings. Cross-method analysis confirmed increased growth trends for both groups across all instrument measures with Group A increased growth trends consistently higher than Group B throughout cross-analysis comparisons. Quantitative pre-/post- results emerged as the singular thematic outlier with no other cross-analysis methods confirming or expanding the only divergent thematic findings.

Quantitative pre- to post-test analysis showed thematic findings for Group A's mean growth trends higher than Group B but not statistically significant differences. Results showed Group A's pre-to-post-mean comprehension of $37.3 \%$ and median comprehension of $87.9 \%$ compared to Group B's pre- to post-mean comprehension of $27.8 \%$ and median comprehension of $17.5 \%$. Group A's pre-to post-mean fluency showed $21.0 \%$ and median fluency showed 87.0\% and Group B's pre-to post-mean fluency showed $16.2 \%$ and median fluency showed $17.5 \%$ in comparison.

Methods confirmed Group A mean growth trend thematic findings quantitatively and qualitatively but did not confirm no statistically significant difference. Quantitative behavior 
domain T-test group statistics showed higher means for Group A's "FULL" skill levels with higher " 3 " intensity rates, as well as higher mean frequency and total sums of behaviors across all behavior domains compared to Group B's mean skill levels higher in the "MID" and "LOW" range with higher "2" (mid-) mean intensity rates. Qualitative auto-coding for Student Engagement Node expanded thematic findings with higher student engagement references in Group A (12) than Group B (5) student engagement references.

Mixed-methods analysis of qualitative Word Tree queries for "engage," and "positive" comparisons converged with quantitative pre- to post-test reading comprehension and fluency mean and median growth comparisons from One-Sample T-Tests both higher for Group A than Group B. Expanding thematic findings further, qualitative code analysis showed Group A's observed behaviors higher for student-controlled learning in positive classroom climates compared to Group B observed behaviors higher for teacher-controlled learning in positive classroom settings.

\section{Table 13}

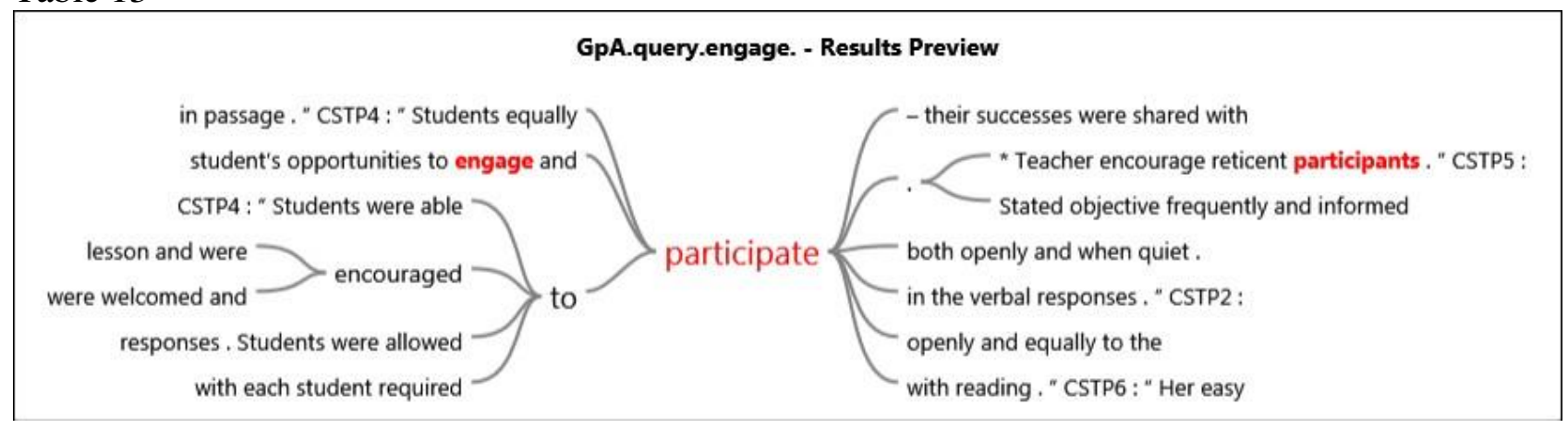



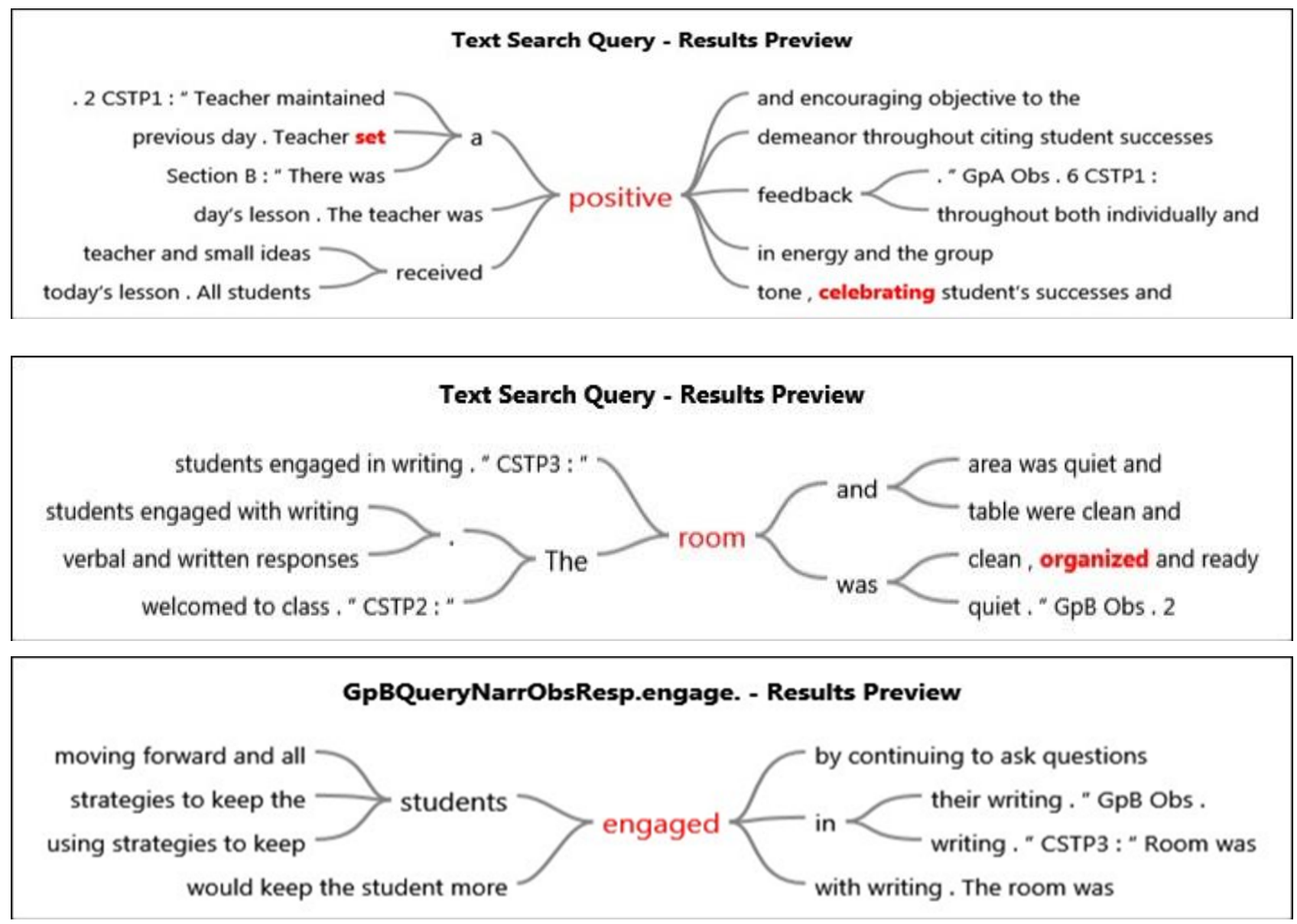

Table 13 Qualitative thematic finding convergence and expansion

Qualitative coding for Group A showed demonstrated higher energy levels confirmed by $29 \%$ coverage of codes such as, "Teacher engages all students-actively involved" and $71 \%$ code coverage of "The group was continually encouraged to join in and eventually all students were actively engaged and were participating." Higher order thinking behaviors directly observed in Group A confirmed "Evidence of higher-level questions, led students to draw evidence-based conclusions as well as inference" and "Bloom's Taxonomy type questions" with $62 \%$ code coverage. Quantitative behavior domain analysis expanded the findings with Group A higher "FULL" skill levels averaged 57\% compared to Group B average of 43\%, higher "3" intensity 
rates average of $55 \%$ with $45 \%$ for Group B, and higher frequency rates for Group A with $63 \%$ than Group B with 37\%. Quantitative pre- to post-test analysis confirm these findings with Group A mean growth higher than Group B in comprehension, Group A with $37.3 \%$ and Group B with 27.8\%, and fluency, Group A with $21 \%$ and Group B with 16.2\%. Median growth rates maintain same positive growth patterns for Group A more than Group B median growth.

Cross-method analysis between all methods showed thematic findings for Group A higher mean growth pre-post testing confirmed with quantitative pre- and post- test analysis between Group A and B. Quantitative behavior domain analysis expands these findings with Group A higher demonstrated behavior sums, frequency, intensity, and skill leveles domonstrated across all domains. Qualitative coding also expanded these findings shown in higher levels of demonstrated engagement and higher active learning, 64\% for Group A, directly observed compared with Group B's 36\% directly observed. Conversely, Group B showed 68\% demonstrated passive learning with Group A’s 7\% passive learning directly observed.

Quantitative pre- and post-test measures were the only outliers emergent from crossmethod analyisis. Findings showed no statistically significant differences between both groups at pre-test and post-test means maintained the same differences.

Overall, patterns emerged when mixed-methods analysis crossed quantitative and qualitative methods. Methods primarily confirmed or expanded thematic findings throughout data analyses connecting results to methods, and strengthening thematic findings outlined in Table 13. Quantitative pre- and post- analysis of mean growth results showed no statistical significance between Group A's instructional approach and Group B's instructional approach. 
This method diverged from qualitative findings and mixed-methods findings that evidenced stronger relationships between student experiences and instruction when other variables, such as classroom climate, teacher behavior, and/or student engagement, are considered. Employing a mixed-methods design produced rich illustrations confirming and expanding thematic findings with parallel trends across methods albeit the exception of quantitative pre- to post- method outlier results.

The findings and results detailed in this chapter demonstrated the depth of clarity provided using mixed-methods to illustrate effective instructional approaches to increase student achievement. The findings also illustrate the depth of understanding the answer to the research question of how students experience, behave, and achieve in different instructional settings when mixed-methods are used. 


\section{CHAPTER 5: CONCLUSION}

\section{Introduction}

\section{Quantitative Summary Findings}

Quantitative data analysis of pre- and post-reading comprehension and fluency data yielded higher positive achievement trends in Group A compared with Group B. Group A's preto post-comprehension mean score comparisons yielded 37.3 average gains. Group A's reading fluency mean comparisons yielded an increase of 54.2 from pre-to post-test analysis, showing substantial increases in test score averages across Group A. Group B, in comparison, yielded an average 27.8 gain from pre- to post-reading comprehension and an average 16.2 gain from preto post-reading fluency test analysis. Positive trends in mean growth were substantial in both Group A and Group B, but the results are not statistically significant. Both groups yielded increased mean scores from pre- to post-test analysis, but the evidence does not signify that the gains are attributable to treatment variables alone.

Although Group A had higher average mean scores at pre-test analysis, positive trends in pre-to post-test average gains align with behavior domain average gains in the highest frequency and intensity levels for all behavior domain categories. Thematic coding reveals higher levels of active learning, higher levels of student and teacher engagement, higher-order thinking opportunities, and higher levels of critical thinking in student-driven collaborative dialogue when learning outcomes are student-controlled.

Similarly, Group B data analysis revealed slightly lower levels of positive trends in pre-to post-test average gains that align with some lower levels of behavior domain average gains at the MID- LOW intensity ratings, and average means scores in the "SOME" categories of skill 
behavior. Finally, thematic coding revealed Group B higher levels of passive learning, lower student and teacher engagement, and higher teacher-led instruction demonstrated behaviors confirmed and expanded through cross-methods analysis (Table 12).

\section{Qualitative Summary Findings}

Qualitative thematic coding provided layers of rich evidence enhancing and/or diminishing quantitative results. Word Tree text query diagrams reported from Group A and Group B observation narrative codes yielded phrases of coded text related to "engage," "positive," "all students," "strategies," "methods," and "teacher engagement." Comparing group diagram data for text queries "engage" and "positive" provided expanding support of teacher-led or student-led learning behaviors and higher positive growth trends for mean and median pre- to post-test analysis.

Cross-analysis connected patterns within qualitative and quantitative results and provided clarity to variable differences, such as student-controlled learning and student behavior outcomes. Productive learning behaviors evidenced in coded observations of Group A distinguish powerful learning outcomes with student-controlled learning. Higher engagement and energy levels, increased participation using higher critical thinking techniques, and positive experiences emerged from coded observation narratives. Alternatively, coded observations from Group B illustrated the difference in teacher and student behaviors with teacher-controlled learning. Higher levels of teacher strategies to engage students, higher levels of passive learning, and higher levels of teacher-led student engagement emerged from coded observation narratives.

Evidence of learning behaviors in Word Tree diagrams "engage" and "positive" from observations of Group B, illustrated mid-level learning behaviors in quiet, calm learning 
environment settings, and moderately productive engagement when teacher strategies are implemented to control learning outcomes. Expansion of these findings emerged from crossmethods analysis with quantitative behavior domain frequency and intensity results comparisons.

Thematic coding emphasizes the interconnectedness of teacher behavior and student behavior response. This evidence contributes to answering how low SES students experience AI model approach to instruction compared to traditional instructional approaches. Rich illustrations detail the connections between student experience and instructional approach models. An explicit example emerged with Group A and Group B comparisons of coded teacher engagement nodes:

1) "The teacher was positive in energy and the group was energetic with their responses..."

2) "Quiet leader, but with expectations of high quality input from students. Students rather quiet today."

These coded observation narratives empirically evidence the direct connectedness of teacher engagement and student behavior responses. Qualitative evidence is a strong indicator of student experiences and achievement outcomes influenced by classroom climate and teacher engagement.

\section{Quantitative Summary Findings}

Domain Behavior frequency and intensity rate comparison analysis of both Group A and Group B evidence Group A yielding higher skill level, frequency and intensity and total sum averages across all four behavior domains. Domain mean frequencies averaged $1.68 \%$ more for Group A than Group B mean frequencies.

Intensity ratings are slightly more complicated. Each domain was assigned six possible scale rates (F3, F2, F1, S3, S2, S1 signifying "F" for Full skill level behavior observed, “3” for 
high, "2" for mid, and "1" for low intensity of skill exhibited in observed behavior). The table details mean differences in each behavior domain for Group A and Group B. Group A data yielded higher mean scores for D1F3 (Domain 1: Comprehension of material, F-Full, 3-high intensity) with a 4.67 average over Group B with .33 average observed behaviors in that category. Group A yielded higher average scores in all other D1 intensity categories except D1S2 with average score for "SOME" comprehension of material with mid-level intensity with Group A averaging 3.3 and Group B averaging higher with 4.1 mean scores. Domain 2: Fluency of material yielded mean scores for Group A higher in D2F3 with 2.83 mean score compared with Group B's .17 mean score, and in D2S3, with Group A averaging 1.0 and Group B averaging .33. All other categories in Domain 2 (D2F2, D2F1, D2S2, D2S1) yielded higher averages for Group B than Group A. Domain 3: Teacher Behavior/Engagement yielded a mean score of 5.83 for Group A and 1.50 mean score for Group B in category D3F3. Category D3F2 averaged a score of .67 for Group A and .17 for Group B. All other categories in Domain 3 (D3F2, D3S2, D3S1) yielded higher mean scores for Group B with both groups averaging .00 in D3F1 intensity category. Domain 4: Student Engagement/Experience (D4F3) yielded mean scores of .33 for Group A and .00 for Group B, and D4S2 with Group A's mean score of 2.83 and Group B's mean score of 2.50. All other categories in Domain 4 (D4F2, D4F1, D4S1) yielded higher mean scores for Group B.

I compared the average intensity rates for each skill level to determine average scores for Full and Some Levels. To do this, I calculated the sum of F3/S3 average scores and divided by two yielding an average of 2.75 for Group A and .33 for Group B. Mean scores for F2/S2 in Group A yielded 3.665 and 4.585 for Group B, and F1/S1 mean for Group A yielded 1.085 and 
1.25 for Group B. Results show Group A, on average, exhibiting higher FULL frequency behaviors and HIGH intensity behaviors in reading comprehension compared to Group B, which, on average, exhibited higher SOME frequency behaviors and MID- to LOW intensity levels in comprehension of material, with similar patterns of results in Domain 2-4. Group A and Group B produce average score outputs placing Group A in the higher average score range and Group B, producing average scores, placed in the lower average score range.

Overall, Group A participants exhibited higher skill levels and intensity rate behaviors across all behavior domains, while Group B participants demonstrated mid-to low skill levels and intensity behaviors, on average, across all four behavior domains. This showed Group A demonstrated higher skill levels in all domain behaviors with the inverse holding true for Group B. These results align with cross-analysis across quantitative and qualitative methods analysis.

\section{Mixed-Method Summary Findings}

Mixed-method analysis findings are promising for alternative instructional models evidencing positive experiences, and higher frequency and intensity behaviors at higher skill levels with positive achievement level trends. The following coded observation narratives support this conclusion: 

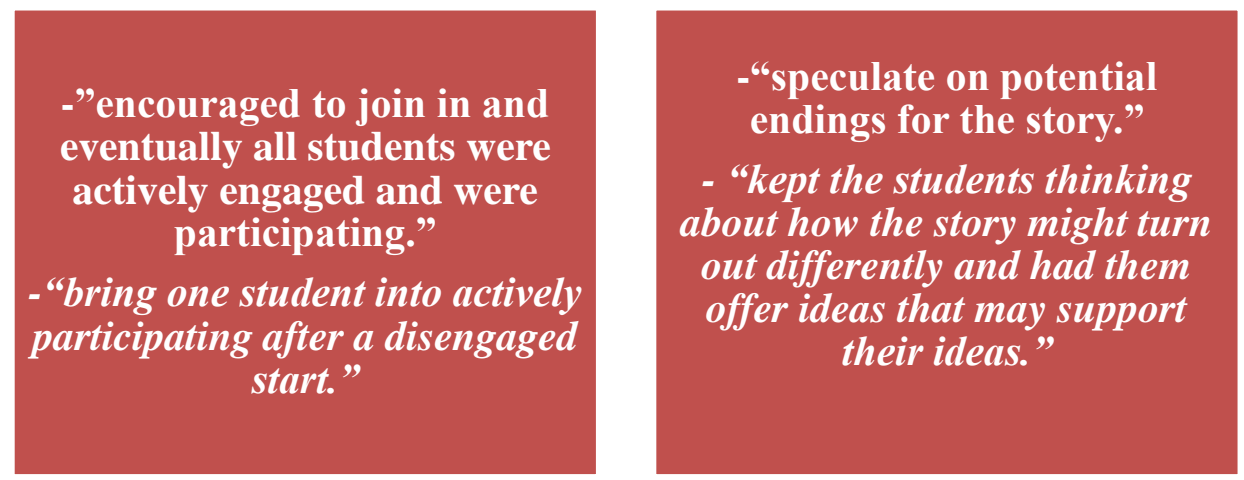

-6encouraged to add ideas

when the teacher asked

questions that had several

possible responses that could

be correct."

- conceptual idea that was

interesting to observe the students grasp."
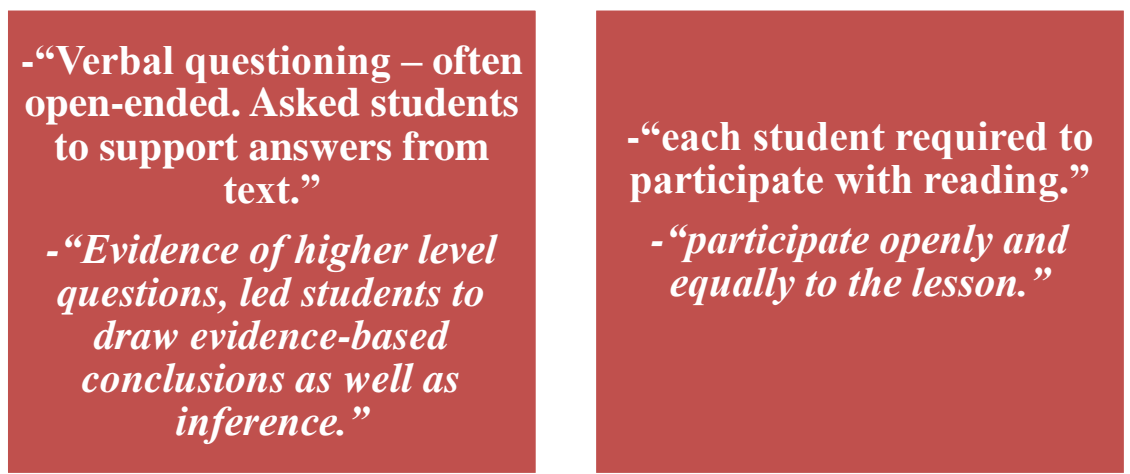

Conversely, Group B intensity averages were higher in "FULL" skill level behavior at "2" (mid) and "1" (low) intensity rates and "SOME" skill level at mid-to low intensity rates. This showed variables such as, limited academic growth opportunities, lower expectations for students, teacher-led instruction, passive student learning, and teacher-driven student engagement showed lower rates of achievement gains for students. The following Group B coded narratives confirm these findings: 
-“Adapted assignment as needed (Sp. Ed. Students,

$$
\text { ELL)." }
$$

- "All students were allowed and encouraged to participate in the lesson to the best of their ability."
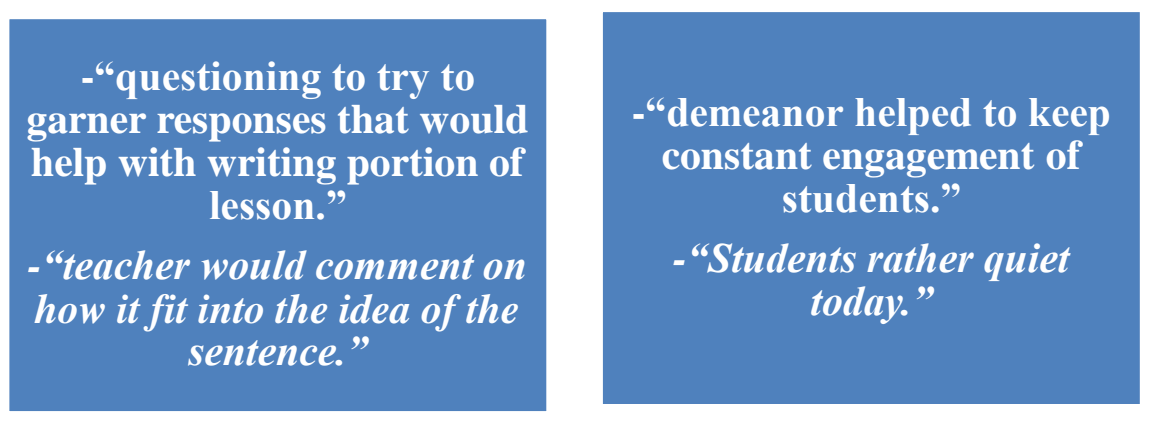
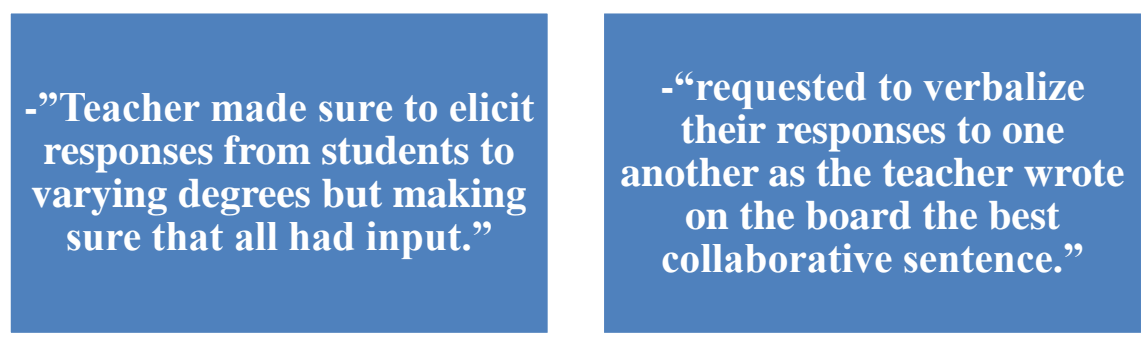

Quantitative pre-post-results and behavior domain results findings expand thematic findings of lower frequency and intensity demonstrated behaviors in reading comprehension and fluency skills in Group B confirm cross-analysis of higher mean intensity rates in category "SOME" skill level for comprehension and fluency of material and "MID- "to "LOW" intensity behavior rates directly observed. This expands thematic findings of positive classroom climate and student-controlled learning expands increased positive learning trends, active participation, and achievement growth trends for students.

Qualitative coding produced layers of extractable findings to support and/or diminish quantitative results. Mixed-methods design provided a clearer understanding of analysis outcomes, interpretations, and implications more than quantitative results alone. Mixed-method analysis provided evidence not captured with quantitative results alone. Mixed-methods design provided powerful methodology that strengthened or weakened results and findings enhancing 
empirically evidenced conclusions and interpretations of statistical findings from this research study.

\section{Conclusions}

Pre- to post-test mean scores for Group A and B both showed positive trends. Group A showed higher means scores at pre-test than Group B with differences maintained at post-test analysis. The quantitative results showed no statistically significance differences between Group A and Group B. Quantitative outlier results and all other mixed-method findings singularly diverged. Final mixed-methods findings of alternative strengths-based instructional approaches look promising. Instruction framed around positive classroom climate, and student-controlled active learning confirm increased positive student experiences, increased self-efficacy, lowered anxiety, higher-level learning behaviors, higher energy and engagement levels, and increased academic achievement growth rates.

Quantitative domain behavior cross-analysis confirmed these findings when mixed methods comparisons revealed parallel outcomes. Highly active learning and engagement in positive classroom climates with student-controlled learning outcomes expand findings of higher mean and median gains in reading pre- to post-test analysis. Additionally, mid-to low levels of active learning and engagement expand findings of mid- to low-average gains in reading pre- to post-test analysis.

Mixed-methods findings confirm and expand evidence of positive student experiences and achievement growth rates when alternative strength-based approaches drive instruction for low SES students at the elementary level. Cross-analysis showed higher mean scores and growth rates across all measures both quantitatively and qualitatively with AI model as an instructional 
approach. Cross-analysis also showed moderate mean scores and growth consistently across all measures both quantitatively and qualitatively. The mixed-method study design generated valuable data source outcomes from both quantitative and qualitative analysis, provided clarity as to how low SES students experience AI model approach compared to traditional instruction.

Based on these findings, I conclude that low SES students respond positively to AI model approaches to instruction at higher rates than traditional instructional approaches. Supporting evidence emerges from mixed-method comparative analysis of quantitative results and qualitative findings. Mixed-methods findings were all in agreement when mean growth rates were considered. One quantitative outlier diverged from those findings. These instruments provided rich data which first detailed student behavior - informing skill levels, effort levels, and patterns of engagement - followed by teacher behavior - instructional style, effort, engagement, and focus - and finally observation narratives revealed major connections of student and teacher behavior, classroom climate, and student achievement.

The mixed-method study design demonstrated the quality of capturing multiple data sources for analysis and comparison. The quantitative results present one outcome of analysis. However, comparative analysis within and between three measures provided a platform to better understand how the elements of strengths-based instruction support academic achievement outcomes for all students.

\section{Interpretations}

Quantitative results coupled with rich qualitative findings evidenced effectiveness of strengths-based approaches on student achievement and experiences. Findings included positive student experiences, high energy levels of active engagement, positive self-efficacy shift trends, 
lowered anxiety levels, self-regulation of learning outcomes (with power and control of learning destiny placed with the student), rich dialogue evidenced higher-order thinking skills and using multiple intelligences, and positive growth in reading comprehension and fluency achievement when instructional objectives framed positive growth mindset. Teacher instruction framed 4DCycle asset-based themes into all learning objectives. Collaborative dialogue celebrated student successes, embraced mistakes as the building blocks for higher levels of cognition, intentional acknowledgement of knowledge capital students bring to the classroom, and the aim to increase positive experience opportunities through rich dialogue, collaboration, synthesis and analysis of text became second-order effects of strengths-based instruction. Most importantly, the teacher impressed upon students an authentic belief in themselves to achieve the highest levels of learning. Quantitative data alone does not capture all the rich evidence that effectively increases student achievement and experiences, especially low SES students.

The results of this research study provide the following considerations:

1) Further comparative evaluation research studies using mixed-methods design are necessary to further current research findings.

2) This study provided promising evidence for strengths-based instructional approaches effectively increase student achievement and positive experience and behavior trends evidenced (though not statistically significant) in pre- to post-test quantitative comparisons. Promising evidence, when outcomes compared between all qualitative and quantitative results, paralleled increased positive growth trends in all measures consistently. All three testing instruments reflect similar growth trends in both Group A and B that supported conclusions for strengths-based instructional models effective in 
raising achievement levels and positive experiences for all students, especially low SES student populations. Longer inquiry periods may produce stronger qualitative findings.

3) Measuring frequency and intensity behaviors in the four domains provided clarity in developing context of student behaviors directly observed by an external observer. Evidence is promising that alternative strengths-based instructional approaches effectively increased positive achievement, behaviors, and experiences, strengthened cross-analysis comparisons and findings.

\section{Future Research}

The intent for conducting this research study was to collect empirical evidence supporting my theoretical position that strengths-based instructional pedagogies will increase academic achievement levels for all students and ultimately, close the achievement gap. Based on the results of this data, I intend to develop a similar research study to measure correlations between strengths-based instruction and student academic achievement. However, I will design the follow-up study with a larger sample size, and a longer inquiry timeline. Some considerations will be comparing achievement outcomes of two classrooms at separate sites over a semester. Other possible considerations include measuring student self-efficacy growth rates as a testing variable.

Student efficacy growth rates emerged as a theme when I analyzed observation data and realized that none of the testing instruments in this study captured changes in student selfperceptions or changes that occurred outside of school because of participation in the AI model. For example, one student said that she could overcome her fears of skiing challenging runs because of the dialogue that emerged from the 4D-Cycle adaptation that framed strengths-based 
objectives into lessons each week. The 4D-Cycle adaptation was a key element, injecting positive purpose into group dialogue each day and week. The four phases were revisited often and students gradually increased their understanding of the phases and incorporated them into daily practice.

This research study and its final findings have deepened my drive to raise social consciousness regarding the efficacy of strengths-based approaches effective in raising academic achievement for all students. Academic achievement includes multitudes of measurable data points not exclusive to assessment scores, contrary to public sentiment. Observing the participants over the six-week study period renewed my drive ensuring all students have access to equal education opportunities where students are valued for their contributions to learning and genuine belief in student academic achievement is the instructional standard not the exception.

\section{Limitations}

One area of concern related to strengths-based pedagogy is the challenge in replicating the approaches to instruction brought to the research study. Strengths-based instruction is not a program to incorporate into portions of instruction; it is organic, which invites subjectivity in application. One outcome of qualitative coding analysis was the awareness of how much teacher personality and style influence strengths-based instructional practice. Narrative observations captured teacher instructional practices in Group A and Group B that described widely accepted practices embraced in the field of education. For instance, both instructional approaches included observations such as "high engagement," "skill objectives clearly defined," "welcomed students," etc. making strengths-based instruction and deficit-based instruction potentially less distinguishable. Another concern is imparting the importance of relinquishing control and power 
of learning. There is a very fine line between collaborative student-teacher relationships and classroom management structured around a hierarchy of power. I have been practicing strengthsbased approaches for two years and a balance of increasing respectful collaborative relationships and reducing authoritative classroom management continues to elude successfully consistent acquisition.

An additional challenge is that the tone and direction of what invites student engagement is the subtle difference found in the coded narratives identifying Group A and Group B instruction comparisons below:

1) "Teacher kept the lesson and the atmosphere engaging and moving forward in a manner that supported all learning styles.”

2) "Students equally participate. Teacher encourages reticent participants."

3) "All students participated; in group one, teacher encouraged others so one student did not dominate. Adeptly, with prompts and recognition was able to bring one student into actively participating after a disengaged start.”

4) "Teacher encouraged students and students all actively were writing sentences and responding to questions from the teacher."

These four coded narratives are challenging to identify as traditional practice or strengths-based practice of instruction. Both groups showed level of effective in engagement of student learning. The traditional instructional approaches are statements one, and four. They appear to document actively engaged students, but closer examination showed:

1) “Teacher kept lesson...engaging", 2) "Students equally participate. Teacher encourages reticent participants," 3) "All students participated...prompts and recognition... able to bring one 
student into actively participating after disengaged..." Subtle differences lie in the placement of power and control of learning; and 3) "Teacher encouraged students and ... responding to questions from the teacher." These are teacher-led strategies. The strengths-based instructional approach statements are the second and third narrative coded. It is only with specialization in strengths-based practices that I am becoming more adept at recognizing the subtleties between successful socially just teaching practices and the reproduction of marginalization teaching practices.

\section{Recommendations}

My recommendations are to develop a similar comparative study measuring strengthsbased instruction and student achievement and experiences with a shift in focus to include prepost-test quantitative data as well as a test of student self-efficacy levels. I am convinced now more than ever that acceptable instructional practices designed from deficit-based lens suffocate and extinguish all hope, joy, and curiosity of the world that our students bring in their elementary years. If students have been conditioned to believe they are failures in learning by fourth grade, what purpose do they have in changing their learning habits? These students have been conditioned to wait for direction passively instead of actively attempting to exercise their higherorder thinking, because they have been reminded for many years that they are wrong. Instead of rewarding every success, no matter how small, these children have been ridiculed for every mistake, no matter how small, reinforcing their belief that they are failures at learning, so they learn strategies to avoid failure and ridicule, lowering their motivation and self-efficacy, and increasing their learning achievement gap and probability of dropping out of school. 
Appendix A:

\section{Evaluative Study of Literacy Intervention Strategies}

Program Evaluation:

How students experience Appreciative Inquiry model as an instructional literacy approach compared to traditional instructional literacy approaches.

\section{Research Questions:}

Primary: How do low SES students at the elementary level experience Appreciative Inquiry model as an instructional literacy approach compared to traditional models of literacy instruction?

Secondary: What do we learn about low SES student experiences and behaviors when comparing different instructional models of literacy instruction?

\section{Comparative Mixed Methods Study:}

1. Quantitative: How do low SES students experience the difference between Appreciative Inquiry model approach to literacy instruction and traditional models of literacy instruction?

Methods: Reading comprehension and fluency assessments administered prior to the study and conclusion of the study. This data will demonstrate comparative growth patterns for both groups.

2. Qualitative: How do students experience different instructional literacy approaches?

Methods: Direct observation from external observer using Note-taking and Narrative Reflection on External Observation Framework Form. This data will be compared for each group to determine correlation of student experiences with academic achievement gains with anecdotal support from qualitative data to the quantitative data findings. 
Appendix B.1:

\section{External Observer Framework Form}

Observation\#: Circle: Group 1 (8:25-9:05) / Group 2 (11:00-11:40)

Number of students being observed:

Part 1-Note-taking: Rate every observed behavior in each domain below using a seven-point scale (1: low, 2: mid, 3: high). Record each behavior observation score in the appropriate behavior domain categories.

Domain 1: Comprehension of material (recall, retell, define, list, memorize, repeat, restate, etc. content of resources):

Full

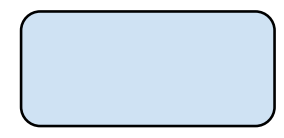

Some

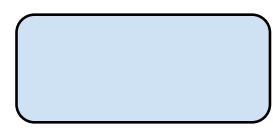

None

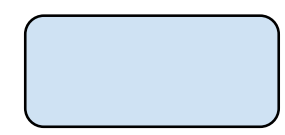

Domain 2: Fluency of material: (oral accuracy and expressions with passages read aloud): Record one scale score for every observed rate of fluency in each category level.

Fluent

Reads words continuously
Some Fluency

Reads 2-4 words at a time
Non-Fluent

Reads word by word
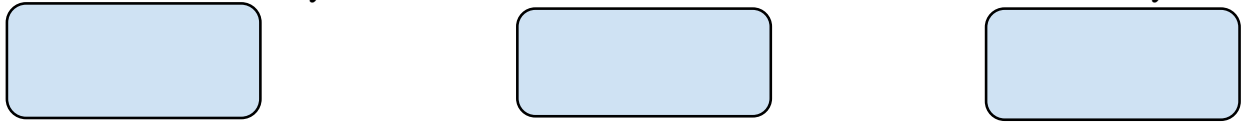

Domain 3: Teacher behavior/engagement (physical and emotional responses to students):

Positive

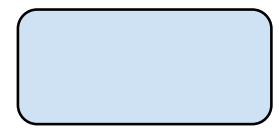

Flat

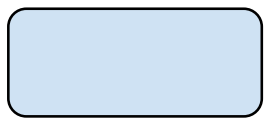

Negative

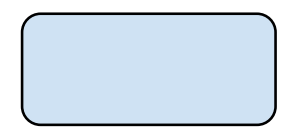

Domain 4: Student engagement/experience (physical and emotional responses to teacher and text):

Positive

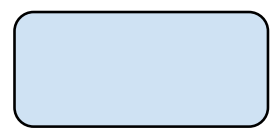

Flat

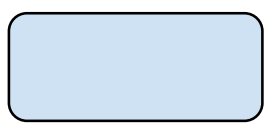

Negative 
Appendix B.2:

External Observer Framework Form

\section{Part 2: Narrative Reflection:}

Section A: Briefly summarize observed behaviors and engagement that evidence practice in any or all the standards below. Using the point-scale from page 1, rate the level of teacher behavior/engagement during the lesson for each standard.

CSTP 1: Engaging and Supporting All Students in Learning

CSTP 2: Creating and Maintaining Effective Environments for Student Learning (CSTP 2)

CSTP 3: Understanding and Organizing Subject Matter for Student Learning (CSTP 3)

CSTP 4: Planning Instruction and Designing Learning Experiences for All Students (CSTP 4): (students equally participate, can relate and participate in group discussions of material in lessons)

CSTP 5: Assessing Students for Learning (CSTP 5) (informal or formal)

CSTP 6: Developing as a Professional Educator (CSTP 6): (evidence of current educational research standards, practices, strategies, etc.).

Section B: Critically analyze the observed teacher and student behaviors and experiences during the session. Provide a detailed summary of the critique. 


\section{Appendix C.1: District Gatekeeper Consent Form:}

$7 / 15 / 16$

Superintendent, USD

District Office

City, State, Zip Code

RE: Permission to Conduct Research Study

Dear Superintendent:

I am writing to request conceptual approval, pending IRB on human subjects, to conduct a research study in your school district. I am currently enrolled in the Social Justice for Educational Leadership Doctoral Program at the University of Redlands in Redlands, CA, and am in the process of writing my dissertation. The study is entitled Program Evaluation: Appreciative Inquiry Model as an Instructional Literacy Approach With low SES Elementary Students. The dates for this study are February 6, 2017 to March 17, 2017.

I hope to recruit 20-24 students in grades four from the elementary school to work in two groups (10-12 students in each group) to receive literacy intervention instruction following the current Title I intervention program at the school. Participants will receive identical literacy instructional lessons. However, an Appreciative Inquiry model as an instructional literacy approach will be embedded into the lessons for the group I will teach. The same intervention lessons and materials will be taught in each group on the same day. The school's Title I Interventionist and I will provide instruction for each group with the Title I Instructional Aide continuing her regular assignment in the Title I program. An external observer, with prior teaching experience in the school district, will observe and record student and teacher behaviors and experiences during the lessons using the External Observation Form (attached) for both groups throughout the study. Student participants will not be interviewed. Parents or guardians of participants will be provided a consent form to be signed approving their child's participation in the study which I will collect prior to study commencement.

If conceptual approval is granted, participants will attend intervention sessions for six weeks in the regular school setting during the instructional day. The intervention sessions will be located in school's Title I reading intervention classroom during two separate forty-minute time blocks (Group 1 from 8:25-9:05 a.m., and Group 2 from 10:00-10:40 a.m.) five days per week. The external observer will observe each group on three random days (alternating weeks beginning the first week) and record behaviors and experiences of the students and the instructor. Observation forms will be pooled and analyzed at the completion of the study. Should this study be published, only pooled results will be documented. All study participants will remain anonymous. No costs will be incurred by either the school or the individual participants.

Your conceptual approval to conduct this study will be greatly appreciated. Once IRB approval is granted I will request formal approval to conduct a research study in your district. If you have any questions, comments, or concerns, please contact me at my email address: Nicol_Erdmier@redlands.edu.

If you agree, please sign below and notify me to schedule a time to pick up the letter from your office. Thank you for your consideration.

Sincerely,

Nicol Erdmier, University of Redlands

Attachments: External Observation Form, Parental Consent Letter

cc: Dr. Wall, Research Advisor, University of Redlands

Approved by:

Superintendent

$\overline{\text { Signature }} \overline{\text { Date }}$ 


\section{Appendix C.2: Site Administrator Consent Form:}

$7 / 15 / 16$

Site Principal

Address

City, State, Zip Code

RE: Permission to Conduct Research Study

Dear Site Administrator:

I am writing to request approval to conduct a research study in your school site. I am currently enrolled in the Social Justice for Educational Leadership Doctoral Program at the University of Redlands in Redlands, CA, and am in the process of writing my dissertation. The study is entitled Program Evaluation: Appreciative Inquiry Model as an Instructional Literacy Approach With low SES Elementary Students. The dates for this study are February 6, 2017 to March 17, 2017.

I hope to recruit 20-24 students in grades four from the elementary school to work in two groups (10-12 students in each group) to receive literacy intervention instruction following the current Title I intervention program at the school. Participants will receive identical literacy instructional lessons. However, an Appreciative Inquiry model as an instructional literacy approach will be embedded into the lessons for the group I will teach. The same intervention lessons and materials will be taught in each group on the same day. The school's Title I Interventionist and I will provide instruction for each group with the Title I Instructional Aide continuing her regular assignment in the Title I program. An external observer, with prior teaching experience in the school district, will observe and record student and teacher behaviors and experiences during the lessons using the External Observation Form (attached) for both groups throughout the study. Student participants will not be interviewed. Parents or guardians of participants will be provided a consent form to be signed approving their child's participation in the study which I will collect prior to study commencement.

If approval is granted, student participants will attend intervention sessions for six weeks in the regular school setting during the instructional day. The students will be in two classrooms (Group 1 and Group 2) for 30-minute sessions five days per week. The external observer will observe each group on three random days per week on alternating weeks and an Observation Framework Form will be filled out for each observation (attached). The observation forms will be pooled for the dissertation study and analyzed at the completion of the study. Should this study be published, only pooled results will be documented. All study participants will remain anonymous. No costs will be incurred by either your school or the individual participants.

Your approval to conduct this study will be greatly appreciated. I will follow up with a telephone call next week and would be happy to answer any questions or concerns that you may have at that time. You may contact me anytime at my email address: Nicol_Erdmier@redlands.edu. If you agree, please sign below and notify me to schedule a time to pick up the letter from your office. Thank you for your consideration.

Sincerely,

Nicol Erdmier, University of Redlands

Enclosures: External Observation Form, District Approval Form, Parent Approval Form cc: Dr. Wall, Research Advisor, University of Redlands

Approved by:

$$
\text { Site Administrator }
$$

$$
\text { Signature }
$$$$
\text { Date }
$$ 


\section{Appendix C.3: Parental Consent Form (English)}

January 30, 2017

RE: Parental Consent for Child Participation in Study

Dear Parent or Guardian:

I am writing to request consent for your child to participate in a research study that will be conducted on February 6, 2017 to March 17 , 2017 at your child's school. I am currently enrolled in the Social Justice for Educational Leadership Doctoral Program at the University of Redlands in Redlands, CA. The research study is entitled: Program Evaluation: Appreciative Inquiry Model as an Instructional Literacy Approach With low SES Elementary Students. The research study is part of my dissertation thesis on strengths-based approaches to teaching and the impact on student achievement.

Appreciative Inquiry Theory (AI) is an approach to teaching that stresses a positive influence on how students learn. This is often called a strengths-based approach to teaching. The teacher takes a lesson and enhances how it is taught by intentionally including and discussing the strengths of students in their ability to learn the concepts from the knowledge and skills they already possess. AI reinforces what students already know to guide them in learning skills taught during each lesson.

The purpose of this study is to determine any impact on student achievement using different approaches to teaching. Data will be collected using test scores from reading comprehension and fluency tests given to all participants before, and after the study period, and observations recorded by an external observer (prior teacher in the school district) who will observe both groups on three days every other week during the study period. The data will be analyzed concluding the study to determine any changes in student achievement in different learning environments. All the data collected in the study is confidential and all names and information identifying participants will be replaced with a coded identifier in data collection to maintain participant confidentiality.

Participants in the study will be randomly divided into two groups and will receive the same reading lessons currently taught in the Title program. The same lessons for both groups will follow Title I program for reading intervention and all students continue to receive the same Title I services they are entitled to during the study. The difference will be the approach to teaching the lessons only. One group will continue to receive regular instruction and the other group will receive the same lesson with an added strengths-based approach to teaching.

This study is intended to determine the best instructional practices in providing the highest quality education for all students. However, the potential risk for participation to consider is a possibility that one teaching approach will impact student achievement more positively, negatively, or has no impact on student achievement. Such risks difficult to foresee until after the study when the data is analyzed. To minimize such risks, the lessons taught for both study groups will be the exact same lessons (taught in the same classroom) that will be taught in the Title I program regardless of the study. The only difference being the approach to teaching the lessons.

This study is designed to collect evidence of any changes in student achievement using two different instructional approaches. Results of the study will be made available following University of Redlands policies and regulations.

Your consent for your child to participate will be greatly appreciated. I have received approval from the site administrator as well as the school district to conduct this study. If you agree, please sign below and return in the envelope provided to my mailbox in the school office. You may contact me anytime with questions or clarifications at the school or my email address: Nicol Erdmier@redlands.edu. Thank you for your consideration.

Sincerely,

Nicol Erdmier, University of Redlands

cc: Dr. Wall, Research Advisor, University of Redlands

Parental consent for

(Name of participant)

$\overline{\text { Parent name: }} \quad$ Signature $\quad$ Date




\section{Appendix C.4: Parental Consent Form (Spanish)}

30 de enero de 2017

RE: Consentimiento de los padres para la participación de los niños en el estudio

Estimado padre o tutor:

Le escribo para solicitar el consentimiento/permiso para que su hijo participe en un estudio de investigación que se llevará a cabo el 6 de febrero de 2017 al 17 de marzo de 2017 en la escuela de su hijo. Actualmente estoy inscrito en el Programa de Doctorado de Justicia Social para Liderazgo Educativo en la Universidad de Redlands en Redlands, CA. El estudio de investigación se titula: "Evaluación del Programa: Modelo de Investigación Apreciativa como un Enfoque de Alfabetización Instruccional con estudiantes de Primaria SES bajos". El estudio de investigación es parte de mi tesis d sobre los enfoques basados en la fuerza de la enseñanza y el impacto en el rendimiento de los estudiantes.

Teoría de Investigación Apreciativa (AI) es un enfoque de la enseñanza que enfatiza una influencia positiva en cómo aprenden los estudiantes. A menudo se le llama enfoque basado en las fortalezas a la enseñanza. El maestro toma una lección y mejora cómo se enseña intencionalmente incluyendo y discutiendo las fortalezas de los estudiantes en su capacidad de aprender los conceptos de los conocimientos y habilidades que ya poseen. AI refuerza lo que los estudiantes ya saben para guiarlos en las destrezas de aprendizaje enseñadas durante cada lección.

El propósito de este estudio es determinar cualquier impacto en los logros de los estudiantes usando diferentes enfoques de la enseñanza. Los datos serán recolectados utilizando los resultados de las pruebas de comprensión de lectura y de fluidez que se han dado a todos los participantes antes y después del período de estudio y observaciones registradas por un observador externo (maestro anterior en el distrito escolar) que observará a los dos grupos cada tres días cada otra semana durante el período de estudio. Los datos serán analizados concluyendo el estudio para determinar cualquier cambio en el rendimiento estudiantil en diferentes entornos de aprendizaje. Todos los datos recogidos en el estudio son confidenciales y todos los nombres e información que identifican a los participantes serán reemplazados con un identificador codificado en la recopilación de datos para mantener la confidencialidad del participante.

Los participantes en el estudio serán divididos al azar en dos grupos y recibirán las mismas lecciones de lectura actualmente enseñadas en el programa Título I. Las mismas lecciones para ambos grupos seguirán el programa Título I para la intervención de lectura y todos los estudiantes seguirán recibiendo los mismos servicios de Título I que tienen derecho durante el estudio. La diferencia será el enfoque para enseñar las lecciones solamente. Un grupo continuará recibiendo instrucción regular y el otro grupo recibirá la misma lección con un enfoque adicional basado en las fortalezas de la enseñanza.

Este estudio tiene como objetivo determinar las mejores prácticas de instrucción para proporcionar la más alta calidad de educación para todos los estudiantes. Sin embargo, el riesgo potencial para la participación a considerar es la posibilidad de que un enfoque de enseñanza influirá en el logro estudiantil más positivamente, negativamente, o no tiene ningún impacto en el logro del estudiante. Estos riesgos son difíciles de prever hasta después del estudio cuando se analizan los datos. En un esfuerzo por minimizar tales riesgos, las lecciones enseñadas para ambos grupos de estudio serán exactamente las mismas lecciones (enseñadas en el mismo salón de clases) que se enseñarán en el programa Título I independientemente del estudio. La única diferencia es el enfoque de la enseñanza de las lecciones.

Este estudio está diseñado para reunir evidencia de cualquier cambio en el rendimiento estudiantil utilizando dos enfoques de instrucción diferentes. Los resultados del estudio estarán disponibles de acuerdo con las políticas y reglamentos de la Universidad de Redlands.

Su consentimiento para que su hijo participe será muy apreciado. He recibido la aprobación del administrador del sitio, así como del distrito escolar, para llevar a cabo este estudio. Si usted está de acuerdo, por favor firme abajo y regrese en el sobre proporcionado a mi buzón en la oficina de la escuela. Puede ponerse en contacto conmigo en cualquier momento con preguntas o aclaraciones en la escuela o mi dirección de correo electrónico: Nicol_Erdmier@redlands.edu. Gracias por su consideración.

Sinceramente,

Nicol Erdmier, Universidad de Redlands

Cc: Dr. Wall, Asesor de Investigación, Universidad de Redlands

El consentimiento de los padres para

(Nombre del participante)

Nombre del padre: Firma Fecha 
Appendix C.5: Assent of a Minor Form

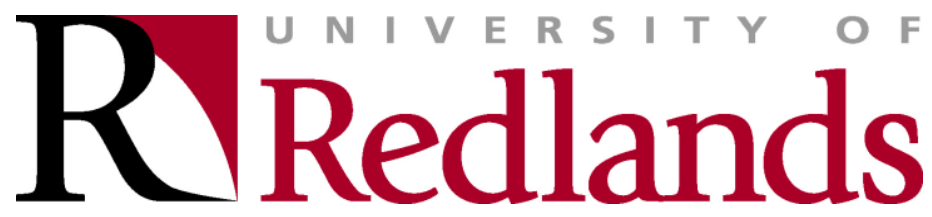

\section{Agreement to Participate in Research}

(For possible use with persons under the age of 18 years)

Your parent or guardian has said that it was okay for you to take part in a research study. Now we want to ask whether you want to take part in the study. Just because your parent or guardian said it was okay doesn't mean that you have to. It's really up to you. No one will be angry if you don't take part in the study. No one will mind if you say that you want to take part in it now, but change your mind later. You can stop participating at any time.

On the rest of this form, you can read some information that will help you decide whether or not you want to participate. If you have any questions at any time, ask.

The title of the project is Program Evaluation: Appreciative Inquiry Model as an Instructional Literacy Approach With low SES Elementary Students

The name of person doing the research is: Nicol Erdmier

Your parent or guardian has other information in case you want to contact the investigator later.

\section{Here's the information that will help you decide whether to participate in the research}

We are inviting you to take part in a research study we are doing. A research study is one way that we can learn more about how student's experience different literacy instructional approaches.

We are inviting you to be in the study because you have reading comprehension and fluency scores that are lower than grade level standards.

If you agree to take part this study, we will ask you to attend Title I intervention sessions during the morning hours of the school day for 40 minutes each day of the week.

There are no risks related to participating in this research study. 
The possible benefits of participating in this research study include higher reading comprehension and fluency scores.

As we said up top, you don't have to participate if you don't want to. No one will be angry if you don't participate. No one will mind if you say that you want to participate now, but change your mind later. You can stop what you're doing in the study at any time.

You can also ask any questions at any time. No one will mind.

If you sign your name below, it means that you agree to take part in this research study.

Print your name in the white box below.

Printed Name of Child/Adolescent Participant

Sign your name in the grey box. Fill in the date, too. (We'll tell you what it is if you don't know.)

\begin{tabular}{|l|l|}
\hline & \\
\hline Signature of Parent or Guardian & Date \\
\hline
\end{tabular}

You can stop here. The researcher will fill in the information below this line.

Print Name of Person Obtaining Assent

\begin{tabular}{|l|l|}
\hline & \\
\hline Signature of Person Obtaining Assent & Date \\
\hline
\end{tabular}


Appendix D:

\section{Research Site:}

This study takes place in a small rural school district serving approximately 2,500 students TK-

12. The elementary school where this study took place serves 295 students with approximately $60 \%$ Hispanic or Latino and approximately $40 \%$ White (Appendix D). The percentage of students by ethnicity and grade level is broken down below.

\begin{tabular}{|c|c|c|c|}
\hline \multicolumn{4}{|c|}{$\begin{array}{l}\text { Percentage of Students by } \\
\text { Ethnicity/Grade Level } \\
2014-15\end{array}$} \\
\hline Ethnic Group & $\%$ & Grade Level & $\#$ \\
\hline $\begin{array}{l}\text { African American } \\
\text { American Indian or } \\
\text { Alaskan Native } \\
\text { Asian } \\
\text { Filipino } \\
\text { Hawaiian or Pacific } \\
\text { Islander } \\
\text { Hispanic or Latino } \\
\text { White (not Hispanic) } \\
\text { Two or More Races } \\
\text { Socioeconomically } \\
\text { Disadvantaged } \\
\text { English Learners } \\
\text { Students with } \\
\text { Disabilities } \\
\text { Migrant Education } \\
\text { Foster Youth }\end{array}$ & $\begin{array}{c}0.4 \% \\
59.8 \% \\
36.3 \% \\
0.7 \% \\
83.1 \% \\
38.3 \% \\
7.5 \%\end{array}$ & $\begin{array}{l}\text { TK } \\
\text { Kindergarten } \\
\text { Grade } 1 \\
\text { Grade } 2 \\
\text { Grade } 3 \\
\text { Grade } 4 \\
\text { Grade } 5 \\
\text { Grade } 6\end{array}$ & $\begin{array}{l}33 \\
33 \\
39 \\
56 \\
35 \\
39 \\
60\end{array}$ \\
\hline
\end{tabular}

S.A.R.C. data provided by the school district 
The following is a breakdown of student performance on state standardized assessments in the 2014-15 academic year. The data was provided by the participating school district.

\begin{tabular}{|c|c|c|c|c|c|c|c|c|c|c|c|c|c|c|}
\hline \multicolumn{15}{|c|}{$\begin{array}{l}\text { CAASPP Assessmant Rasults Dlsaggregalad by Studant Groups } \\
\qquad 2014-15\end{array}$} \\
\hline & \multicolumn{7}{|c|}{ Engllsh Languag Arts/LPracy } & \multicolumn{7}{|c|}{ Mathematlos } \\
\hline & & & & \multicolumn{4}{|c|}{ Activenent Lavd } & & & & \multicolumn{4}{|c|}{ Adiswmert Lavd } \\
\hline & Total & $\begin{array}{c}\text { Nunter } \\
\text { Testod }\end{array}$ & $\begin{array}{l}\text { Prosurt } \\
\text { Tetod }\end{array}$ & 1 & 2 & 3 & 4 & $\begin{array}{l}\text { Told } \\
\text { Enolinant }\end{array}$ & Rernbe & $\begin{array}{l}\text { Provont } \\
\text { Tostod }\end{array}$ & 1 & 2 & 3 & 4 \\
\hline & \multicolumn{7}{|c|}{ Grade 3} & \multicolumn{7}{|c|}{$\operatorname{cosen} 3$} \\
\hline M Students Triod & 52 & 50 & 928 & 4208 & $20 \%$ & $13.0 \%$ & $B: B$ & 52 & 51 & 20.1\% & nor. & 3aRs. & $240 \%$ & 4.08 \\
\hline Mate & 52 & $z$ & $51.9 \%$ & 5008 & $30 \%$ & 4.08 & 4.08 & 52 & 27 & $51.2 \%$ & $40 \%$ & $300 \%$ & $190 \%$ & 4.08 \\
\hline Fonals & 52 & 23 & 428 & $\mathbf{x O S}$ & $\mathrm{xOK}$ & 35008 & 13008 & 52 & 24 & $46 \%$ & $200 \%$ & 3月0\%. & $20 \%$ & 4.08 \\
\hline Arian Anorican & 2 & 1 & $1 . \%$ & $\cdot$ & $\cdot$ & $\cdot$ & $\cdot$ & 52 & 1 & $19 \%$ & $\cdot$ & $\cdot$ & $\cdot$ & $\cdot$ \\
\hline istan & 52 & 1 & $1 . \%$ & $\cdot$ & $\cdot$ & $\cdot$ & $\cdot$ & 52 & 1 & $19 \%$ & $\cdot$ & $\cdot$ & $\cdot$ & $\cdot$ \\
\hline tepanc $\alpha$ Lutro & 52 & $\mathbf{z}$ & $538 \%$ & $5.0 \%$ & $\operatorname{sex}$ & 7.08 & 4.08 & 52 & 20 & 5nes. & $40 \%$ & $390 \%$ & $10.0 \%$ & 3.08 \\
\hline Mitre (ndt Hspanich) & 52 & 19 & 3658 & 2008 & $21.0 \%$ & 2008 & 15008 & 52 & 19 & $35.5 \%$ & 3008 & 208 & $200 \%$ & 508 \\
\hline Tres or More Races & 52 & 1 & $1 . \%$ & $\cdot$ & $\cdot$ & $\cdot$ & $\cdot$ & 52 & 1 & 198 & $\cdot$ & $\cdot$ & $\cdot$ & $\cdot$ \\
\hline Sodocroronikaly Dleadverthogd & 52 & 45 & 8558 & $40 \%$ & 30.08 & $180 \%$ & 2.08 & 52 & 46 & $\approx 5$ & 41.08 & 3508 & 2008 & 408 \\
\hline Englinh Lemons & 52 & 20 & 3858 & $50.0 \%$ & $350 \%$ & 10.08 & $5.0 \%$ & 52 & 21 & \$18. & 52.08 & $390 \%$ & 508 & 5.08 \\
\hline \multirow[t]{2}{*}{ gtodents wht Distilites } & 52 & 1 & $1 . \%$ & • & $\cdot$ & $\cdot$ & $\cdot$ & 52 & 1 & 198 & $\cdot$ & $\cdot$ & $\cdot$ & $\cdot$ \\
\hline & \multicolumn{7}{|c|}{$\operatorname{cosec} 4$} & \multicolumn{7}{|c|}{ Grade 4} \\
\hline M Stusents Testod & 80 & 32 & 97.08 & 30.08 & 25.08 & 12.08 & 22.08 & 30 & 30 & $100.0 \%$ & 42.08 & 3.08 & $20 \%$ & 12.08 \\
\hline Malo & 80 & 13 & 32.18 & 54.08 & 15.08 & ack & 2808 & 30 & 13 & n.e.s & 543508 & 20.08 & $90 \%$ & 1508 \\
\hline Fonate & 83 & 19 & 57.88 & 21.08 & 2.08 & 2508 & 21.08 & 30 & 20 & $\cos$ & 21.08 & 4508 & 10.08 & 10.08 \\
\hline Hyanic or Latro & 80 & 21 & cs.08 & 50.08 & 12.08 & 10.08 & 1208 & 30 & 22 & 00.78 & 92.08 & 2108 & $50 \%$ & $20 \%$ \\
\hline Whts (not Hesparich) & 80 & 11 & $33 . x$ & $0.0 \%$ & 3608 & 3608 & W.OS & 30 & 11 & $35 x$ & $20 \%$ & 5508 & 13.08 & 13.08 \\
\hline Bodocrononizaly Deadvantaped & 80 & $\mathbf{x}$ & 78.88 & 38.08 & 31.88 & 15.08 & 15.08 & 30 & 27 & 81.85 & 48.08 & 41.08 & $40 \%$ & $7.0 \%$ \\
\hline Englsh Lemens & 80 & 13 & 30.18 & 52.08 & 2308 & 15.08 & $0.0 \%$ & 30 & 14 & 42.88 & 71.08 & 20.08 & $0.0 \%$ & $0.0 \%$ \\
\hline \multirow[t]{2}{*}{ Gtoderts vith Disbilibes } & 83 & 4 & 12.18 & $\cdot$ & $\cdot$ & $\cdot$ & • & 33 & 4 & 12.18 & $\cdot$ & • & $\cdot$ & $\cdot$ \\
\hline & \multicolumn{7}{|c|}{ Gnde 5} & \multicolumn{7}{|c|}{$\operatorname{Crsa} 5$} \\
\hline W Strodents Tesbod & 85 & 34 & 97.18 & 50.08 & 12.08 & 18.08 & 12.08 & 85 & 34 & 97.18 & 50.08 & 20.08 & $60 \%$ & $60 \%$ \\
\hline Volo & 85 & 16 & 45.78 & 630.08 & $60 \%$ & 2508 & $60 \%$ & 85 & 16 & 45.78 & sc.os & $\mathrm{z} .08$ & $180 \%$ & $60 \%$ \\
\hline fornale & 85 & 18 & 51.18 & 5508 & 17.08 & 11.08 & 17.08 & 85 & 18 & 51.88 & 61.08 & 3808 & $0.0 \%$ & $60 \%$ \\
\hline Heparic or Litro & 85 & 20 & 9.18 & 80.08 & $50 \%$ & $15: 08$ & $0.0 \%$ & 35 & $\mathbf{2 0}$ & 5.18 & 85.08 & 10.08 & $50 \%$ & $0.0 \%$ \\
\hline Whls (not Hispanich) & 85 & 14 & 40.08 & 20.08 & 21.08 & 21.08 & 20.08 & 8 & 14 & 4008 & 21.08 & 57.08 & $7.0 \%$ & 1408 \\
\hline Bocibocoromizaly Disavariaged & 85 & 2 & 65.78 & 7408 & 908 & 1308 & 408 & 85 & 23 & 65.78 & 7408 & 2208 & $40 \%$ & $0.0 \%$ \\
\hline Ençish Lamers & 85 & 12 & $3 . x$ & 20.08 & 0.08 & 808 & $0.0 \%$ & 85 & 12 & 3.58 & $1000 \%$ & $0.0 \%$ & $0.0 \%$ & $0.0 \%$ \\
\hline \multirow[t]{2}{*}{ Gtodents wht Disabilies } & $x$ & 2 & $57 \%$ & $\cdot$ & $\cdot$ & $\cdot$ & $\cdot$ & 85 & 2 & $57 \%$ & $\cdot$ & $\cdot$ & $\cdot$ & $\cdot$ \\
\hline & \multicolumn{7}{|c|}{ Grade 6} & \multicolumn{7}{|c|}{$\operatorname{Cras} 8$} \\
\hline W Strodents Testod & 61 & 60 & 92.48 & sack & $30.0 \%$ & $250 \%$ & $120 \%$ & E1 & $\boldsymbol{D}$ & 28.88 & 48.08 & 20.08 & 25.08 & $7.0 \%$ \\
\hline Nalo & 61 & 25 & 41.08 & $520 \%$ & 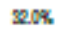 & 808 & $8.0 \%$ & 61 & $\mathbf{z}$ & 41.08 & 6008 & 2008 & 16.08 & $40 \%$ \\
\hline Fonte & 61 & 35 & 5.18 & $20.0 \%$ & 20\%. & $3.0 \%$ & $140 \%$ & E1 & $\mathbf{x}$ & 5.88 & 40.08 & 2008 & 31.08 & $20 \%$ \\
\hline tesen & 61 & 1 & $1.6 \%$ & $\cdot$ & $\cdot$ & $\cdot$ & $\cdot$ & 61 & 1 & $1.5 \%$ & $\cdot$ & $\cdot$ & $\cdot$ & . \\
\hline Aparic or Lntro & 61 & 32 & 52.58 & $500 \%$ & $280 \%$ & $120 \%$ & 308 & 61 & $x$ & 52.58 & 6008 & 13.08 & 12.08 & $0.0 \%$ \\
\hline Whts (not Hispenic) & 61 & 27 & $4 x$ & 150\%. & $30 \%$ & $300 \%$ & $20 \%$ & E1 & 27 & 4.58 & 2608 & 2608 & 80,08 & 15.08 \\
\hline Bociooconomicaly Disatvariaged & 61 & 47 & 77.08 & $360 \%$ & $360 \%$ & $280 \%$ & $40 \%$ & 61 & 47 & 77.08 & 5808 & $25: 08$ & 12.08 & $20 \%$ \\
\hline Enclsh Lamers & 61 & 16 & $\mathbf{x}, 08$ & $500 \%$ & s8c\% & $130 \%$ & $0.0 \%$ & 61 & 16 & $\mathbf{x . 0 8}$ & 81.28 & 1308 & $60 \%$ & $0.0 \%$ \\
\hline Btsonts vith Disian & 61 & 4 & 6.5. & $\cdot$ & $\cdot$ & $\cdot$ & . & E1 & 4 & $6 \mathrm{ER}$ & $\cdot$ & , & , & . \\
\hline
\end{tabular}


Appendix E:

Sample Instructional Materials/Lesson structure

Title I weekly lesson outline used during Title I literacy instruction:

Five students sit at the Reading Center with the teacher, and five students sit at the Writing

Center with the Instructional Aide for 20 minutes of instruction then switch centers for the second 20 minutes. Lessons follow the same structure each week.

Week 1:

Day 1: Title I lesson plan

*Reading Center with Title I teacher:

Students read The Story of Basketball passage independently.

Students circle important words together with pencil.

Students write the important words on the board and do a quick verbal summary of the story.

*Writing Center with Title I Instructional Aide:

Students Review Key Words in Sacred Pets passage as a group.

Students write a prediction of the story, then listen to the story read aloud on disc.

Students compare and discuss their predictions as a group.

Day 1: Title I lesson plan with AI instructional approach

*Reading Center with Title I teacher:

Teacher introduces Phase 1 of 4-D Cycle (adapted): "Discovery-What you already know" (The Recognition of capital phase).

Students dialogue about what they already know about reading and the skills they use for reading while teacher dictates student statements on poster board.

The group has an open dialogue while reviewing their statements to discuss the meaning and importance of their skills, and how those skills relate to growth and achievement in school and life.

Students read The Story of Basketball to each other out loud. Each student reads a paragraph and assist each other with pronunciation as needed. Students are encouraged to ask for clarification from each other about questions they may have of the story.

*Writing Center with Title I Instructional Aide: (no change in lesson delivery for both study groups).

Students Review Key Words in Sacred Pets passage as a group.

Students write a prediction of the story, then listen to the story read aloud on disc.

Students compare and discuss their predictions as a group. 
Appendix F:

Table of Abbreviations

$\begin{array}{ll}\text { AI } & \begin{array}{l}\text { Appreciative Inquiry } \\ \text { ISI }\end{array} \\ \text { NSLP } & \begin{array}{l}\text { National School Lunch Program } \\ \text { SES }\end{array} \\ \text { SSS } & \begin{array}{l}\text { Socioeconomic status } \\ \text { Student Success Skills }\end{array} \\ \text { CSTP } & \text { California Standards for the Teaching Profession } \\ \text { EL } & \text { English Learners } \\ \text { ELA } & \text { English Language Arts } \\ \text { IEP } & \text { Individual Education Program } \\ \text { IRB } & \text { Institutional Review Board } \\ \text { NAEP } & \text { National Assessment of Educational Progress } \\ \text { PI } & \text { Primary Investigator } \\ \text { DOK } & \text { Depth of Knowledge }\end{array}$




\section{Appendix G:}

\section{Research Study Timeline/Methodology Graphic}
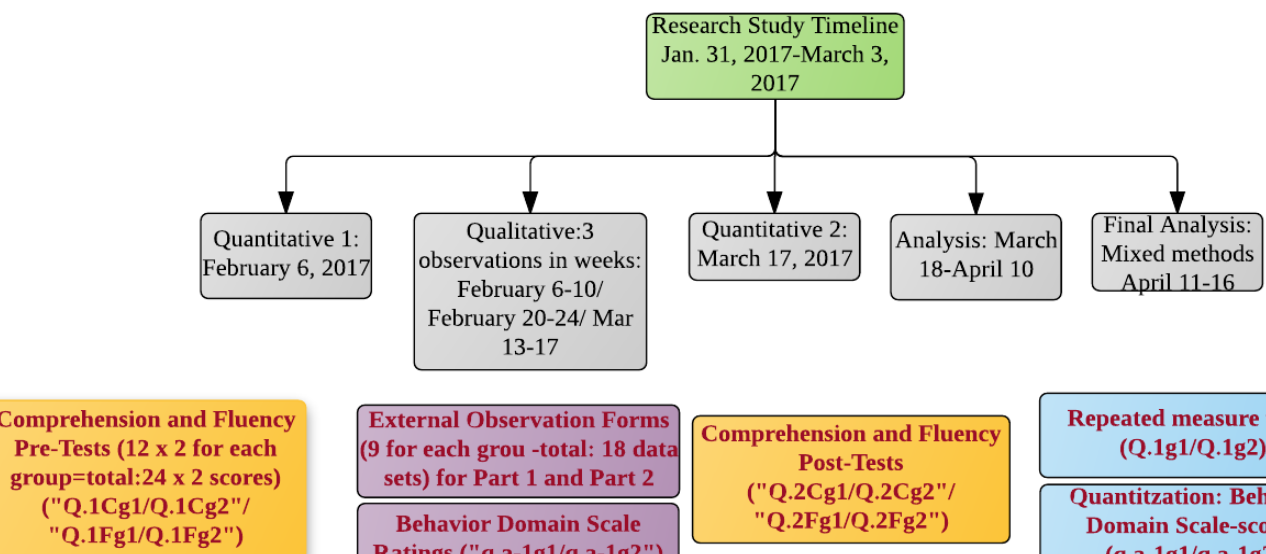

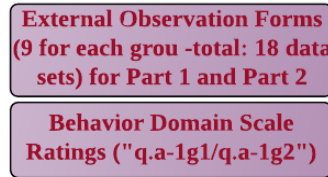

Ratings ("q.a-1g1/q.a-1g2") ("q.bg1/q.bg2")
Comprehension and Fluency Post-Tests ("Q.2Cg1/Q.2Cg2"/ "Q.2Fg1/Q.2Fg2")

Instructional Climate Frequency scores -(by Domains) ("q.a-2g1/q.a-2g2")

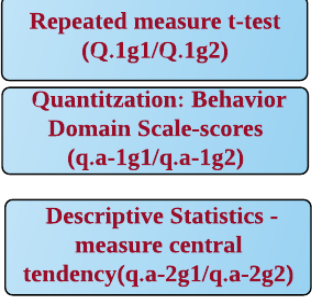

Frequency Analysis ANOVA (q.a-2g1/q.a-2g2)
Frequency Analysis - chi-square test of independence (q.a-2g1 and q.a-2g2)

Transpose into Word Document - Categorical Coding (q.bg1/q.bg2)

Thematic Coding (q.bg1/q.bg2)-

Narrative data represented in quote format (q.bg1/q.bg2)
Mixed-method Comparative analysis -within- and

between-method triangulation

Parallel mixed analysis -within/between groups

\section{Cluster / Cluster} correspondance analysis -congruence/incrongruence -within/between groups

Peer Debrifing: Final Conclusions validity 
Appendix H:

Code 1: Narrative Reflection transcription

Observation Form GpA and GpB-1:

Topic: CSTP 1: Engaging and Supporting all Students in Learning.

Response: Teacher engaged students by having each one read a paragraph or two, helping them to sound out words utilizing learned strategies and techniques while encouraging and prompting when appropriate.

Response: Teacher sought student participation in an active sentence writing environment. Lesson was continued from a previous reading session.

Code/Category: Engagement Attributes

Topic: CSTP 2: Creating and Maintaining Effective Environments for Student Learning.

Response: Small, manageable groups of students made student learning very engaged! Students were called on by name to respond or collaborative response was also encouraged.

Response: The teacher allowed and welcomed all responses and kept the lesson moving forward and all students engaged in writing.

Code/Category: Effective Environments

Topic: CSTP 3: Understanding and Organizing Subject Matter for Student Learning.

Response: The story had a conceptual idea that was interesting to observe the students grasp. The teacher suggested ideas and encouraged all student responses positively.

Response:: Room was clean, organized and ready for students to learn.

Code: Organizing Subject Matter

Topic: CSTP 4: Planning Instruction and Designing Learning Experiences for all Students (students equally participate, can relate and participate in group discussions of material in lesson).

Response: Both groups participated with the same level of engagement and were able to give ideas and input on the story. The teacher kept the discussion active and thoughtful.

Response: Teacher encouraged students and students all actively were writing sentences and responding to questions from the teacher.

Code: Learning Experiences

Topic: CSTP 5: Assessing Students for Learning (informal and formal).

Response: Formal with each student required to participate with reading.

Response: Formal writing with teacher giving examples of sentence structure and how to make a stronger sentence by adding words, etc.

Code: Assessing Learning

Topic: CSTP 6: Developing as a Professional Educator (evidence of current educational research standards, practices, strategies, etc.).

Response: Her easy going and engaging methods are thoughtful and practiced.

Response: Teacher's calm demeanor helped to keep constant engagement of students in the lesson and to keep the students writing their sentences.

Code: Professional Development

Section B: Critically analyze the observed teacher and student behaviors and experiences during the session. Provide a detailed summary of the critique.

Response: The groups were covering the previous day's lesson. The teacher was positive in energy and the group was energetic with their responses. Students were allowed to participate both openly and when quiet. The teacher would gently nudge the students toward response and, thus, inclusion.

Response: Teacher was effective by using strategies to keep students engaged with writing. The room was quiet

Code: All Behaviors

Observation Form GpA and GpB-2

Topic: CSTP 1: Engaging and Supporting all Students in Learning. 
Response: Full/3 - Teacher maintained a positive demeanor throughout citing student successes and predicting successes with today's lesson. All students received positive feedback throughout both individually and as a group. Response: Students were welcomed and lesson involved reading and drawing conclusions, and summarize story to write sentences.

Code/Category: Engagement Attributes

Topic: CSTP 2: Creating and Maintaining Effective Environments for Student Learning.

Response: Full/3 - Students were welcomed and encouraged to participate - their successes were shared with other students.

Response: Teacher kept class working and environment neat and clean.

Code/Category: Effective Environments

Topic: CSTP 3: Understanding and Organizing Subject Matter for Student Learning.

Response: Full/3 - Reviewed objective (Main Idea) and reviewed yesterday's lesson. Reviewed differences between Main idea and supporting details.

Response: Teacher helped to engage students by calling on them individually or as a group to highlight important words.

Code: Organizing Subject Matter

Topic: CSTP 4: Planning Instruction and Designing Learning Experiences for all Students (students equally participate, can relate and participate in group discussions of material in lesson).

Response: Full/3 - All students participated. In group 1 teacher encouraged others so one student did not dominate. Adeptly, with prompts and recognition was able to bring one student into actively participating after a disengaged start.

Response: Reading assignment and then group construction of sentences. Students were asked to think of using different words.

Code: Learning Experiences

Topic: CSTP 5: Assessing Students for Learning (informal and formal).

Response: Full/2 - Verbal questioning - often open-ended. Asked students to support answers from text.

Response: Teacher utilized group responses to make outline of important points. Student responses showed comprehension of subject matter.

Code: Assessing Learning

Topic: CSTP 6: Developing as a Professional Educator (evidence of current educational research standards, practices, strategies, etc.).

Response: Full/3 - Evidence of higher level questions, led students to draw evidence-based conclusions as well as inference.

Response: Effective strategies to engage students to learn and practice new and fun ways to write sentences.

Code: Professional Development

Section B: Critically analyze the observed teacher and student behaviors and experiences during the session. Provide a detailed summary of the critique.

Response: It was apparent to me what the objective of the lesson was and what had been covered the previous day. Teacher set a positive tone, celebrating student's successes and gave student's opportunities to engage and participate. Stated objective frequently and informed students when they had met it. Lesson moved smoothly from "one?" activity to the rest - good use of time.

Response: Teacher used strategies to continually challenge students to verbal and written responses. The room and area was quiet and conducive to learning and would the teacher request input from all students equally and with open-ended questions which would keep the student more engaged in their writing.

Observation Form GpA and GpB-3

Topic: CSTP 1: Engaging and Supporting all Students in Learning.

Response: 3 - *Teacher engages all students - actively involved. *Solicits answers from all students. *Celebrates successes.

Response: Teacher is assisting students in completing revising and/or editing a summary of story they read.

Code/Category: Engagement Attributes

Topic: CSTP 2: Creating and Maintaining Effective Environments for Student Learning. 
Response: -3 *small group. *accepting. *emphasizes mistakes as building blocks.

Response: Classroom neat and orderly. Teacher is prepared for students.

Code/Category: Effective Environments

Topic: CSTP 3: Understanding and Organizing Subject Matter for Student Learning.

Response: 3-*Using Title I passages that are inherently organized. *Modeling and eliciting questioning. *Prove through evidence in passage.

Response: Notes from reading selection were on the whiteboard. Teacher directed students to them as needed.

Code: Organizing Subject Matter

Topic: CSTP 4: Planning Instruction and Designing Learning Experiences for all Students (students equally participate, can relate and participate in group discussions of material in lesson).

Response: 3-Students equally participate. *Teacher encourage reticent participants.

Response: Students know objective - write a summary that includes details and main idea.

Code: Learning Experiences

Topic: CSTP 5: Assessing Students for Learning (informal and formal).

Response: 3-*Informal Q/A assessment. *Extension assignment Fun - involved research and report back.

Response: Assisted students. Asked students to read words to each other.

Code: Assessing Learning

Topic: CSTP 6: Developing as a Professional Educator (evidence of current educational research standards, practices, strategies, etc.).

Response: 3-*Teacher has strategy of "Appreciate Learning" so engraved, her methods are very natural and effective.

Response: Adapted assignment as needed (Sp. Ed. Students, ELL).

Code: Professional Development

Section B: Critically analyze the observed teacher and student behaviors and experiences during the session. Provide a detailed summary of the critique.

Response: $1^{\text {st }}$ group of 5-*Teacher questioned what was learned previously. *Brought all students out (one 'sleepyhead' rose up to meet high energy. *Bloom's Taxonomy type questions. $2^{\text {nd }}$ group of 4-*Discussion prompted and reinforced by peers. *Never an opportunity to check-out.

Response: Teacher provided a calm, orderly learning environment that supported diverse needs and learning styles.

* Teacher called to Principal duties 11:20.

Code: All Behaviors

Observation Form GpA and GpB-4

Topic: CSTP 1: Engaging and Supporting all Students in Learning.

Response: All students welcomed and engaged in the lesson.

Response: Students welcomed as they came to the table.

Code/Category: Engagement Attributes

Topic: CSTP 2: Creating and Maintaining Effective Environments for Student Learning.

Response: Students understood lesson and participated actively in responses to questions.

Response: Classroom and work table was clean and prepped for lesson.

Code: Effective Environments

Topic: CSTP 3: Understanding and Organizing Subject Matter for Student Learning.

Response: Teacher went over the planned objective of the lesson. The students understood and responded

accordingly.

Response: The board contained items discussed from previous lesson in bullet form.

Code: Organizing Subject Matter 
Topic: CSTP 4: Planning Instruction and Designing Learning Experiences for all Students (students equally participate, can relate and participate in group discussions of material in lesson).

Response: Students were able to participate openly and equally to the lesson and the teacher kept the discussion upbeat and engaging by adding personal experiences.

Response: Students were called on randomly or were requested to verbalize their responses to one another as the teacher wrote on the board the best collaborative sentence.

Code: Learning Experiences

Topic: CSTP 5: Assessing Students for Learning (informal and formal).

Response: Informal questioning of students to gather ideas in support of their conclusions.

Response: As the students verbalized their response the teacher would comment on how it fit into the idea of the sentence.

Code: Assessing Learning

Topic: CSTP 6: Developing as a Professional Educator (evidence of current educational research standards, practices, strategies, etc.).

Response: (No response recorded)

Response: All students were allowed and encouraged to participate in the lesson to the best of their ability.

Code: Professional Development

Section B: Critically analyze the observed teacher and student behaviors and experiences during the session. Provide a detailed summary of the critique.

Always keeping the students in control and engaged in the lessons by her easygoing presence and encouraging remarks to any question asked by a student or by elaborating with a student on their response to a question. Response: All students were allowed and encouraged to participate in the lesson to the best of their ability.

Code: All Behaviors

Observation Form GpA and GpB-5

Topic: CSTP 1: Engaging and Supporting all Students in Learning.

Response: All students were aware of the lesson and were encouraged to participate in the verbal responses.

Response: Students were welcomed to the table and requested to sit down.

Code/Category: Engagement Attributes

Topic: CSTP 2: Creating and Maintaining Effective Environments for Student Learning.

Response: Students greeted as they came to table and sat down. A couple of students were slower to engage, but they were continually urged into the action and were successful after encouragement.

Response: All students were asked to read passage allowing others to hear them.

Code/Category: Effective Environments

Topic: CSTP 3: Understanding and Organizing Subject Matter for Student Learning.

Response: Table and room was organized and ready for students to learn.

Response: Students were asked after reading to think about words that were strong and would be the subject word for building sentences.

Code: Organizing Subject Matter

Topic: CSTP 4: Planning Instruction and Designing Learning Experiences for all Students (students equally participate, can relate and participate in group discussions of material in lesson).

Response: The group was continually encouraged to join in and eventually all students were actively engaged and were participating.

Response: (Nothing recorded here).

Code: Learning Experiences 
Topic: CSTP 5: Assessing Students for Learning (informal and formal).

Response: Informal - The questions were asked and the students were allowed to speculate on potential endings for the story.

Response: (Nothing recorded here).

Code: Assessing Learning

Topic: CSTP 6: Developing as a Professional Educator (evidence of current educational research standards, practices, strategies, etc.).

Response: The teacher kept the students thinking about how the story might turn out differently and had them offer ideas that may support their ideas.

Response: (Nothing recorded here).

Code: Professional Development

Section B: Critically analyze the observed teacher and student behaviors and experiences during the session. Provide a detailed summary of the critique.

Response: There was a positive and encouraging objective to the lesson. That allowed students to have even small successes when responses were made to the group. The students always had the opportunity to add their thoughts to the discussion. All discussion was encouraged by the teacher and small ideas received positive feedback.

Response: (Nothing recorded here).

Code: All Behaviors

Observation Form GpA and GpB-6

Topic: CSTP 1: Engaging and Supporting all Students in Learning. Response: All students recognized and welcomed as they came to table.

Response: Students were greeted and welcomed to class.

Code/Category: Engagement Attributes

Topic: CSTP 2: Creating and Maintaining Effective Environments for Student Learning.

Response: Students are greeted and immediately began discussion on subject from the previous day's reading.

Response: The room and table were clean and prepped for writing lessons.

Code: Effective Environment

Topic: CSTP 3: Understanding and Organizing Subject Matter for Student Learning.

Response: game was played using Bingo boards that allowed students a chance to visualize the response or give input as to the correct response if they did not have the correct picture.

Response: Students partnered up to read the story. Students came back to table to discuss vocabulary. After verbal discussion, teacher and students did verbal construction of sentences.

Code: Organizing Subject Matter

Topic: CSTP 4: Planning Instruction and Designing Learning Experiences for all Students (students equally participate, can relate and participate in group discussions of material in lesson).

Response: All students played the game enthusiastically and were encouraged to add ideas when the teacher asked questions that had several possible responses that could be correct.

Response: All students participated in the verbal discussion. Teacher made sure to elicit responses from students to varying degrees but making sure that all had input. Students rather quiet today.

Code: Learning Experiences

Topic: CSTP 5: Assessing Students for Learning (informal and formal).

Response: Very informal.

Response: Formal questioning to try to garner responses that would help with writing portion of lesson.

Code: Assessing Learning 
Topic: CSTP 6: Developing as a Professional Educator (evidence of current educational research standards, practices, strategies, etc.).

Response: Completely effective at keeping up the pace with both verbal and written responses to questions by all students.

Response: Quiet leader, but with expectations of high quality input from students.

Code: Professional Development

Section B: Critically analyze the observed teacher and student behaviors and experiences during the session. Provide a detailed summary of the critique.

Response: Teacher utilized strategies to keep the students engaged by continuing to ask questions about the story. This would allow students to come up with the responses needed to write the sentence/s.

Code: All Behaviors 


\section{Appendix I:}

\section{$2^{\text {nd }}$ Code -Thematic Coding}

\begin{tabular}{|c|c|c|c|c|}
\hline Category/Subcategory & $\begin{array}{l}\text { Study } \\
\text { Group }\end{array}$ & $\begin{array}{l}\text { Ref. } \\
\text { No. }\end{array}$ & Narrative & Memos \\
\hline & AI & $6-6$ & $\begin{array}{l}\text { "Helping to sound out words, utilizing } \\
\text { learned strategizing techniques while } \\
\text { encouraging and prompting when } \\
\text { appropriate." } \\
\text { "Quiet leader, but with expectation } \\
\text { of high quality input from students." }\end{array}$ & $\begin{array}{l}\text {-Sounds active, teacher guiding learning, referring to } \\
\text { techniques they already know (4D "DISCOVERY" } \\
\text { phase). }\end{array}$ \\
\hline \multirow[t]{5}{*}{ Assessment } & & $1-5$ & \multirow[b]{2}{*}{$\begin{array}{l}\text { "Formal [assessment] with each } \\
\text { student required to participate with } \\
\text { reading." } \\
\text { "Formal writing with teacher giving } \\
\text { examples of sentence structure and } \\
\text { how to make a stronger sentence by } \\
\text { adding words, etc." } \\
\text { "Teacher utilized group responses to } \\
\text { make outline of important points. } \\
\text { Students responses showed } \\
\text { comprehension of subject matter." }\end{array}$} & $\begin{array}{l}\text { "Required" sets high expectation level (opposed to } \\
\text { "request' to participate). }\end{array}$ \\
\hline & TI & $\begin{array}{l}1-5 \\
2-5\end{array}$ & & Teacher active, students' passive recipients. \\
\hline & $\mathrm{AI}$ & $\begin{array}{l}3-5 \\
5-5 \\
4-5\end{array}$ & $\begin{array}{l}\text { "Informal [assessment] Q/A." } \\
\text { "Inform questions for students to } \\
\text { speculate alternative outcomes" } \\
\text { "Inform questioning of students to } \\
\text { gather ideas in support of their } \\
\text { conclusions" }\end{array}$ & $\begin{array}{l}\text { Students are GATHERING ideas, teacher facilitating } \\
\text { opportunities to prompt self-driven learning. } \\
\text { No opportunity to be PASSIVE, only ACTIVE } \\
\text { LEARNING. }\end{array}$ \\
\hline & TI & $3-5$ & $\begin{array}{l}\text { "Assisted students- Asked students } \\
\text { to read work to each other." }\end{array}$ & \\
\hline & $\mathrm{AI}$ & $6-5$ & "Very informal" & \\
\hline \multirow[t]{3}{*}{ Objectives } & AI & $2-3$ & $\begin{array}{l}\text { "reviewed objective and yesterday's } \\
\text { lesson, reviewed differences between } \\
\text { main idea and supporting details" }\end{array}$ & \\
\hline & $\mathrm{AI}$ & $2-\mathrm{B}$ & $\begin{array}{l}\text { "apparent what the objective was and } \\
\text { what had been covered the previous } \\
\text { day" }\end{array}$ & \\
\hline & TI & $3-4$ & $\begin{array}{l}\text { "Students knew objective-write a } \\
\text { summary that includes details and } \\
\text { main idea." }\end{array}$ & \\
\hline \multirow[t]{2}{*}{ Evidence } & AI & $2-5$ & $\begin{array}{l}\text { "Verbal questioning, often open- } \\
\text { ended. Asked students to support their } \\
\text { answers from text." }\end{array}$ & ACTIVE learning \\
\hline & $\mathrm{AI}$ & $3-3$ & "prove through evidence in passage" & \\
\hline
\end{tabular}




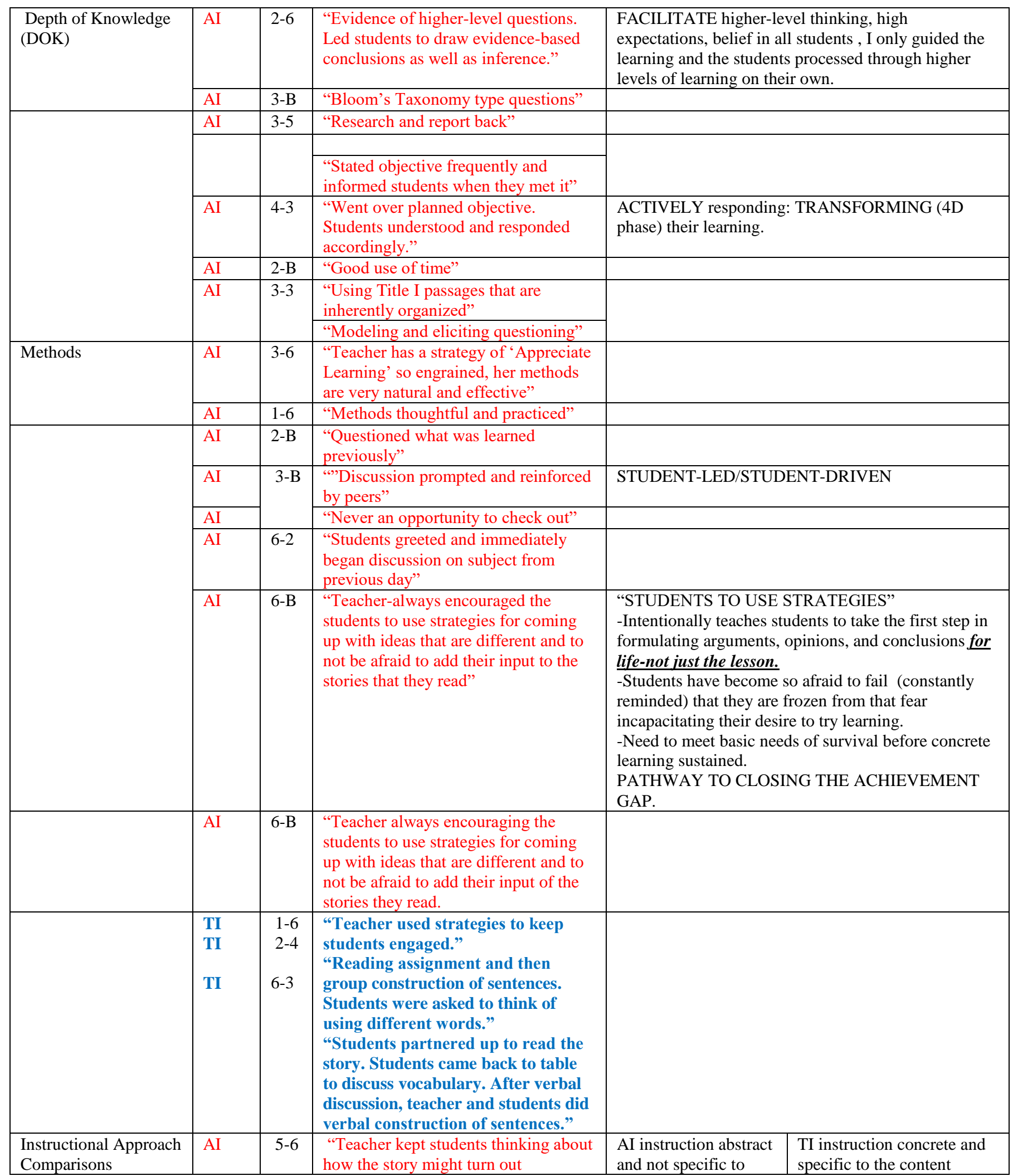




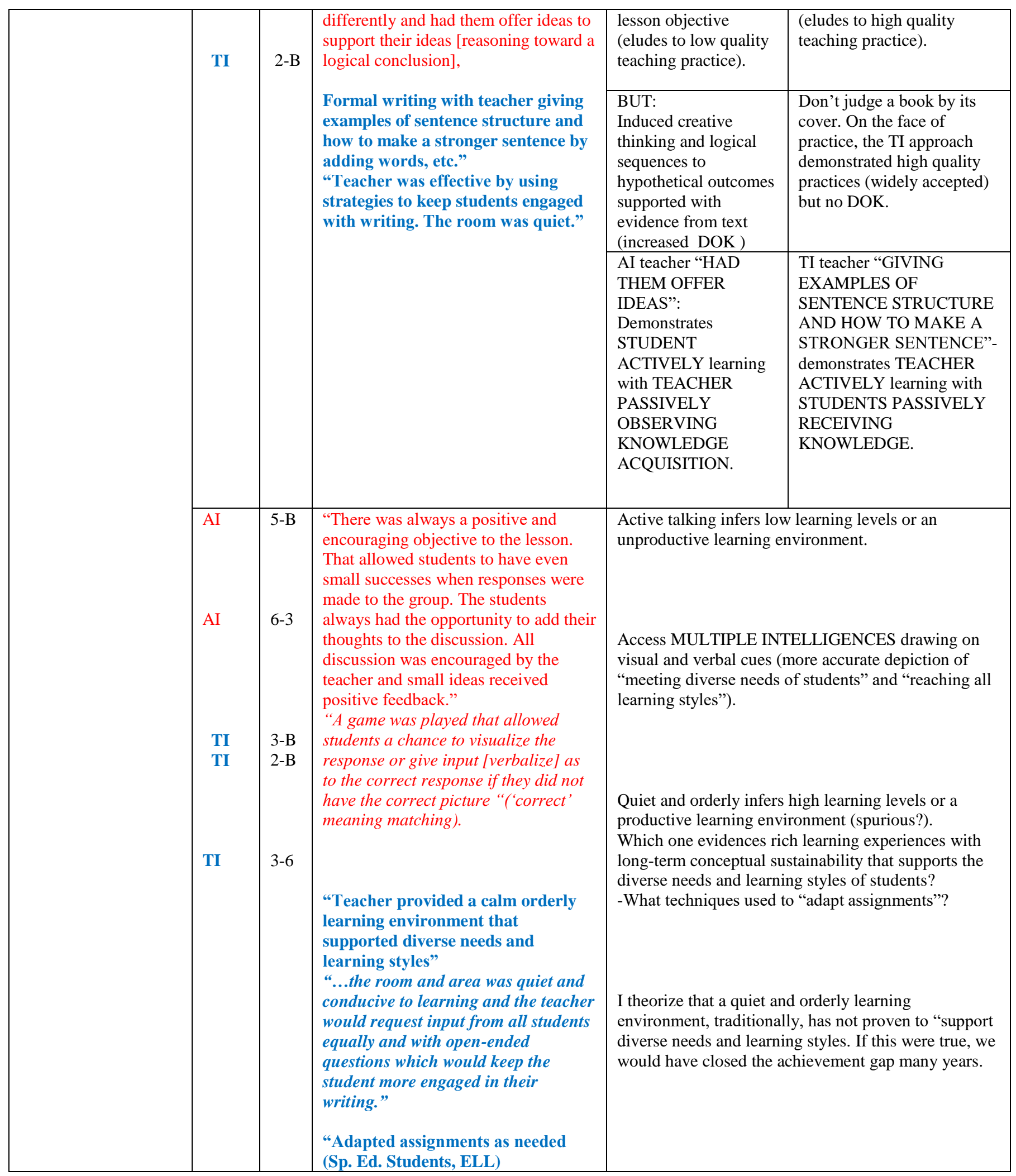




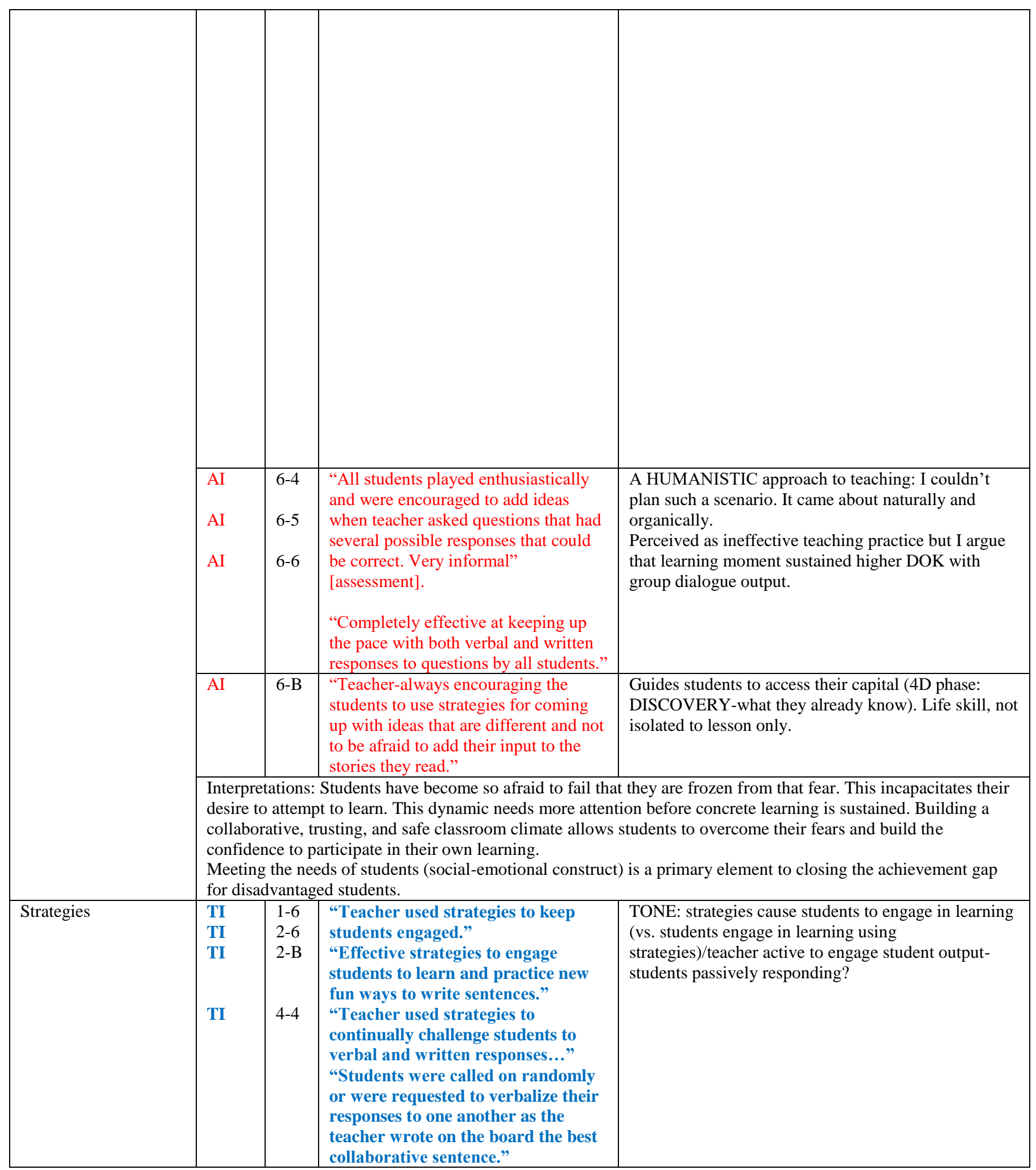




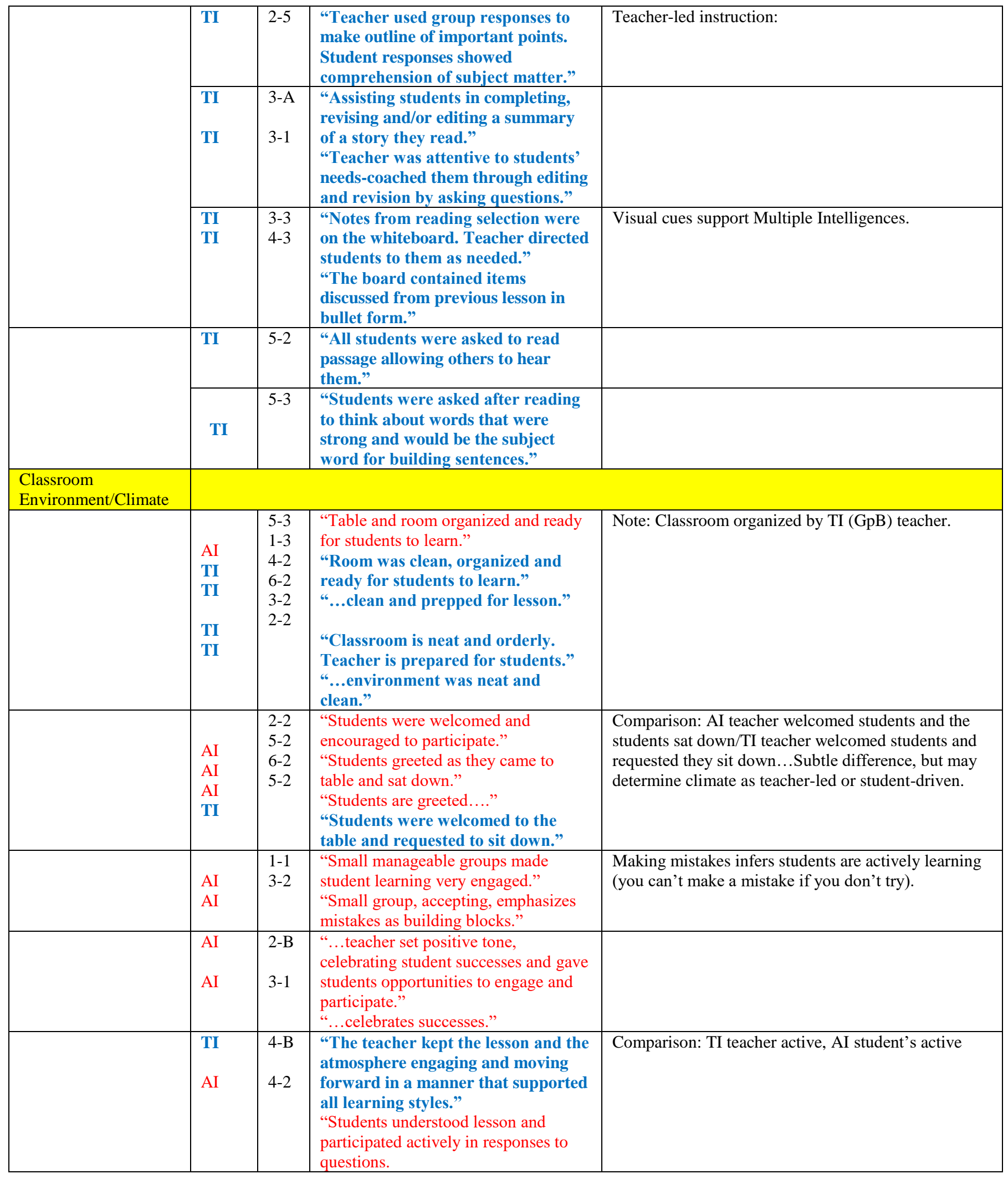




\begin{tabular}{|c|c|c|c|c|}
\hline & $\begin{array}{l}\text { TI } \\
\text { TI } \\
\text { TI }\end{array}$ & $\begin{array}{l}1-\mathrm{B} \\
2-\mathrm{B} \\
6-4\end{array}$ & $\begin{array}{l}\text { "...the room was quiet." } \\
\text { "...the room and area was quiet and } \\
\text { conducive to learning." } \\
\text { "....students rather quiet today." }\end{array}$ & \\
\hline & TI & $3-\mathrm{B}$ & $\begin{array}{l}\text { "Teacher provided a calm orderly } \\
\text { learning environment that } \\
\text { supported diverse needs and } \\
\text { learning styles." }\end{array}$ & \\
\hline Personality & $\begin{array}{l}\text { AI } \\
\text { AI } \\
\text { TI }\end{array}$ & $\begin{array}{l}1-6 \\
3-6 \\
1-6\end{array}$ & $\begin{array}{l}\text { "Her easy going and engaging } \\
\text { methods are thoughtful and practiced." } \\
\text { "Teacher has a strategy of "Appreciate } \\
\text { Learning" so engrained, her methods } \\
\text { are very natural and effective." } \\
\text { Teacher's calm demeanor was } \\
\text { effective by using strategies to keep } \\
\text { students engaged with writing," }\end{array}$ & AI model approach to instruction. \\
\hline Practice & $\begin{array}{l}\text { TI } \\
\text { TI } \\
\text { TI } \\
\text { TI } \\
\end{array}$ & $\begin{array}{l}3-1 \\
1-2 \\
4-6 \\
6-4\end{array}$ & $\begin{array}{l}\text { "Always keeping students in control } \\
\text { and engaged in lessons by her easy- } \\
\text { going presence and encouraging } \\
\text { remarks to any question asked by a } \\
\text { student-or by elaborating with a } \\
\text { student on their response to a } \\
\text { question." } \\
\text { "Teacher was attentive to students" } \\
\text { needs." }\end{array}$ & $\begin{array}{l}\text { Establishes mutually respectful, collaborative } \\
\text { relationships with teacher and student. Teacher shows } \\
\text { genuine interest in student responses. } \\
\text { NOTE: I am finding that the stronger bond of } \\
\text { collegiality with students the less classroom } \\
\text { management is needed; however-it is extremely } \\
\text { difficult to manage the fine line between teacher and } \\
\text { student as colleagues and teacher needs to manage } \\
\text { student behavior in the classroom (needs more } \\
\text { development). }\end{array}$ \\
\hline
\end{tabular}




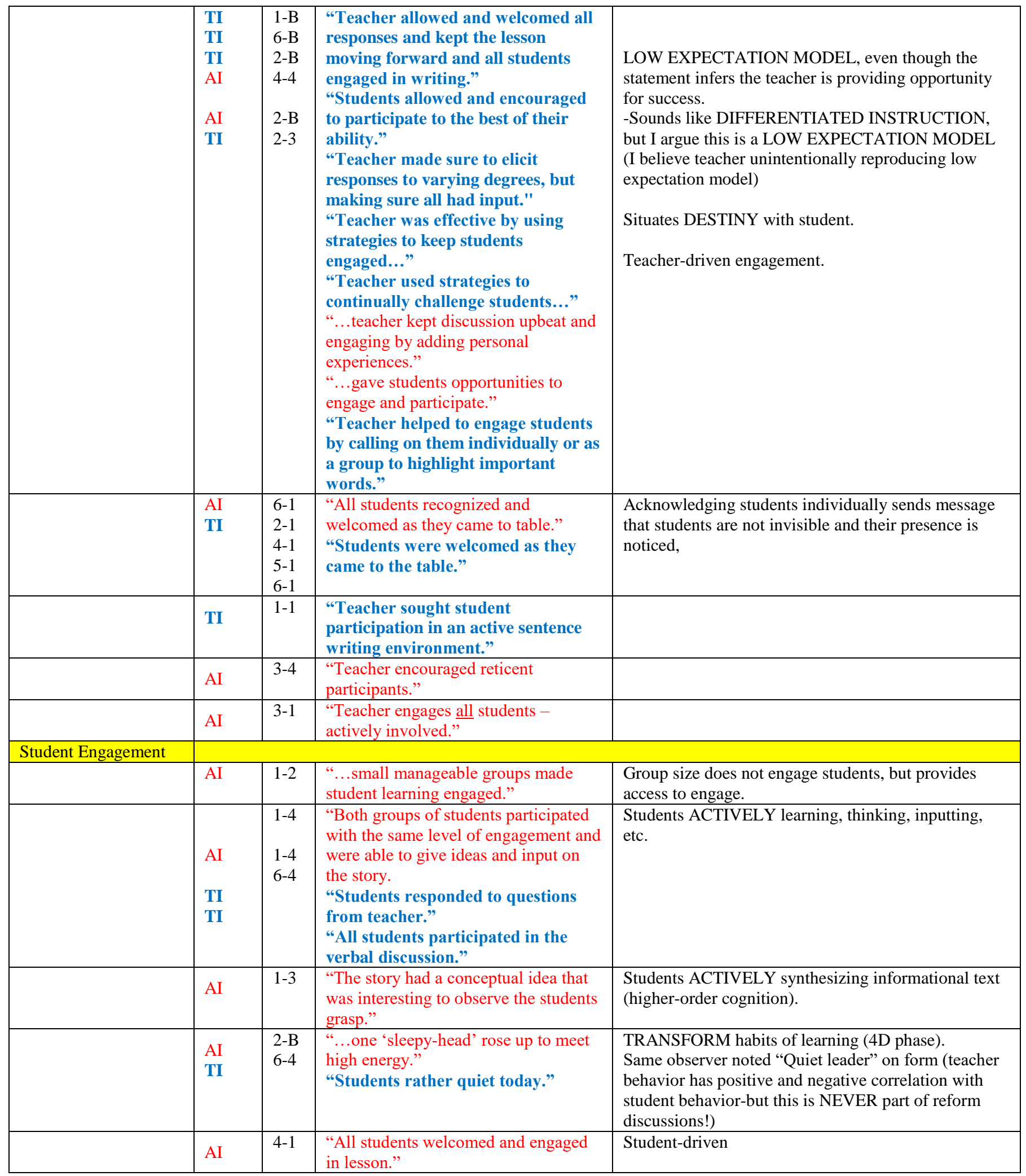




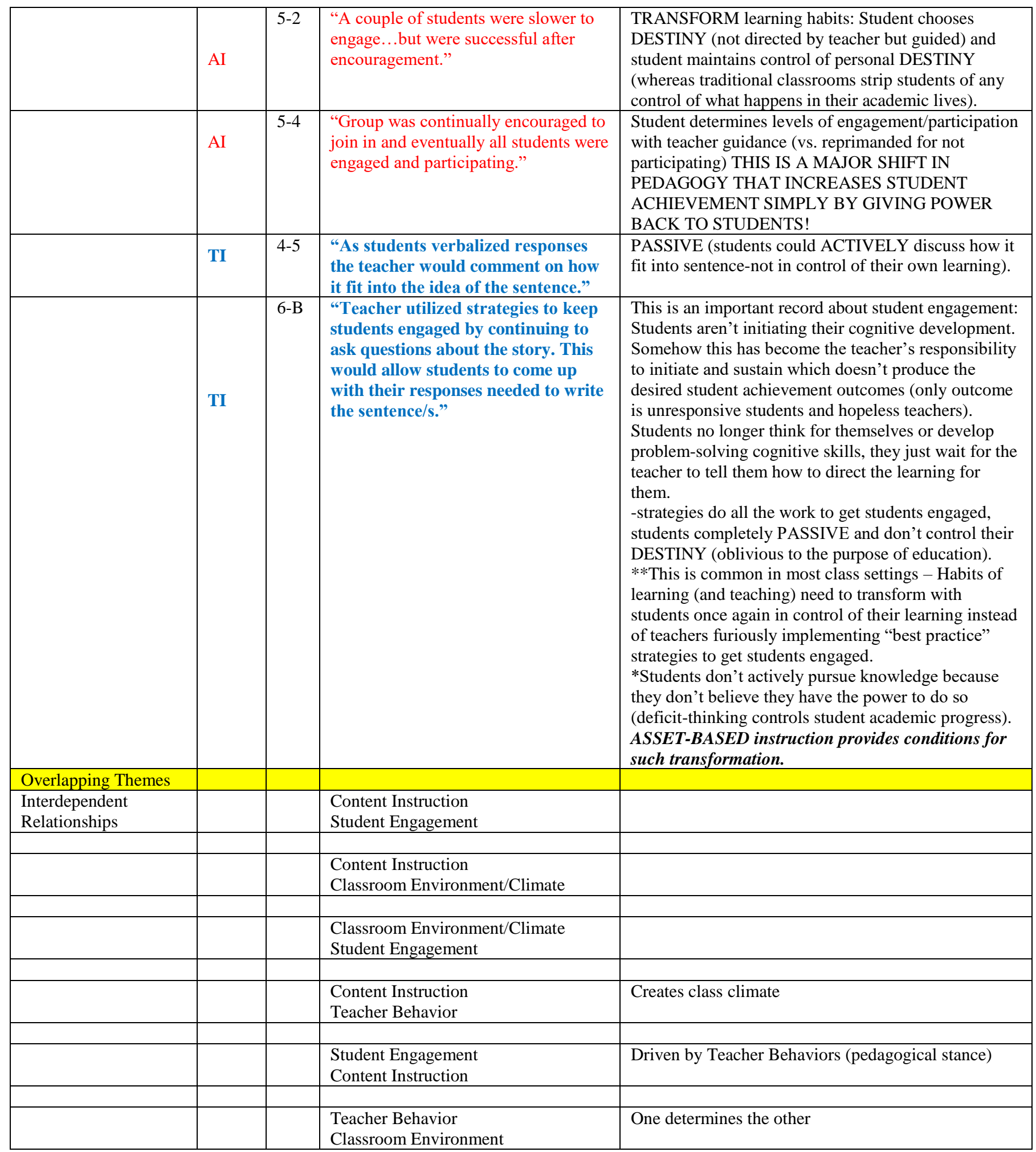


Appendix J:

CSTP narrative observation quotes:

CSTP 1: Engaging and Supporting All Students in Learning

Response: Teacher engaged students by having each one read a paragraph or two, helping them to sound out words utilizing learned strategies and techniques while encouraging and prompting when appropriate. 
Response: Full/3 - Teacher maintained a positive demeanor throughout citing student successes and predicting successes with today's lesson. All students received positive feedback throughout both individually and as a group.

Response: 3- *Teacher engages all students - actively involved. *Solicits answers from all students. *Celebrates successes.

Response: All students welcomed and engaged in the lesson.

Response: All students were aware of the lesson and were encouraged to participate in the verbal responses.

Response: All students recognized and welcomed as they came to table.

Response: Teacher sought student participation in an active sentence writing environment. Lesson was continued from a previous reading session.

Response: Students were welcomed and lesson involved reading and drawing conclusions, and summarize story to write sentences.

Response: Teacher is assisting students in completing revising and/or editing a summary of story they read.

Response: Students welcomed as they came to the table.

Response: Students were welcomed to the table and requested to sit down.

Response: Students were greeted and welcomed to class.

\section{CSTP 2:}

Response: Small, manageable groups of students made student learning very engaged! Students were called on by name to respond or collaborative response was also encouraged.

Response: Full/3 - Students were welcomed and encouraged to participate - their successes were shared with other students.

Response: -3 *small group. *accepting. *emphasizes mistakes as building blocks.

Response: Students understood lesson and participated actively in responses to questions.

Response: Students greeted as they came to table and sat down. A couple of students were slower to engage, but they were continually urged into the action and were successful after encouragement.

Response: Students are greeted and immediately began discussion on subject from the previous day's reading.

Response: The teacher allowed and welcomed all responses and kept the lesson moving forward and all students engaged in writing. 
Response: Teacher kept class working and environment neat and clean.

Response: Classroom neat and orderly. Teacher is prepared for students.

Response: Classroom and work table was clean and prepped for lesson.

Response: All students were asked to read passage allowing others to hear them.

Response: The room and table were clean and prepped for writing lessons.

\section{CSTP 3:}

Response: The story had a conceptual idea that was interesting to observe the students grasp. The teacher suggested ideas and encouraged all student responses positively.

Response: Full/3 - Reviewed objective (Main Idea) and reviewed yesterday's lesson. Reviewed differences between Main idea and supporting details.

Response: 3-*Using Title I passages that are inherently organized. *Modeling and eliciting questioning. *Prove through evidence in passage.

Response: Teacher went over the planned objective of the lesson. The students understood and responded accordingly.

Response: Table and room was organized and ready for students to learn.

Response: game was played using Bingo boards that allowed students a chance to visualize the response or give input as to the correct response if they did not have the correct picture.

Response: Room was clean, organized and ready for students to learn.

Response: Teacher helped to engage students by calling on them individually or as a group to highlight important words.

Response: Notes from reading selection were on the whiteboard. Teacher directed students to them as needed.

Response: The board contained items discussed from previous lesson in bullet form.

Response: Students were asked after reading to think about words that were strong and would be the subject word for building sentences.

Response: Students partnered up to read the story. Students came back to table to discuss vocabulary. After verbal discussion, teacher and students did verbal construction of sentences.

CSTP 4:

Response: Both groups participated with the same level of engagement and were able to give ideas and input on the story. The teacher kept the discussion active and thoughtful.

Response: Full/3 - All students participated. In group 1 teacher encouraged others so one student did not dominate. Adeptly, with prompts and recognition was able to bring one student into actively participating after a disengaged start. 


\section{APPRECIATIVE INQUIRY MODEL AS AN INSTRUCTIONAL APPROACH}

Response: 3-Students equally participate. *Teacher encourage reticent participants.

Response: Students were able to participate openly and equally to the lesson and the teacher kept the discussion upbeat and engaging by adding personal experiences.

Response: The group was continually encouraged to join in and eventually all students were actively engaged and were participating.

Response: All students played the game enthusiastically and were encouraged to add ideas when the teacher asked questions that had several possible responses that could be correct.

Response: Teacher encouraged students and students all actively were writing sentences and responding to questions from the teacher.

Response: Reading assignment and then group construction of sentences. Students were asked to think of using different words.

Response: Students know objective - write a summary that includes details and main idea.

Response: Students were called on randomly or were requested to verbalize their responses to one another as the teacher wrote on the board the best collaborative sentence.

Response: (Nothing recorded here).

Response: All students participated in the verbal discussion. Teacher made sure to elicit responses from students to varying degrees but making sure that all had input. Students rather quiet today.

\section{CSTP 5:}

Response: Informal with each student required to participate with reading.

Response: Full/2 - Verbal questioning - often open-ended. Asked students to support answers from text.

Response: 3-*Informal Q/A assessment. *Extension assignment Fun - involved research and report back.

Response: Informal questioning of students to gather ideas in support of their conclusions.

Response: Informal - The questions were asked and the students were allowed to speculate on potential endings for the story.

Response: Very informal.

Response: Formal writing with teacher giving examples of sentence structure and how to make a stronger sentence by adding words, etc.

Response: Teacher utilized group responses to make outline of important points. Student responses showed comprehension of subject matter.

Response: Assisted students. Asked students to read words to each other. 
Response: As the students verbalized their response the teacher would comment on how it fit into the idea of the sentence.

Response: (Nothing recorded here).

Response: Formal questioning to try to garner responses that would help with writing portion of lesson.

\section{CSTP 6:}

Response: Her easy going and engaging methods are thoughtful and practiced.

Response: Full/3 - Evidence of higher level questions, led students to draw evidence-based conclusions as well as inference.

Response: 3-*Teacher has strategy of "Appreciate Learning" so engraved, her methods are very natural and effective.

Response: (No response recorded)

Response: The teacher kept the students thinking about how the story might turn out differently and had them offer ideas that may support their ideas.

Response: Completely effective at keeping up the pace with both verbal and written responses to questions by all students.

Response: Teacher's calm demeanor helped to keep constant engagement of students in the lesson and to keep the students writing their sentences.

Response: Effective strategies to engage students to learn and practice new and fun ways to write sentences.

Response: Adapted assignment as needed (Sp. Ed. Students, ELL).

Response: All students were allowed and encouraged to participate in the lesson to the best of their ability.

Response: (Nothing recorded here).

Response: Quiet leader, but with expectations of high quality input from students.

\section{Section B:}

Response: The groups were covering the previous day's lesson. The teacher was positive in energy and the group was energetic with their responses. Students were allowed to participate both openly and when quiet. The teacher would gently nudge the students toward response and, thus, inclusion.

Response: It was apparent to me what the objective of the lesson was and what had been covered the previous day. Teacher set a positive tone, celebrating student's successes and gave student's 
opportunities to engage and participate. Stated objective frequently and informed students when they had met it. Lesson moved smoothly from "one?" activity to the rest - good use of time.

Response: $1^{\text {st }}$ group of 5-*Teacher questioned what was learned previously. *Brought all students out (one 'sleepy-head' rose up to meet high energy. *Bloom's Taxonomy type questions. $2^{\text {nd }}$ group of $4-*$ Discussion prompted and reinforced by peers. *Never an opportunity to check-out.

Always keeping the students in control and engaged in the lessons by her easygoing presence and encouraging remarks to any question asked by a student or by elaborating with a student on their response to a question.

Response: There was a positive and encouraging objective to the lesson. That allowed students to have even small successes when responses were made to the group. The students always had the opportunity to add their thoughts to the discussion. All discussion was encouraged by the teacher and small ideas received positive feedback.

Response: Teacher- Always encouraging the students to use strategies for coming up with ideas that are different and, to not be afraid to add their input to the stories that they read.

Response: Teacher was effective by using strategies to keep students engaged with writing. The room was quiet

Response: Teacher used strategies to continually challenge students to verbal and written responses. The room and area was quiet and conducive to learning and would the teacher request input from all students equally and with open-ended questions which would keep the student more engaged in their writing.

Response: Teacher provided a calm, orderly learning environment that supported diverse needs and learning styles. * Teacher called to Principal duties 11:20.

Response: All students were allowed and encouraged to participate in the lesson to the best of their ability.

Response: (Nothing recorded here).

Response: Teacher utilized strategies to keep the students engaged by continuing to ask questions about the story. This would allow students to come up with the responses needed to write the sentence/s.

\section{References:}

Barrett-Tatum, J. (2015). Examining English Language Arts Common Core State Standards Instruction through Cultural Historical Activity Theory. Education Policy Analysis Archives, 23(63).

Beecher, J. (1988). Note-Taking: What Do We Know about the Benefits? ERIC Digest Number 12. 
Blas, E. A. (2014). Information Literacy in the 21st Century Multicultural Classroom: Using Sociocultural Literacy. Education Libraries, 37, 33-41.

Brackett, M. A., Reyes, M. R., Rivers, S. E., Elbertson, N. A., \& Salovey, P. (2011). Classroom Emotional Climate, Teacher Affiliation, and Student Conduct. The Journal of Classroom Interaction, 46(1), 27-36.

Connor, C. M., Morrison, F. J., Fishman, B. J., Ponitz, C. C., Glasney, S., Underwood, P. S., Schatschneider, C. (2009). The ISI Classroom Observation System: Examining the Literacy Instruction Provided to Individual Students. Educational Researcher, 38(2), 8599.

Cooperrider, D., \& Whitney, D. D. (2005). Appreciative Inquiry: A Positive Revolution in Change. Berrett-Koehler Publishers.

Darden, E. (2011). The Same Starting Line: How School Boards Can Erase the Opportunity Gap between Poor and Middle-Class Children. Appleseed.

Darling-Hammond, L. (2015). Want to Close the Achievement Gap? Close the Teaching Gap. American Educator, 38(4), 14-18.

Fifolt, M., \& Lander, L. (2013). Cultivating Change Using Appreciative Inquiry. New Directions for Student Services.

Gay, G. (2010). Culturally Responsive Teaching: Theory, Research, and Practice. Teachers College Press.

Goatley, V. J., \& Hinchman, K. A. (2013). Using Research to Make Sensible Literacy Decisions within Current Educational Initiatives. Language and Literacy Spectrum, 23, 57-68.

Hanushek, E. A., \& Rivkin, S. G. (2007). School Quality and the Black-White Achievement Gap. Education Working Paper Archive. High-Flying High-Poverty Schools. (2013). American Educator, 36(4), 8.

Kosmoski, G. J., Gay, G., \& Vockell, E. L. (1990). Cultural Literacy and Academic Achievement. The Journal of Experimental Education, 58(4), 265-272.

Lehner, R., \& Hight, D. L. (2006). Appreciative Inquiry and Student Affairs: A Positive Approach to Change. College Student Affairs Journal, 25(2), 141-151.

Lehner, R., \& Ruona, W. (2004). Using Appreciative Inquiry to Build and Enhance a Learning Culture. 5

LEMBERGER, M. E., BRIGMAN, G., WEBB, L., \& MOORE, M. M. (2011). Student Success Skills: An Evidence-based Cognitive and Social Change Theory for Student

Achievement. The Journal of Education, 192(2/3), 89-99.

Madden, M., \& Leftwich, S. (2008). Teaching against the Grain: Enacting Constructivist Beliefs within Institutional. Journal on Educational Psychology, 1(4), 33-45.

Madland, D., \& Bunker, N. (2011). The Middle Class Is Key to a Better-Educated Nation: A Stronger Middle Class Is Associated with Better Educational Outcomes. Center for 
American Progress.

NAEP Nations Report Card - Interpreting NAEP Reading Results. (n.d.). Retrieved February 28, 2016, from https://nces.ed.gov/nationsreportcard/reading/interpret_results.aspx

Perry, K. H. (2012a). What Is Literacy? --A Critical Overview of Sociocultural Perspectives. Journal of Language and Literacy Education, 8(1), 50-71.

Perry, K. H. (2012b). What Is Literacy? --A Critical Overview of Sociocultural Perspectives. Journal of Language and Literacy Education, 8(1), 50-71.

Roza, M., \& Lake, R. (2015). Title I: Time to Get It Right. Center on Reinventing Public Education.

Sheets, R. H. (2009). What Is Diversity Pedagogy? Multicultural Education, 16(3), 11-17.

Simon, R., Campano, G., Broderick, D., \& Pantoja, A. (2012). Practitioner Research and Literacy Studies: Toward More Dialogic Methodologies. English Teaching: Practice and Critique, 11(2), 5-24.

Title I - Improving The Academic Achievement Of The Disadvantaged. (2005, December 19). [Laws]. Retrieved February 28, 2016, from http://www2.ed.gov/policy/elsec/leg/esea02/pg1.html

Title I - What is Title I? (n.d.). Retrieved February 28, 2016, from http://titleone.departments.pwcs.edu/modules/cms/pages.phtml?pageid=134347

Trowbridge, N. (1972). Self-Concept and Socio-Economic Status in Elementary School Children. American Educational Research Journal, 9(4), 525-537.

Walker-Dalhouse, D., \& Risko, V. J. (2008). Reading Research into the Classroom: Learning from Literacy Successes in High-Achieving Urban Schools. The Reading Teacher, 61(5), 422-424.

Warren, G., \& Manthey, G. (2011). Transforming Education: For the Love of Learning. Leadership, 41(1), 34-35.

Willis, A. I. (2009). EduPolitical Research: Reading between the Lines. Educational Researcher, $38(7), 528-536$. 